\title{
Zur stratigraphischen Gliederung der jungpleistozänen Sedimente im nördlichen Oberrheintalgraben
}

\author{
Von Erich Becker, Mörfelden
}

\author{
Mit 1 Karte, 13 Abbildungen und 9 Tabellen im Text
}

\begin{abstract}
$\mathrm{Z} u$ sammenfassung. Die quartäre Grabenfüllung des nördlichen Oberrheintales baut sich aus den petrographisch gut unterscheidbaren, fluviatilen Sedimenten von Rhein, Main und Neckar auf. An der Oberfläche dieser fluviatilen Ablagerungen kam es im Jungpleistozän und Holozän zur Bildung von Flugsanddecken verschiedener Mächtigkeit und Ausdehnung; auf größeren Flächen wurden die Flugsande zu Dünen unregelmäßiger Form und Anordnung aufgeweht. Die verschiedene petrographische Ausbildung dieser Flugsande machte eine Abgrenzung folgender Flugsand-Faziesräume notwendig:
\end{abstract}

1. Das Maingebiet mit seinen mittel-grobkörnigen und meist kalkfreien Flugsanden.

2. Die Bergsträßer Flugsandvorkommen, in denen feinkörnige, kalkhaltige äolische Sedimente überwiegen.

3. Das Lorsch-Viernheimer Dünengebiet, dessen Flugsande sich von denen des Bergsträßer Raumes nur wenig unterscheiden.

4. Der Sprendlinger Horst mit seinen, den Mainflugsanden petrographisch ähnlichen, äolischen Sedimenten.

Die vollständigste Profilentwicklung war im Maingebiet zu beobachten. In diesem Raum überlagern die äolischen Deckschichten, wie die eingehende Untersuchung der fluviatilen Ablagerungen deutlich gezeigt hat, auf großen Flächen die Reste eines letztinterglazialen Bodens an der Oberfläche der alt- bis mittelpleistozänen Kelsterbacher Terrasse. Gelegentlich sind Flugsande und Dünen auch auf den geringmächtigen Ablagerungen einer vermutlich Oberen Niederterrasse verbreitet, besonders wo diese randlich auf die Kelsterbacher Terrasse übergreift.

Aus dem Profilaufbau der Dünen im Maingebiet läßt sich, teilweise in Anlehnung an die Lößstratigraphie, folgender Geschehnisablauf rekonstruieren: Auf den, der fluviatilen Akkumulation entzogenen, älteren Terrassenflächen überwogen im Frühwürm intensive Abtragungs- und Verlagerungsvorgänge. Am Ende dieses durch kühlfeuchte Klimabedingungen gekennzeichneten Zeitabschnittes dürfte die Bildung der lehmstreifigen Basiswechselfolge der Dünen erfolgt sein. Über den, durch einen schwer einstufbaren (W I/II?), geringmächtigen Kryoturbationshorizont nach oben begrenzten Basisschichten folgt die Hauptmasse der, meist mehrere Meter mächtigen, Dünensande. Diese im tieferen Teil stellenweise durch einen schwach ausgeprägten Naßfleckenhorizont (W II/III?) gegliederte Flugsandabfolge dürfte stratigraphisch dem Würm III-Löß der hessischen Gliederung entsprechen.

Die unter den besonderen Klimabedingungen des Spätglazials auf diesen Dünensanden einsetzende Bodenentwicklung führte bis zum Alleröd-Interstadial bereits zur Bildung von Sandparabraunerden (Bänderflugsande), während im Vergleich dazu auf den jüngsten Lößdecken stellenweise schwach ausgeprägte Parabraunerden entstanden. Durch die Einlagerung einer im MittelAlleröd (Laacher-See-Ausbruch) gebildeten Bims-Tuffschicht im Hangenden der Bänderflugsande ist eine absolute Zeitmarke gegeben. Die Verwitterung der mit Flugsanden vermischten Bims-Tuffe $\mathrm{zu}$ einem braunerdeartigen Boden begann vermutlich noch während des Alleröd-Interstadials. Aus den während des Kälterückschlages in der Jüngeren Tundrenzeit gebildeten Flugsanden entstanden unter dem Einfluß des postglazialen Klimaoptimums tiefgründige Braunerden, stratigraphisch vergleichbar den Steppenböden aus Löß im benachbarten Rheinhessen sowie den Lockerbraunerden der hessischen Mittelgebirge. Diese Bodenentwicklung wurde, wie durch paläolithische Funde und die C14-Bestimmung an Holzkohlen aus einer Brandschicht nachgewiesen werden konnte, im 6.-7. Jahrh. n. Chr. durch eine letztmalige stärkere Flugsandaufwehung beendet. Die jüngsten Flugsande sind auf den Dünen meist nur schwach verwittert.

In einem besonderen Abschnitt wurden Fragen der Entstehung der für Sande charakteristischen Bänderung (Sandparabraunerde) erörtert. Bei diesen Bändern handelt es sich, wie aus den Befunden eingehender Untersuchungen hervorging, um meist dünne Ton-Eisenanreicherungshorizonte; das eingeschlämmte Material entstammt wahrscheinlich im wesentlichen nicht überlagernden $B_{V^{-}}$ Horizonten, sondern dem Sediment selbst. Die Verlagerung und Anreicherung der mobilisierbaren 
Substanzen dürfte sowohl mechanisch als auch durch die Einwirkung chemischer Prozesse erfolgt sein. Wie aus den stratigraphischen Untersuchungen hervorging, lag die Hauptbänderbildung bereits vor dem Alleröd-Interstadial; unter gegebenen Bedingungen kann es jedoch auch heute noch zur Bänderbildung kommen.

$\mathrm{Su} \mathrm{mmary}$. In the Quarternary the northern Upper Rhine rift valley was filled with the fluviatile deposits (pebbles and sands) of the rivers Rhine, Main and Neckar. During the Würm ice age and in the Holocene the surface of these fluviatile deposits was covered with eolian sand plains and dune fields of varying thickness and extension.

The most complete stratigraphie sequence of the eolian cover was found in the Lower Main district. In this region the eolian deposits cover, over large areas, the remnants of a Riß-Wurm interglacial involution layer at the surface of the Old-to Middle Pleistocene Kelsterbach terrace. Based on the stratigraphic sequence of the dunes in the Main region and by comparison with the loess stratigraphy of Hesse it was possible to reconstruct the following chronology: In early Würm intensive soil erosion and solifluction perdominated on the terrace surfaces. A basal alternation of loamy and sandy layers presumably at the end of this cool-wet climatic epoch originated. These basal layers are limited upward by an involution layer of slight thickness, which is possibly equal to the fossil soil Würm I/II of the loess sequence. In the Maddle Würm this horizon was covered by dune-sands of great thickness. The dunes may be correlated with Würm III loess. A rare tundra gley (Naßfleckenboden) is found in the basal parts of the dunes in places. During the last Glacial the dune-sands weathered to a sandy grey-brown podsolic soil (Sand-Parabraunerde) comparable to the grey-brown soil (Parabraunerde) found on loess.

An absolute age marker is given by a pumice layer (Laacher See eruption) intercalated in Middle Alleröd. The Laacher See pumice is mixed with drift sand and probably weathered in Upper Alleröd to a brown earth (Braunerde). In the Younger Dryas epoch the pumice brown earth was covered by drift sand again. In the Holocene this drift sand weathered to brown earth of great thickness, stratifically comparable to the chernosem in Rhinehesse and the "Lockerbraunerden" in the mountainous regions of Hesse. It has been demonstrated by palaeolithic findings and the $\mathrm{C}^{14}$ method that this intensive pedogenesis was interrupted in the 6-7th century $\mathrm{B}$. C. by new sand drift. This youngest drift sand is weathered to a lesser extent.

A special section deals with the genesis of the clay-iron bands (sandy grey-brown podsolic soil). The enrichment in bands is the result of leaching and migration by chemical and mechanical processes extending through the whole eolian complex.

In haltsverzeichnis

Seite

1. Einleitung

1.1. Das Arbeitsgebiet . . . . . . . . . . . . . . . . . . . . . . . . . . . . . 7

1.2. Problemstellung . . . . . . . . . . . . . . . . . . . . . . . . . 8

2. Quartäre Bildungen im Maingebiet

2.1. Fluviatile Ablagerungen . . . . . . . . . . . . . . . . . . . . . . . . . . 8

2.1.1. Allgemeines . . . . . . . . . . . . . . . . . . . . . . . . . . . . 8

2.1.2. Das Hochflutbett . . . . . . . . . . . . . . . . . . . . 9

2.1.3. Die Untere Niederterrasse (UNT) und ihre Hochflutlehmdecke . . . . . . . 9

2.1.4. Die Obere Niederterrasse (?) (ONT) . . . . . . . . . . . . . . . . . . 11

2.1.5. Die Kelsterbacher Terrasse . . . . . . . . . . . . . . . . . . . . . . 12

2.2 Interglaziale Bodenreste . . . . . . . . . . . . . . . . . . . . 13

2.3. Zusammenfassende Betrachtung . . . . . . . . . . . . . . . . 15

2.4. Aolische Ablagerungen . . . . . . . . . . . . . . . . . . . . . . . 15

2.4.1. Flugsande . . . . . . . . . . . . . . . . . . . . . . . . 15

2.4.2. Dünen und ihr Aufbau . . . . . . . . . . . . . . . . . . 21

2.4.2.1. Allgemeines . . . . . . . . . . . . . . . . . . . . 21

2.4.2.2. Die Basisschichten . . . . . . . . . . . . . . . 21

2.4.2.3. Bänderflugsande . . . . . . . . . . . . . . . . . . . 24

2.4.2.4. Die Deckschichten . . . . . . . . . . . . . . . . . . . . 25

2.5. Die Klima- und Bodenentwicklung im Untermaingebiet seit dem Riß/Würm

Interglazial .................... . . 31 
Seite

3. Quartäre Bildungen im Gebiet von Rhein und Neckar

3.1. Fluviatile Ablagerungen . . . . . . . . . . . . . . . . . . . . 37

3.1.1. Allgemeines . . . . . . . . . . . . . . . . . . . . 37

3.1.2. Hochflutlehmdecke . . . . . . . . . . . . . . . . . . 37

3.1.3. Niederterrassen . . . . . . . . . . . . . . . . . 37

3.2. Aolische Ablagerungen ... . . . . . . . . . . . . . . 38

3.2.1. Flugsande . . . . . . . . . . . . . . . . . . . . . . . . . 38

3.2.2. Der stratigraphische Aufbau der Dünen . . . . . . . . . . . . 38

3.2.2.1. Der Zapfenboden . . . . . . . . . . . . . . . . . 40

3.2.2.2. Die Bänderbraunerde . . . . . . . . . . . . . . . . . 42

3.2.2.3. Die jüngsten Flugdecksande . . . . . . . . . . . . . . . 42

3.3. Das Lorsch-Viernheimer Dünengebiet . . . . . . . . . . . . . . . . . . . . . 42

3.4. Das Alter der Schichten .. . . . . . . . . . . . . . . . . . . 42

4. Die Flugsandvorkommen des Sprendlinger Horstes . . . . . . . . . . . . . . . . . 43

5. Das Bänderproblem . . . . . . . . . . . . . . . . . . . 44

Literaturverzeichnis . . . . . . . . . . . . . . . . . . . . . . . . 49

\section{Einleitung}

\subsection{Das Arbeitsgebiet}

Das Untersuchungsgebiet umfaßt den nördlichsten Teil des Oberrheintalgrabens und entspricht damit etwa dem wirtschaftsgeographischen Begriff des südlichen Rhein-MainGebietes. Diese zwischen der rheinhessischen Tertiärtafel im Westen und dem Odenwald und Sprendlinger Horst im Osten eingesenkte quartäre Grabenzone erfährt auf drei Seiten eine natürliche Begrenzung. Im Westen zieht der Rhein eine scharfe Grenzlinie. Sein Lauf markiert hier die auch morphologisch deutlich hervortretende, schroffe tektonische Abbruchzone des rheinhessischen Tertiärblockes gegen den in diesem Bereich $25-30 \mathrm{~km}$ breiten Bruchgraben. Den nördlichen Abschluß des langgestreckten Rheintalgrabens und damit auch des Arbeitsgebietes bildet der Main am Südrand der Vortaunuslandschaft. Der von den Ausläufern des kristallinen Odenwaldes nach Norden vorspringende schmale Sporn des aus Rotliegend-Sedimenten aufgebauten, morphologisch nicht sehr scharf ausgeprägten Sprendlinger Horstes soll als östlicher Begrenzungsraum angenommen werden. Nach Süden, wo in Fortsetzung der breiten Grabensenke eine natürliche Grenze nicht gegeben ist, möge die Linie Darmstadt-Oppenheim als ungefährer Anhalt dienen. Eine scharfe willkürliche Grenze soll dort schon deshalb nicht gezogen werden, weil zahlreiche Vergleichsbegehungen und Profilaufnahmen auch in den weiter südlich gelegenen Flugsandund Dünengebieten erfolgten.

In diesen derart umgrenzten Bruchgraben wurden von Rhein, Main und Neckar sowie zahlreichen Odenwaldbächen während des Pleistozäns Sand- und Geröllmassen eingeschüttet. Ihre Mächtigkeit beträgt heute stellenweise mehrere $100 \mathrm{~m}$. Aus den oberflächennahen Partien dieser sandig-kiesigen Ablagerungen wurden während des Würm-Glazials und fortwirkend bis in die junge Vergangenheit die feinkörnigen Komponenten als Flugsande ausgeblasen und zu Dünen oder flächenhaft ausgebreiteten Decken aufgeweht. Da diese die unterlagernden fluviatilen Sedimente auf großen Flächen heute verhüllenden Flugsande im allgemeinen nicht wesentlich über die Aufschüttungsbereiche von Rhein, Main und Neckar hinausgehen, ergibt sich im nördlichen Oberrheintalgraben die Möglichkeit einer Abgrenzung folgender Flugsand-Faziesräume: 1) Das Gebiet der Mainflugsande, 2) Das Bergsträßer Flugsandgebiet, 3) Das Lorsch-Viernheimer Dünengebiet, 4) Die Flugsandvorkommen des Sprendlinger Horstes. 
Die vorliegende Arbeit entstand auf Anregung von Professor Dr. Sснӧnhals, Gießen, als Dissertation am Geologischen Institut in Frankfurt (Main).

Meinem hochverehrten Lehrer, Professor Dr. SchönHALs, bin ich für zahlreiche Anregungen und Hinweise anläßlich mehrerer Geländebegehungen sowie das stete Interesse am Fortgang der Arbeit und fördernde Kritik bei der Auswertung und Darstellung der Ergebnisse zu bleibendem Dank verpflichtet. Dr. Altemüllek, Institut für Bodenbearbeitung an der Forschungsanstalt für Landwirtschaft, Braunschweig-Völkenrode, danke ich sehr herzlich für die Anfertigung einer Anzahl von Bodendünnschliffen und die Unterstützung bei der Auswertung dieser Dünnschliffe. Für die Untersuchung einer Anzahl von Bodenproben bin ich Dr. EckHaRdT, Dr. Fastabend, Dipl.Physiker Geyh und Dr. Mattiat, alle an der Bundesanstalt für Bodenforschung in HannoverBuchholz, zu großem Dank verpflichtet. Mein besonderer Dank gebührt Professor Dr. Frechen, Bonn, für die Untersuchung einer Bims-Tuffprobe und Dr. Jokns, Darmstadt, für die Bestimmung einer Anzahl von Scherbenfunden. Großen Dank schulde ich auch Professor Dr. Lehmann, Frankfurt (Main), für die freundliche Zuweisung eines Arbeitsplatzes im Sedimentpetrographischen Labor des Geographischen Institutes, sowie Dr. Semmel, Hessisches Landesamt für Bodenforschung in Wiesbaden, für zahlreiche Hinweise und wertvolle Ratschläge bei der Durchführung dieser Arbeit. Die Geländearbeiten wurden durch eine Sachbeihilfe der Deutschen Forschungsgemeinschaft unterstützt, wofür an dieser Stelle vielmals gedankt sei.

\subsection{Problemstellung}

Auf den ausgedehnten Terrassenflächen des nördlichen Oberrheintales war das jüngste geologische Geschehen - wie bereits erwähnt - gekennzeichnet durch die Ablagerung von Flugsanddecken und die Aufwehung von Dünen unterschiedlicher Größe und Anordnung. Stratigraphische Untersuchungen dieser Windsedimente blieben bisher fast ausschließlich auf das Bergsträßer Gebiet beschränkt, was in erster Linie wohl auf die meist ungünstigen Aufschlußverhältnisse in den übrigen Flugsandgebieten zurückzuführen ist.

Durch den Bau der Autobahn-Eckverbindung Mönchhof (östlich Raunheim)-Darmstadt wurden nun in den beiden vergangenen Jahren besonders im Maingebiet eine Vielzahl von Flugsanddünen angeschnitten. Wie schon ein erster Überblick zeigte, handelt es sich bei diesen Dünen nicht um die Aufhäufung einheitlicher Sandmassen, sondern um meist mehrfach gegliederte, verschiedene Flugsandabfolgen. Diese vorübergehend sehr günstigen Aufschlußverhältnisse ließen daher eine zusammenfassende stratigraphische Bearbeitung der Flugsande im nördlichen Oberrheintal angebracht erscheinen. Gleichzeitig ergab sich durch die nähere Untersuchung der die Flugsandkomplexe gliedernden fossilen Bodenreste die Möglichkeit einer Aufhellung der Bodengeschichte dieses Raumes.

\section{Quartäre Bildungen im Maingebiet}

\subsection{Fluviatile Ablagerungen}

\subsubsection{A $11 \mathrm{gem}$ eines}

Die Lagerungsverhältnisse der fluviatilen Sedimente des randlich gelegenen Untermaingebietes gestalten sich infolge differenzierter tektonischer Bewegungen des Untergrundes weit weniger einheitlich als im Grabeninneren der Oberrheintalsenke, wo sich weitgehend der normale quartäre Flachlandtypus entwickeln konnte. Auf eine eingehende Darstellung (s. E. BECKER, Diss. 1965) der zwischen Kelsterbach und der Mainmündung ausgebildeten Terrassenstufen soll hier verzichtet werden. Wir beschränken uns auf eine kurze Beschreibung der morphologisch und petrographisch unterscheidbaren Stufen und werden die Problematik ihrer exakten Datierung nur so weit behandeln, als dies zum Verständnis der stratigraphischen Einordnung der überlagernden Flugsande notwendig erscheint.

Das von unserer Betrachtung erfaßte linksmainische Gebiet erstreckt sich zwischen Frankfurt/Kelsterbach und der Mainmündung über eine Entfernung von $30-40 \mathrm{~km}$. Die größte Verbreitung im Untersuchungsgebiet erreicht die alt- bis mittelpleistozäne Kelster- 
bacher-Terrasse, die sich $15-20 \mathrm{~km}$ nach Süden verfolgen läßt. Diese zwischen Frankfurt und Kelsterbach mit einer Steilkante morphologisch deutlich gegen die jüngeren Bildungen abgesetzte Terrassenstufe taucht nach Westen allmählich unter jüngere Terrassensedimente ab. Diese jungpleistozänen Terrassenablagerungen, zwischen Raunheim und Kelsterbach als relativ schmale Randsäume ausgebildet, dehnen sich westlich eines bei Raunheim nach Süden abzweigenden Mainaltarmes weit nach Süden aus und verhüllen hier die älteren Kelsterbachschotter.

\subsubsection{Das Hochflutbett}

Meist unmittelbar über dem mehrfach gestauten Flußspiegel liegt das vorwiegend als Grünland genutzte und bei jedem Hochwasser überschwemmte Hochflutbett des Mains. Das westlich Kelsterbach zunächst $25-75 \mathrm{~m}$ breite, an der Oberfläche meist ebene Hochflutbett verbreitert sich nach Westen auf maximal $400-500 \mathrm{~m}$ bei Bischofsheim. Die Ablagerungen des Hochflutbettes sind durch ein hellbraunes, vorwiegend schluffig-feinsandiges, stets bis in den Oberboden kalkhaltiges Sediment, das häufig Muschelschalen führt, gekennzeichnet. Das nachstehende Profil wurde in einem Pipeline-Graben auf der Höhe des Hofgutes Klaraberg unmittelbar am Flußufer aufgenommen (Bl. Hochheim 5916; R 3463 940: H 5545 700):

1) $\quad 0-17(17 \mathrm{~cm})$ dunkelgraubrauner $10 \mathrm{Y} \mathrm{R} \mathrm{4/2}$, lehmiger Sand bis sandiger Lehm, stark schluffig, schwach humos, sehr stark durchwurzelt (Wiese), wenig aggregiert

2) 17- $77(60 \mathrm{~cm})$ dunkelbrauner $7,5 \mathrm{RY} 4 / 4$, schluffig-lehmiger Sand, kalkhaltig, mäßig durchwurzelt, nicht aggregiert

3) $77-91(14 \mathrm{~cm})$ dunkelbrauner 7,5 YR 4/4, lehmiger, glimmerreicher Schluff, kalkhaltig bis stark kalkhaltig

4) 91-119 $(28 \mathrm{~cm})$ dunkelbrauner 7,5 YR 4/4, schluffiger Feinsand, schwach geschichtet, kalkfrei bis schwach kalkhaltig

5) 119-129 (10 cm) dunkelbrauner 7,5 YR 4/4, lehmiger Schluff, kalkhaltig bis stark kalkhaltig

6) 129-141 (12 cm) rötlichgelber 7,5 YR 7/6 Feinsand, locker, kalkfrei bis schwach kalkhaltig

7) $141-155(14 \mathrm{~cm})$ Schotterlage mit Buntsandsteingeröllen von $8-10 \mathrm{~cm} \phi$, zahlreiche

8) 155-244 $(90 \mathrm{~cm}) \quad \begin{aligned} & \text { Keramikbruchstücke und Ziegelreste (15. Jh.), häufig } \\ & \text { vorwiegend Sand mit einzelnen lehmigen Schlufflagen. }\end{aligned}$

2.1.3. Die Untere Niederterrasse (UNT) und ihre

Hochflut lehmdecke

Die stets in Ackernutzung stehende, meist ebene, nur gelegentlich durch Altwasserrinnen schwach gegliederte Oberfläche der Unteren Niederterrasse liegt etwa 2-3 m über dem schmalen Grünlandstreifen des Hochflutbettes ( $92,5 \mathrm{~m}$ über NN). Morphologisch deutlich ausgeprägt nimmt diese Terrassenstufe zwischen Kelsterbach und Raunheim nur einen verhältnismäßig schmalen Streifen von $400-500 \mathrm{~m}$ Breite ein, erlangt dann aber westlich Raunheim ziemlich unvermittelt eine erhebliche räumliche Ausdehnung nach Süden bis etwa zur Linie Königstädten-Ginsheim. Allerdings dürfen wir, das sei einschränkend hinzugefügt, bei dieser sich auf etwa $5 \mathrm{~km}$ verbreiternden Terrassenstufe nicht mehr ausschließlich von einem Aufschüttungsbereich der UNT sprechen, da, wie die Untersuchungen gezeigt haben, gelegentlich auch ältere Ablagerungen zumeist im gleichen Niveau mit den UNT-Sedimenten auftreten können. Durch das Fehlen deutlicher morphologischer Unterschiede in diesem Gebiet lassen sich die verschiedenaltrigen Ablagerungen im Gelände meist nur schwer voneinander trennen.

Der maximal 3-4 m mächtige Akkumulationskörper der UNT setzt sich vorwiegend aus rötlichbraun gefärbten, lockeren, zum Teil kreuzgeschichteten Sanden und Schotterlagen zusammen. Wenn auch die sandigen Schichten im allgemeinen vorherrschen, so kann doch gelegentlich eine stärkere Geröllführung beobachtet werden. Die stets frischen Kiese 
und Schotter zeigen die bereits vielfach beschriebene charakteristische Zusammensetzung der Mainablagerungen mit einer starken Buntsandsteinvormacht. Typisch und zur Abgrenzung gegen ältere Bildungen gut geeignet ist die stets zu beobachtende Beimengung von Muschelkalkgeröllen, deren Anteil an der Gesamtzusammensetzung der Schotter meist jedoch nur wenige Prozentanteile beträgt. Gelegentlich kann der Muschelkalkanteil allerdings auch sehr stark anwachsen, wie dies in Baugruben bei Rüsselsheim und Schwanheim mehrfach beobachtet wurde.

Die $\mathrm{Hochflutlehmdecke} \mathrm{der} \mathrm{UNT.} \mathrm{Die} \mathrm{sandig-kiesigen} \mathrm{Ablagerungen}$ der UNT tragen stets eine feinkörnige Hochflutlehmdecke von gelegentlich bis zu $1,5 \mathrm{~m}$ Mächtigkeit. Im ausgedehnten Akkumulationsbereich der UNT zeigt diese, im obersten Horizont zuweilen auch äolisch beeinflußte, Deckschicht eine typische Dreigliederung in einen oberen dunkelbraun gefärbten, lehmig-sandigen, einen mittleren rotbraunen, lehmig-tonigen und einen unteren stets kalkreichen, lehmig-schluffigen Horizont. Einen guten Einblick in den Schichtaufbau zeigt das folgende, an der Baustelle der Caltex-OIRaffinerie westlich der Autobahn Frankfurt (Main)-Köln aufgenommene Profil (Bl. Hochheim 5916; R 3462090 : H 5543 460):
1) $\mathrm{Ap} O-25(25 \mathrm{~cm})$
dunkelgraubrauner 10 YR 3/2, lehmiger Sand, schwach humos,
2) $\mathrm{B}_{\mathrm{V}} 25-55 \quad(30 \mathrm{~cm})$
3) $\mathrm{fB} 55-96 \quad(41 \mathrm{~cm})$ wenig aggregiert, stark durchwurzelt
brauner 7,5 YR 4/4, lehmiger Sand, feinsandig, kohärentes Gefüge, gelegentlich schwach rostgefleckt, vereinzelte 4-5 mm starke Ton- anreicherungsbänder (schokoladenbraun), diffuser Ưbergang
3) $\mathrm{fB} \quad 55-96 \quad(41 \mathrm{~cm})$
dunkelroter 2,5 YR 3/6, sandig-lehmiger Ton, kleinpolyedrisches Gefüge, durchsetzt mit zahlreichen schwärzlichbr. stecknadelkopf- großen $\mathrm{Fe}-\mathrm{Mn}$-Konkretionen, zuweilen auch $\mathrm{Fe}-\mathrm{Mn}$-Abscheidungen als Beläge auf den Gefügeelementen, allmählicher Ưbergang zu
4) C $96-134 \quad(38 \mathrm{~cm})$
gelblichroter 5 YR 5/6, feinsandig-schluffiger, kalkhaltiger Lehm, deutlich geschichtet, pseudomycelartige Kalkabscheidungen, nach unten zunehmend sandig
5) $\mathrm{D} 134+$ rötlichbraune Sande und Kiese der UNT.

Dieser typische Profilaufbau verdankt seine Entstehung sowohl geologischen als auch bodengenetischen Vorgängen. Für eine geologische Schichtigkeit des oberen Profilabschnittes besonders in flußferneren Gebieten sprechen die Lagerungsverhältnisse in einem Aufschluß am Rande eines engbegrenzten Dünengebietes am Ostpark bei Rüsselsheim-Horlache. Hier wird der rotbraune, tonige Horizont von etwa 1,2 $\mathrm{m}$ mächtigen Flugsanden überlagert, die an der Oberfläche (Profiltiefe etwa $30-40 \mathrm{~cm}$ ) zu einer schwach entwickelten Braunerde verwittert sind.

Läßt sich auf Grund dieses eindeutig geologischen Schichtaufbaues eine Profildifferenzierung durch Verlagerungsvorgänge aus dem Oberboden nahezu ausschließen, so kann bei abnehmender Mächtigkeit und abnehmendem Sandgehalt des Oberbodens in Flußnähe der Einfluß der pedogenetischen Prozesse bei der Horizontbildung nur schwer erfaßt werden. Die Ergebnisse der zur Klärung dieser Fragen durchgeführten sedimentologischen und mikromorphologischen Untersuchungen lassen sich zu folgender genetischer Deutung des Decklehmprofils zusammenfassen:

Nach Ablagerung der sandig-kiesigen UNT erfolgte innerhalb eines längeren Zeitraumes durch häufige Überflutungssedimentation die Bildung der kalkhaltigen Hochflutlehmdecke. Diese Akkumulation kam vermutlich während einer verstärkten erosiven Phase des Mains allmählich zum Stillstand. Damit konnte zunächst an der Oberfläche eine stärkere Entkalkung einsetzen. Unter dem Einfluß eines gegenüber den heutigen Verhältnissen wesentlich wärmeren Klimas setzte dann in diesem teilweise entkalkten Sediment eine intensive Bodenbildung ein, die in dem feinkörnig-schluffigen Substrat zu einer merkbaren Tonmineralneubildung in situ führte. Daneben kann ein geringer Anteil der tonigen Substanz vermutlich auch auf Einschlämmung zurückgeführt werden. Ein erneu- 
ter Klimaumschwung beendete diese Bodenbildungsphase; in Flußnähe kam es nachfolgend $\mathrm{zu}$ wechselnder äolischer und fluviatiler, in den flußfernen Gebieten dagegen zu überwiegend äolischer Sedimentation. Die teilweise vorherrschend sandigen bis $80 \mathrm{~cm}$ mächtigen äolischen Ablagerungen wurden in dem bis zur Gegenwart reichenden Zeitraum zu einer schwach bis mäßig entwickelten Braunerde umgebildet. Das geologisch

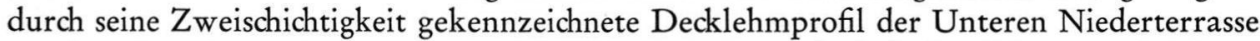
repräsentiert demnach auch zwei zeitlich getrennte, typologisch deutlich unterscheidbare Bodenbildungen. Die eingehende Erörterung der altersmäßigen Einstufung dieser verschiedenen Horizonte soll zusammen mit der Diskussion der äolischen Deckschichtenprofile erfolgen.

\subsubsection{Die Obere Niederterrasse (?) ( ONT)}

An die UNT schließt sich eine, morphologisch gegen diese nur durch eine zwei bis drei $\mathrm{m}$ hohe Stirnkante abgesetzte, weitere als Obere Niederterrasse zu bestimmende Terrassenstufe an ( $95 \mathrm{~m}$ über NN). Die flächenhafte Ausdehnung dieser Flußaufschüttung läßt sich nur schwer bestimmen, da infolge fehlender morphologischer Unterschiede eine sichere Abgrenzung gegen die nach Süden an die Oberfläche tretenden älteren Ablagerungen nur in wenigen Fällen möglich ist. Zwischen Kelsterbach und Raunheim dürfte die Gesamtbreite dieser Terrasse $400-600 \mathrm{~m}$ jedoch nicht überschreiten. Wie in einzelnen Bodeneinschlägen und den wenigen größeren Aufschlüssen beobachtet werden konnte, keilen die Ablagerungen der ONT-Stufe nach Süden allmählich aus und überdecken dann vielfach nur noch als dünner Schleier die älteren Aufschüttungen. Die Stirnkante dieser Terrasse läuft bis Raunheim der B 43 fast parallel, biegt im Ortsbereich scharf nach Süden $a b$ und ist am östlichen Ufer eines Mainaltlaufes bis Königstädten gut zu verfolgen.

Der rötliche, frische, im Durchschnitt 3-4 m mächtige Schotterkörper wird bei Zurücktreten der sandigen Komponente vorwiegend aus rötlichen Buntsandsteingeröllen unterschiedlicher Größe, hellen Quarz- und Quarzitgeröllen sowie vereinzelt beigemengten Kieselschiefer- und Hornsteigeröllen aufgebaut. Nicht selten tragen die Buntsandsteingerölle an ihrer Oberfläche als Anzeichen geringer Verwitterungseinflüsse dünne, meist lückenhafte, schwärzliche Manganüberzüge. Eine Beimengung von Muschelkalkgeröllen, wie sie für die UNT typisch ist, konnte in diesen Ablagerungen nicht beobachtet werden. Die Einlagerung zahlreicher grober Buntsandsteinblöcke vorwiegend an der Basis des Schotterkörpers beweist eindeutig den kaltzeitlichen Charakter dieser Terrasse. Eine Hochflutlehmdecke ist in deutlichem Gegensatz zur UNT an der Oberfläche der schotterreichen Oberen Niederterrasse nicht ausgebildet, so daß dort, wo ihre Oberfläche beackert wird, an der dichten Schotterbestreuung der Felder diese fluviatile Aufschüttung leicht erkannt werden kann. Zu stärkeren Flugsandüberwehungen kam es vor allem im südwestlichen Verbreitungsgebiet zwischen Raunheim und Königstädten, während zwischen Kelsterbach und Raunheim nur randlich von Süden her dünne Flugsandschleier auf diese Terrasse übergreifen. Der rötliche, nahezu unverwitterte Schotterkörper wird stets mit scharfer Grenze von stark verwitterten gelben bis gelblichweißen Sanden und Schottern unterlagert. Diese deutliche petrographische Grenze zwischen gelben und roten Schottern war in der Sandgrube Willersinn westlich Kelsterbach zeitweise gut aufgeschlossen.

An der Oberfläche dieser geröllreichen Terrasse entwickelte sich eine Braunerde geringer Basensättigung. Unter der rezenten Bodenbildung fällt ein stellenweise bänderartig aufgelöster, zuweilen stark kryoturbat gestörter Tonanreicherungshorizont auf, dessen Taschen gelegentlich noch mit einem hochflutlehmartigen, meist schwach kalkhaltigen, feinkörnigen Material gefüllt sind. Die Bildung dieses Horizontes dürfte bereits vor dem letzten Kälterückschlag in der jüngeren Tundrenzeit erfolgt sein und steht damit in keinem zeitlichen Zusammenhang mit der starken Verlehmung der Hochflutablagerungen der UNT. 
Gewisse Möglichkeiten für die zeitliche Datierung dieser Aufschüttung ergeben sich aus dem Fund einiger Zahnfragmente von „Mammonteus primigenius" in der Grube Willersinn. Dr. Adam (Stuttgart) ${ }^{1}$ ) kommt auf Grund eingehender Untersuchungen der fragmentären Molaren zu dem Ergebnis, daß die beiden dem roten Schotterkörper entstammenden Zahnreste ins Jungpleistozän, also ins Würm zu stellen sind, während dem in den gelben Schottern gefundenen Molarenrest ein vermutlich höheres Alter zukommt.

\subsubsection{Die Kelsterbacher Terrase}

In dem von uns betrachteten Flußabschnitt westlich Kelsterbach tritt die Kelsterbacher Terrasse morphologisch nur noch wenig hervor, dagegen kam es in dem östlich anschließenden Gebiet zur Herausbildung einer 10-15 m hohen markanten Geländekante. Diese in nahezu ostwestlicher Richtung zwischen Frankfurt (Main)-Louisa und Kelsterbach sich erstreckende Terrassenstufe tritt bei Kelsterbach dicht an den heutigen Flußlauf heran und bildet dort ein bis auf $20 \mathrm{~m}$ über den Flußspiegel ansteigendes Steilufer. Nach Westen verflacht sich die Stirnkante dann sehr rasch und taucht unter jüngere Schotter ab. Westlich des Sprendlinger Horstes erreicht die Kelsterbacher Terrasse eine große flächenhafte Ausdehnung. Die fluviatilen Aufschüttungen, bis etwa $10 \mathrm{~km}$ weit nach Süden gut zu verfolgen, bedecken hier eine Fläche von mehr als $150 \mathrm{~km}^{2}$.

Die Kelsterbacher Terrasse wird von gelblichen bis gelblichweißen, meist stark verwitterten Schottern und Sanden aufgebaut, wobei grobkörnige Sande und Kiese bei weitem überwiegen. Randlich, besonders im südlichen Bereich, treten die gröberen Gerölle immer mehr zurück. Im Vertikalprofil zeigen die Ablagerungen im allgemeinen einen bemerkenswert einheitlichen petrographischen Aufbau.

Die Altersstellung der Kelsterbacher Terrasse blieb bis heute umstritten. Auf eine umfassende Diskussion der zahlreichen zu dieser Frage veröffentlichten Beiträge soll an dieser Stelle verzichtet werden (s. E. BECKER, Diss. 1965).

Zusammenfassend bleibt festzustellen, daß sich am Aufbau dieser morphologisch einheitlichen Terrasse Schotterkörper stratigraphisch verschiedener Akkumulationsphasen beteiligen, wobei das absolute Alter der einzelnen Aufschüttungskomplexe bis heute nicht bestimmt werden konnte. Die ältesten Schotter jedenfalls gehören nach den Untersuchungen von BAAs (1932) vermutlich dem Brüggen-Glazial an.

Gegliedert wird der Terrassenkörper neben anderen petrographischen Merkmalen vor allem durch meist humose Tonpakete unterschiedlicher Mächtigkeit und Ausdehnung. Umstritten blieb bis heute die Horizontbeständigkeit und damit der stratigraphische Wert dieser Toneinschaltungen. Eigene Beobachtungen sprechen dafür, daß die Tonhorizonte mehr oder weniger rasch seitlich auskeilen und nach einiger Entfernung in anderem. Niveau wieder einsetzen. Die endgültige Klärung dieser Fragen steht jedoch noch aus und bleibt als wichtige Aufgabe der Quartärgeologie dieses Gebietes bestehen.

Was das Alter des gesamten fluviatilen Aufschüttungskomplexes betrifft, wird man wohl WaGNER (1950, S. 191) im wesentlichen zustimmen dürfen, der die tektonische Herausbildung zur morphologisch hervortretenclen Terrasse in das Präriß verlegte. Während des Rißglazials wurden dann die herausgehobenen östlichen Teile der Kelsterbacher Terrasse vermutlich zum Abtragungsgebiet, worauf auch zahlreiche anschließend wieder mit Kelsterbachschottern aufgefüllte Erosionsrinnen an der Oberfläche dieser Ablagerungen deutlich hinweisen. Altpleistozäne Bodenbildungen sowie rißeiszeitliche äolische Ablagerungen konnten auf dieser Terrasse bisher nicht nachgewiesen werden.

1) Dr. Semmel (Wiesbaden) stellte mir freundlicherweise das Gutachten von Dr. Adam für meine Zwecke zur Verfügung. 


\subsection{Interglaziale Bodenreste}

Erste Anzeichen einer weit verbreiteten intensiven Bodenbildung an der Oberfläche der Kelsterbachschotter finden sich heute vorwiegend noch in den Gebieten, wo mächtige würmeiszeitliche Flugsanddecken einen vollständigen späteren Abtrag dieser fossilen Bodenbildungen verhinderten. In größerer rïumlicher Verbreitung waren diese kryoturbat stark gestörten Bodenrelikte in den letzten Jahren in mehreren Kiesentnahmestellen für den Autobahnbau östlich Raunheim zeitweise gut erschlossen. In Form tiefer Taschen, Tropfen und Keulen wurden hier die Reste einer fossilen Bodenbildung in die Terrassensande intensiv eingewürgt. Die gelegentlich bis zu $2 \mathrm{~m}$ tiefen und 1,5 $\mathrm{m}$ breiten sackartigen Einstülpungen vermitteln einen deutlichen Eindruck von der ehemals wohl erheblichen Mächtigkeit der ungestörten Bodendecke.

Die Intensität der Kryoturbationsvorgänge wird besonders an einzelnen, in den Schottern eingeschlossenen, isolierten Bodenresten erkennbar. Die meist rundlich geformten Bodenrelikte wurden offenbar durch eine vertikale Rotationsbewegung aus dem übrigen Bodenverband gerissen und förmlich in den Terrassenkörper eingedreht. Die Füllung der Taschen besteht aus einem kräftig dunkelbraun bis schwach rötlichbraun gefärbten, lehmig-schluffigen, gelegentlich auch später tonigen Material, das sich von dem umgebenden Schotterkörper deutlich abhebt. In die vorwiegend dichte, nur wenig gegliederte, kohärente Bodenmasse sind Gerölle unterschiedlicher Größe und Anzahl eingestreut. Gelegentlich kann eine stärkere Anreicherung der sonst meist regellos verteilten Gerölle im Inneren einer solchen Tasche beobachtet werden.

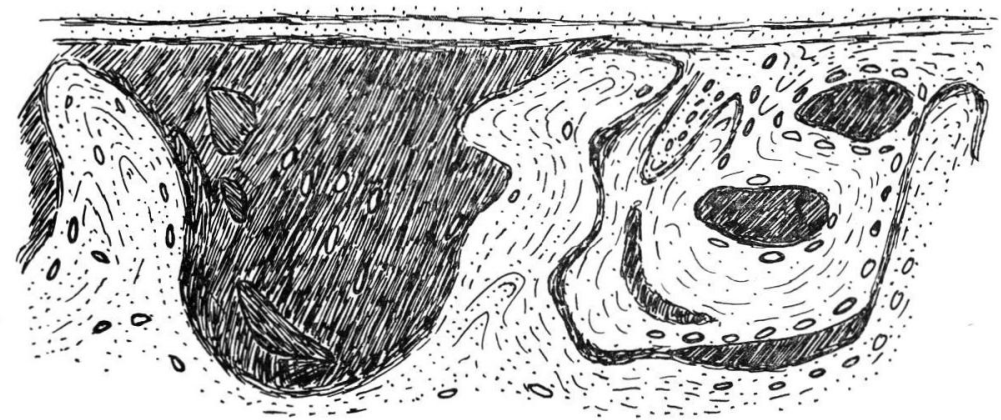

Abb. 1. In Terrassenkiese eingewürgte Reste des Eem-Interglazialbodens.

Mönchhof (östlich Rüsselsheim). ${ }^{1 / 40}$.

Im Schliffbild fällt die bemerkenswert dichte Kornpackung dieses Bodens auf. Stellenweise liegen grobe Körner in einer feinkörnigen Grundmasse eingebettet. Daneben kommen auch Partien gleichartiger Körnung von Grobsand und Schluff vor. Insgesamt ist der Bodenaufbau jedoch durch eine ungleichartige Packung gekennzeichnet. Die feinkörnige Zwischenmasse ist schwach braunerdeartig geflockt. Teilweise zeigen die gröberen Körner eine allerdings nur undeutliche Hüllenbildung.

Vergleichbare, jedoch meist weniger stark ausgeprägte Kryoturbationshorizonte konnten auch in den zahlreichen übrigen, im gesamten Arbeitsgebiet verstreuten Kiesgruben beobachtet werden. Häufig sind allerdings nur noch geringe Reste des Frostbodens erhalten. Aus ihren Vorkommen jeweils an der Oberfläche der Terrasse unter einer jüngeren äolisch beeinflußten Überlagerung darf geschlossen werden, daß es sich um zeitlich äquivalente Bildungen handelt.

Diese Verwitterungsdecken sind vermutlich während des letzten Interglazials (Eem) entstanden. Das dürfte einmal aus den besonderen Lagerungsverhältnissen hervorgehen, zum anderen würden bei einer älteren Einstufung dieser Böden die Anzeichen einer letztwarmzeitlichen Bodenbildung aber völlig fehlen. Es erscheint jedoch unwahrscheinlich, daß 


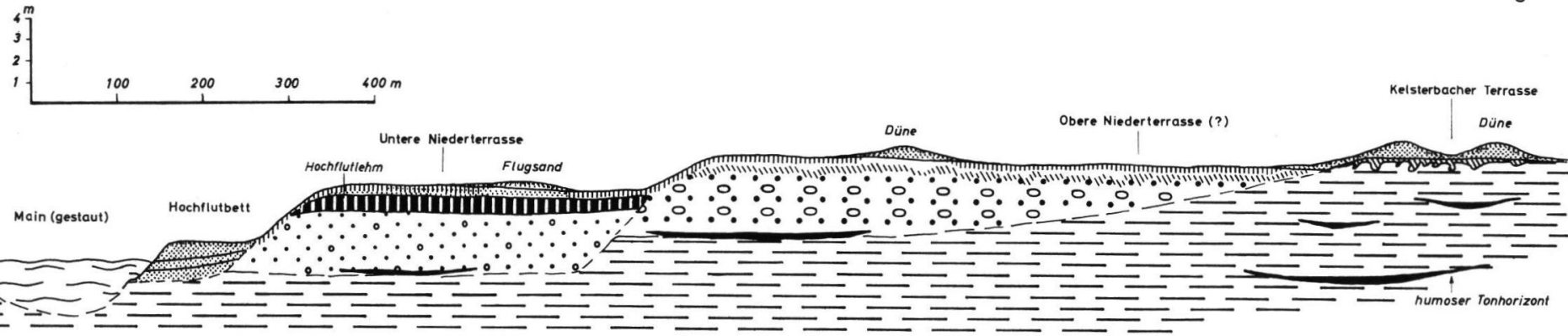

Abb. 2. Schematische Darstellung des Terrassenaufbaus im südl. Maingebiet zwischen Kelsterbach und Raunheim (nähere Erläuterung im Text). 
in einem Gebiet mit vorherrschender Flugsandakkumulation während des letzten Glazials diese jüngeren Bildungen restlos verschwunden sein sollen, während eine in ein älteres Interglazial zu stellende Verwitterungsdecke auf größeren Flächen erhalten blieb, zumal gerade für das Rißglazial auf der Kelsterbacher Terrasse mit stärkeren Abtragungsvorgängen (s. o.) gerechnet werden muß.

\subsection{Zus a m menfassende Betrachtung}

Wie aus den bisherigen Darlegungen hervorgeht, läßt sich auch in einem räumlich engbegrenzten und morphologisch wenig gegliederten Flußabschnitt eine Terrassengliederung durchführen. Die fluviatilen Aufschüttungen der einzelnen Stufen des südlichen Untermaingebietes werden charakterisiert durch einen bestimmten petrographischen Aufbau sowie durch die an ihrer Oberfläche gebildeten, typologisch verschiedenen Böden. Dabei ergeben sich - wie bereits angedeutet - auch aus dem jeweiligen Aufbau des Bodenprofils bestimmte Hinweise auf die Bildungsperiode der verschiedenen Terrrassenkörper.

Noch im Anfangsstadium befindet sich die Bodenentwicklung auf den Sedimenten des Hochflutbettes. Auf diesen, vorwiegend in junger historischer Zeit aufgeschütteten, noch bis zur Oberfläche kalkhaltigen Ablagerungen kam es bisher lediglich zur Ausbildung eines rendzinaartigen Auebodens (Borowina). Die durch eine kleine Geländekante gegen das Hochflutbett abgesetzten, aus frischen, rötlichbraunen Sanden und gelegentlich kalkgeröllführenden Schottern aufgebaute UNT trägt stets eine bis zu 1,5 m mächtige Hochflutlehmdecke. Die deutliche Dreigliederung dieser feinkörnigen Ablagerungen beruht einmal auf primären Sedimentationsunterschieden, zum anderen auf zeitlich verschiedenen Bodenbildungsprozessen. Während nämlich der feinkörnige, braune, kalkhaltige (spätpleistozäne ?) Hochflutlehm in einer ersten, wahrscheinlich frühholozänen Bodenbildungsphase im oberen Teil zu einem kräftig rötlichbraunen, tonigen Lehm verwitterte, entstanden aus den später auf dieser Bodenoberfläche abgelagerten Sedimenten Braunerden geringer bis mittlerer Entwicklungstiefe.

Der - vermutlich im Frühwürm aufgeschüttete - Terrassenkörper der ONT baut sich überwiegend aus rötlich gefärbten, wenig verwitterten, groben Kiesen und Schotterlagen auf. An der Oberfläche dieser von lehmigen Hochflutablagerungen freien Terrasse entwickelte sich eine basenarme Braunerde unterschiedlicher Entwicklungstiefe. Im Inneren des Terrassenkörpers zu beobachtende rotbraune, kryoturbat gestörte Bänder deuten auf die Entwicklung einer Sandparabraunerde bereits im ausgehenden Glazial hin.

Die ältesten Bodenreste im südlichen Maingebiet finden wir auf der Kelsterbacher Terrasse. An Stellen, wo die Oberfläche dieser Terrasse unter jungpleistozänen, äolischen Deckschichten begraben wurde, blieben in den Einstülpungen eines mächtigen Kryoturbationshorizontes die Relikte eines rötlichbraunen Interglazialbodens (Riß/Würm) erhalten. In seinem Gefüge den heutigen Braunerden ähnlich, wird dieser Boden vor allem durch die für Interglazialböden typischen rötlichen Farbtöne gekennzeichnet. Die in großer flächenhafter Verbreitung auftretenden, stark verwitterten Schotter und Sande der Kelsterbacher Terrasse bilden den Rahmen und Untergrund der jungpleistozänen Terrassenaufschüttungen. Auf Grund eingehender petrographischer und floristischer Untersuchungen sind die liegenden Schotter und Sande ins älteste Glazial, die Brüggen-Kaltzeit, zu stellen. Welche Altersstellung den hangenden, durch die unregelmäßige Einlagerung von Tonhorizonten mehrfach gegliederten, fluviatilen Ablagerungen zuzuweisen ist, muß derzeit noch offenbleiben.

\subsubsection{Flugs ande}

\subsection{Aolische Ablagerungen}

Auf den weiten, der fluviatilen Aufschotterung entzogenen Terrassenflächen sowie in den schmalen Flußrandgebieten kam es während des letzten Glazials und noch bis ins frühe Postglazial zu ausgedehnten Flugsandverwehungen. Dabei wurden vorwiegend die 
älteren Aufschüttungen (Kelsterbacher Terrasse) nahezu lückenlos von äolischen Sedimenten überdeckt. Lediglich im Bereich der vom Sprendlinger Horst sich nach Westen zu verbreiternden jungen Bachauen ist eine vorwiegend inselartige Auflösung der geschlossenen Flugsandflächen durch Erosion und Überlagerung durch junge Hochflutlehme zu beobachten. Auch dort, wo der kiesige Untergrund auf größeren Flächen dicht an die Oberfläche tritt und demzufolge auf den geologischen Karten als Terrassenablagerung ausgeschieden wurde, läßt sich meist noch ein dünner, lückenhafter Flugsandschleier nachweisen.

Der dem Flugsand genetisch verwandte Löß fehlt dagegen in diesem Gebiet vollkommen. Lößfrei blieb ebenfalls das morphologisch stärker hervortretende Hügelland des Sprendlinger Horstes am Ostrand des Oberrheintalgrabens. Auch die aus anderen Flußrandgebieten bekanntgewordene charakteristische Abfolge Flugsand-Sandlöß-Löß (Breddin 1925; Dewers 1934/35; Müller 1955) ist in dem von uns untersuchten Teil der nördlichen oberrheinischen Tiefebene nicht $\mathrm{zu}$ beobachten. $\mathrm{Da}$ jedoch zusammen mit der Flugsandbildung zweifellos auch feinere Komponenten aus den Terrassenablagerungen ausgeweht wurden, wie die umgebenden Lößlandschaften hinlänglich beweisen, dürfte dieser Raum vermutlich als riesiges Lößauswehungsgebiet zu betrachten sein.

Der größte Teil des $200-300 \mathrm{~km}^{2}$ umfassenden Überwehungsgebietes wird von flächenhaft ausgebreiteten, wenig gegliederten Flugsanddecken unterschiedlicher Mächtigkeit überzogen. An zahlreichen, völlig regellos verteilten Stellen wurden die Flugsande zu Dünen unterschiedlicher Höhe und Ausdehnung aufgeweht. Neben den über das gesamte Gebiet verstreuten Einzelvorkommen entstanden während der intensiven äolischen Sedimentation besonders am West-Nordwest-Rañd der Aufschüttungsebene (Kelsterbacher Terrasse) auch größere geschlossene Dünenfelder. Sowohl in den Einzelvorkommen als auch in größerem Verband lassen die Dünen in der äußeren Gestalt sowie in der Anordnung zueinander meist jede Gesetzmäßigkeit vermissen. Das Vorherrschen eines bestimmten Formentyps, wie dies von Poser (1948, S. 273) in den meist durch eine Formengemeinschaft gekennzeichneten Dünenfeldern anderer Dünen- und Flußrandgebiete eindrucksvoll aufgezeigt wurde, läßt sich im Unteren Maingebiet nicht beobachten. Lediglich an einzelnen Stellen treten strichdünenartige, in ihrer Längserstreckung gleichsinnig sw-ne orientierte Formen etwas stärker hervor, ohne daß dadurch jedoch das Gesamtbild eines unruhig kuppigen Reliefs wesentlich verändert würde.

Das Ausgangsmaterial für die Mehrzahl der im folgenden zu besprechenden Bodenbildungen besteht in fast allen Fällen aus Flugsand. Es erscheint daher angebracht, diese äolischen Sedimente etwas eingehender zu behandeln. Die aus den Mainterrassen ausgewehten Flugsande sind meist schwach gelblichbraun gefärbt, relativ grobkörnig und nur gelegentlich sehr schwach kalkhaltig. Während die flächenhaft ausgebreiteten Flugsande nur sehr selten eine schwache Schichtung zeigen, sind vornehmlich die größeren Dünen durch eine meist gut ausgeprägte Feinschichtung gekennzeichnet. Die am Aufbau dieser Flugsande beteiligten dünnen Schichtlagen unterscheiden sich hinsichtlich ihrer jeweiligen Kornzusammensetzung meist sehr deutlich voneinander.

Zur Bestimmung der Korngrößenverteilung in den ungeschichteten Flugsanden wurde an 10 Stellen des Untersuchungsgebietes aus $50 \mathrm{~cm}$ Tiefe jeweils eine Probe entnommen und mit Hilfe des Schallfix-Siebgerätes und der KöHN'schen Pipette die Gewichtsanteile der einzelnen Fraktionen bestimmt. Wie aus der beigefügten Tabelle zu ersehen ist, zeigen die Ergebnisse dieser Analysen eine gute Übereinstimmung. Das Maximum der Kornverteilung liegt bei allen untersuchten Proben stets zwischen 200 und $500 \mu$, übersteigt jedoch in keinem Falle 75\% der Gesamtmenge. Ein gelegentlich stärkeres Anwachsen des Grobsandanteils auf über $20 \%$ kann als ebenso charakteristisch gelten wie der geringe Gesamtanteil der Fraktionen unter 0,1 mm, der nicht selten noch unter 2\% der Gesamt- 
menge liegt. Dieser geringe Schluffgehalt kann zumindest teilweise auf den meist niedrigen Feinkornanteil des Auswehungsmaterials zurückgeführt werden.

Die quantitative Auswertung der Analysenergebnisse erfolgte in der heute allgemein üblichen Weise mit Hilfe von Summenkurven. Berechnet wurden in vorliegendem Falle jedoch lediglich die für unsere Fragestellung wesentlichen Werte des "Mittleren Korndurchmessers" (Md = Median diameter) und der "Materialsortierung" (So-Wert).

Der Md-Wert wird dabei graphisch aus der Summenkurve bestimmt, indem der dem Schnittpunkt der 50\% Ordinate mit der Kurve entsprechende Korndurchmesser auf der Abszisse einfach abgelesen wird. In gleicher Weise ergeben sich auch die zur Berechnung der Sortierung erforderlichen Werte für die Schnittpunkte mit der 25\% (Q $\left.{ }_{1}\right)$ und 75\% $\left(Q_{3}\right)$ Ordinate. Den Wert für die Sortierung (So) erhält man aus der von TRAsK (1932) aufgestellten und heute international gebräuchlichen Formel:

$$
\text { So }=\sqrt{\frac{\mathrm{Q}_{1}}{\mathrm{Q}_{3}}}
$$

Nach Trask entsprechen dann den verschiedenen So-Werten folgende Sortierungsgrade:

$$
\begin{array}{ll}
1,2 & \text { sehr gut sortiert } \\
1,2-1,5 & \text { gut sortiert } \\
1,5-2,5 & \text { mäßig sortiert } \\
2,50 & \text { schlecht sortiert }
\end{array}
$$

Sindowski (in Bentz 1961, S. 173) fand nun bei seinen Untersuchungen der mechanischen Kornzusammensetzung an Binnendünen So-Werte zwischen 1,2-1,3, was allgemein einer guten Sortierung entsprechen würde. Die von uns errechneten So-Werte für die ungeschichteten Mainflugsande liegen dagegen zwischen 1,25-1,75. Mehr als die Hälfte der untersuchten Proben zeigen demnach mit Werten über 1,5 eine nur mäßige Sortierung. Diese gegenüber den von SINDOwSKI angegebenen Werten auffallende Abweichung könnte

\begin{tabular}{|c|c|c|c|c|c|c|c|c|c|c|c|c|c|}
\hline Lokatitat u. Proben - Nr. & $>2,0$ & $2,0-1,0$ & $1,0-0,5$ & $0,5-0,2$ & Q2- $-0,125$ & $<0.125$ & $0,1-0,063$ & Q.063-0,02 & $0,02-0,0063$ & $0,0063-0,002$ & $<0,002$ & Md-Wert & So-Wert \\
\hline $\begin{array}{l}\text { 1) Flugsandrücken S. Rüsselsheim } \\
\qquad 14 / 34\end{array}$ & 4,5 & 23,2 & 35,9 & 29,9 & 6,02 & 0,38 & - & - & - & - & - & 650 & 1,8 \\
\hline 2.)Am Autobahnknoten Mönchhod & - & 1,2 & 25,0 & 65,3 & 7.9 & 0,3 & - & - & - & - & - & 350 & 1,47 \\
\hline $\begin{array}{c}\text { 3.) Bodeneinschlag nw. Klärwerk } \\
\text { Langen } 76\end{array}$ & - & 1,5 & 17,1 & 58,8 & 17,4 & 4,7 & 3.1 & 1,1 & - & 0,5 & - & 310 & 1,27 \\
\hline $\begin{array}{l}\text { 4.) Helenenbrunnenschneise w. } \\
\text { Egeisbach } 80\end{array}$ & 0.3 & 4,4 & 16,7 & 41,6 & 25,1 & 9,6 & 7,8 & 1,3 & 0,2 & 0,3 & - & 275 & 1.77 \\
\hline 5) Autobahnknoten Haßloch 82 & 0,1 & 7,3 & 27,3 & 50,6 & 12,7 & 1,8 & - & - & - & - & - & 390 & 1,54 \\
\hline $\begin{array}{l}\text { 6.) Heegberge o. Reitplatz } \\
\text { Erzhausen } \mathrm{Hg} \quad 1\end{array}$ & 0.4 & 9,8 & 16,3 & 46,2 & 26,0 & 1,1 & - & - & - & - & - & 290 & 1,58 \\
\hline 7.) Sandgrube w. Schwanheim 37 & - & 1,9 & 22,2 & 65,0 & 8,9 & 1,9 & - & - & - & - & - & 390 & 1,29 \\
\hline 8.) Konigstadter Forst & - & 0,2 & 4,6 & 56,8 & 36,2 & 1,9 & - & - & - & - & - & 230 & 1,25 \\
\hline 2) a. Hofgut Bayerseich $41 / 44$ & 0.4 & 2,9 & 18,8 & 49,7 & 25,5 & 2,4 & 1,8 & 0,6 & - & - & - & 310 & 1.67 \\
\hline $\begin{array}{l}\text { 10.) n. Eppertshausen im Berkes } \\
40 / 47\end{array}$ & 0.1 & 2,7 & 12,3 & 53,2 & 28,2 & 3,1 & 2,2 & 0,7 & - & 0,2 & - & 270 & 1,53 \\
\hline
\end{tabular}
vielleicht darauf zurückgeführt werden, daß in den ungeschichteten Flugsanden nur eine geringe Entmischung während des Windtransportes erfolgte oder aber das geschichtete Material wurde durch Pflanzen- und Tiertätigkeit wieder gemischt.

Tab. 1 : Korngroßenverteilung in ungeschichteten Mainflugsanden

2 Eiszeitalter und Gegenwart 


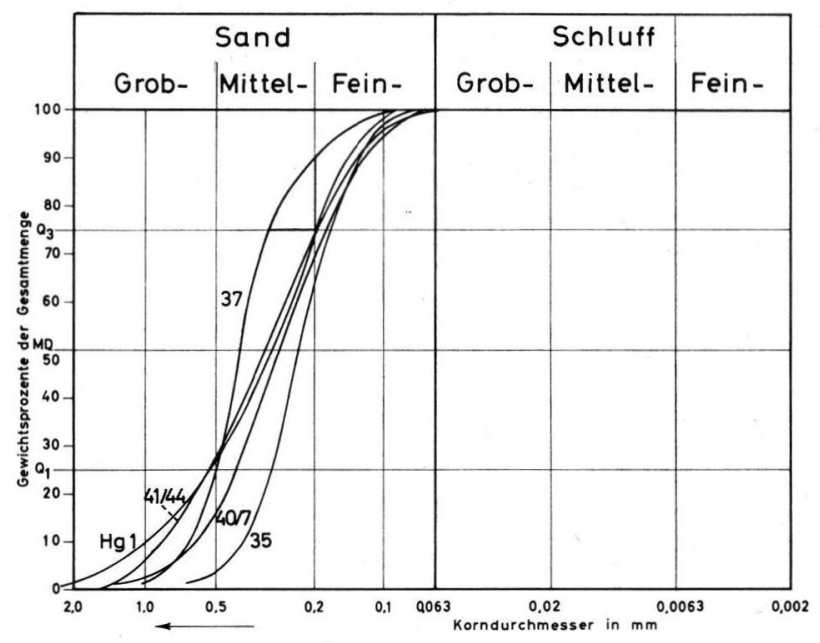

Abb. 3. Graphische Darstellung (Summenkurven) der Korngrößenverteilung in ungeschichteten Mainflugsanden. Auswertung Tab. 1 und Text.

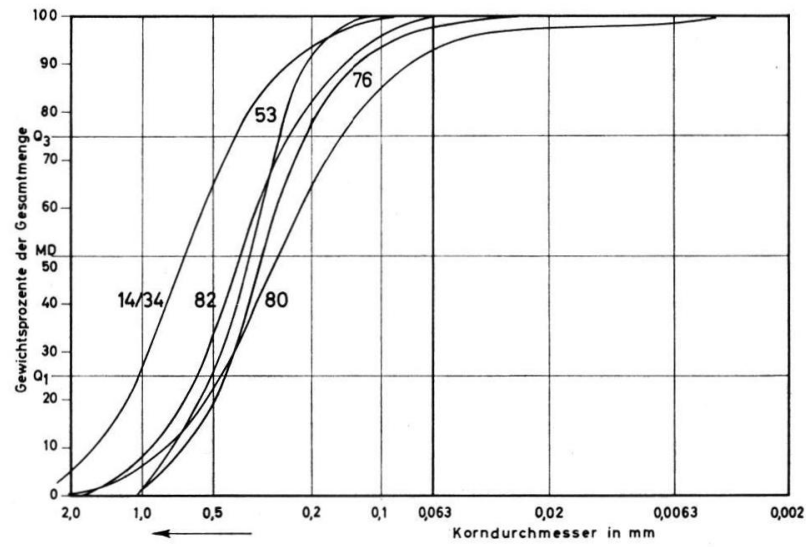

Abb. 4. Graphische Darstellung (Summenkurven) der Korngrößenverteilung in ungeschichteten Mainflugsanden. Auswertung Tab. 1 und Text.

Aus Gründen der besseren Übersicht soll bereits in diesem Abschnitt zur Petrographie der Flugsande auch auf die Kornverteilung in den Dünen näher eingegangen werden. Wie bereits erwähnt, zeigen die Dünenkomplexe meist eine ausgezeichnete Feinschichtung. Durch vergleichende Profiluntersuchungen gelang es, die am Aufbau der Gesamtschichtenfolge beteiligten verschiedenartigen fein- und grobkörnigen Schichtlagen im wesentlichen in 6 jeweils durch eine bestimmte Kornzusammensetzung charakterisierte, auch visuell gut unterscheidbare Standardeinheiten aufzuteilen. Die einzelnen, durch mechanische Analysen in ihrer Kornverteilung quantitativ bestimmten Einheiten werden entsprechend dem wachsenden Anteil der gröberen Fraktionen mit den Zahlen 1-6 belegt. Dem grobkörnigsten Flugsand käme demnach der Wert 6 zu. Einschränkend muß bei dieser Einteilung jedoch vermerkt werden, daß die rein äolische Sedimentation der Einheiten 1 und 2 nicht ganz geklärt werden konnte.

$\mathrm{Zu}$ teilweise überraschenden Ergebnissen führte die rechnerische Auswertung dieser Körnungsanalysen. So schwanken die Md-Werte innerhalb weiter Grenzen von 195-1290. 
Tab. 2 : Korngrößenverteilung in Flugsandeinzellagen (Dünensande)

\begin{tabular}{|c|c|c|c|c|c|c|c|c|c|c|c|c|c|}
\hline Proben - Nr. & $>2,0 \mathrm{~mm}$ & $2,0-1,0$ & $1,0-0,5$ & $0,5-0,2$ & $0,2-0,125$ & $<0,125$ & $0,1-0,063$ & $0,063 \ldots, 0,02$ & $0,02-0,0063$ & $0,0063-0,002$ & $<0,002$ & Md-Wort & So-Went \\
\hline Standard 1 & 1 & 1,7 & 10,82 & 35,21 & 14,26 & - & 0,4 & 16,35 & 5,61 & 2,8 & 2,9 & 195 & 3,74 \\
\hline Standard 2 & - & 2.9 & 17.34 & 35,24 & 10,08 & - & 9,7 & 14.1 & 5,9 & 0,14 & 0,98 & 120 & 2,6 \\
\hline Standard 3 & - & - & 5,29 & 70,16 & 23,25 & 1,19 & - & - & - & - & - & 200 & 1,36 \\
\hline Standard 6 & 0,05 & 16,0 & 47.3 & 21,25 & 10,44 & 4.9 & - & - & - & - & - & 620 & 1.7 \\
\hline Standard 5 & 12,0 & 38,33 & 17,88 & 14,26 & 10,29 & 6,62 & - & - & - & - & - & 1050 & 1,0 \\
\hline Standard 6 & 22.4 & 38,5 & 8,73 & 13,29 & 11.6 & 5,0 & - & - & - & - & - & 1290 & 2,1 \\
\hline Basisflugsande Mönehna 51 B & - & 3,94 & 55,9 & 36,12 & 1,4 & 0,6 & - & - & - & - & - & - & - \\
\hline Nasfleckenzone Mönchnol $71 \mathrm{~B}$ & 0,5 & 1,8 & 10,4 & 54,6 & 23,5 & - & 4.4 & 2,5 & 1.2 & - & - & - & - \\
\hline
\end{tabular}

Noch stärker streuen jedoch die So-Werte. Mit den ungeschichteten Flugsanden sowohl hinsichtlich ihrer Md-Werte als auch den So-Werten können lediglich die mittleren Standardeinheiten 3 und 4 verglichen werden. Die stärksten Abweichungen von dem für Flugsande charakteristischen Kurvenbild zeigen die Summenkurven Standard 1 und 2. $\mathrm{Da}$ die Genese dieser Schichten jedoch nicht endgültig geklärt ist, sei hier auf eine weitere Ausdeutung verzichtet.

Deutlich, wenn auch weniger ausgeprägt, unterscheidet sich aber auch der Kurvenverlauf der reinen Flugsandschichten voneinander. Vergleicht man nun die aus diesen Kurven errechneten So- und Md-Werte miteinander, so besteht offenbar zwischen beiden ein enger, möglicherweise gesetzmäßiger genetischer Zusammenhang: Mit der Erhöhung des Md-Wertes ist stets auch ein Ansteigen des So-Wertes verknüpft. Je grobkörniger demnach die Zusammensetzung einer Flugsandschicht ist, desto schlechter ist auch die Sortierung.

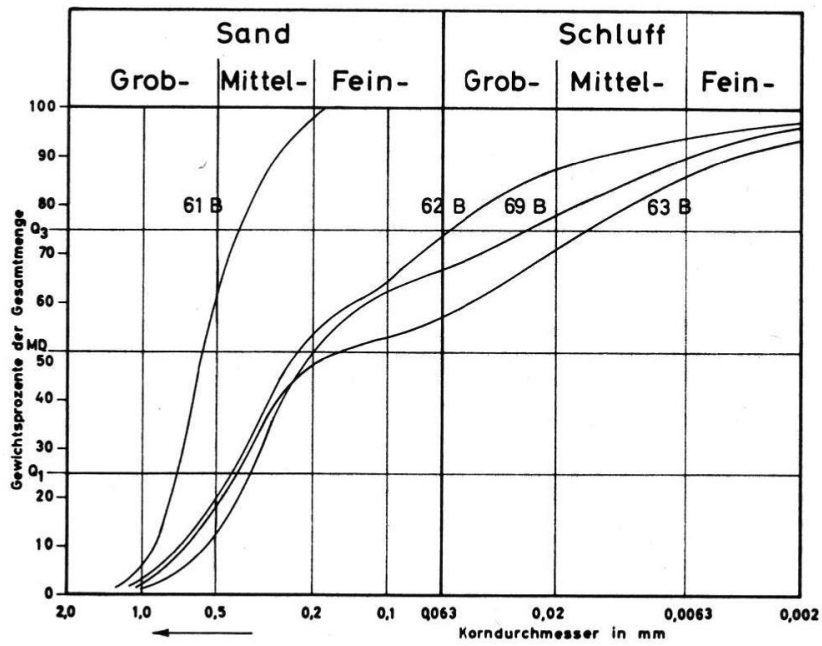

Abb. 5. Graphische Darstellung (Summenkurven) d. Korngrößenzusammensetzung einzelner Schichtlagen der basalen Wechselfolge (61 B Flugsand; 69 B Standard 1; 62 B Standard 2). Auswertung Tab. 2 und Text. 


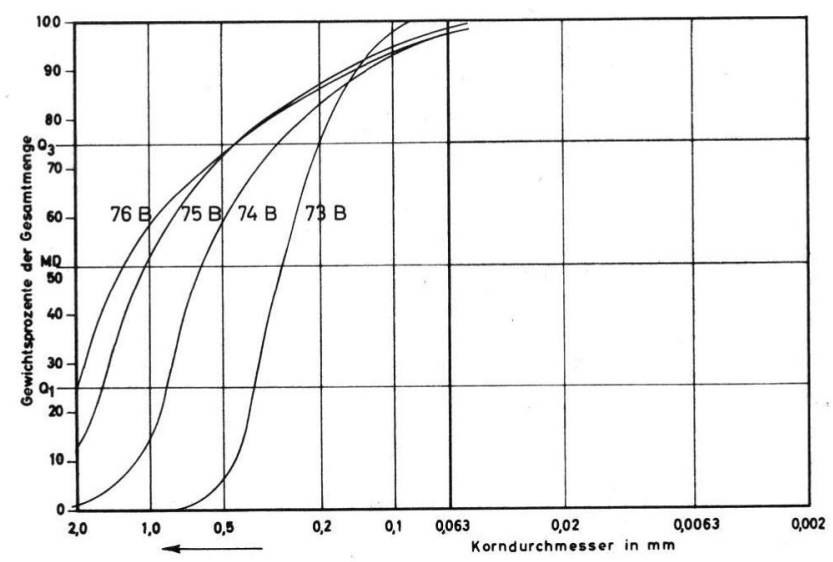

Abb. 6. Graphische Darstellung (Summenkurven) d. Korngrößenzusammensetzung von Flugsandeinzellagen (73 B Standard 3; 74 B Standard 4; 75 B Standard 5; 76 B Standard 6). Auswertung s. Tab. 2 und Text.

Neben der charakteristischen Kornverteilung werden die Mainflugsande besonders durch ihre auffallende Kalkarmut gekennzeichnet. Merkbare Karbonatgehalte von 3-5\% sind lediglich in den schluffigen Basisschichten der Dünensande festzustellen, während in den eigentlichen Dünensanden selten zu beobachtende, schwache osteokollartige Kalkabscheidungen um dünne Wurzeln eine meist nur sehr geringe Karbonatführung andeuten. Diese Kalkarmut wird bedingt durch den fehlenden oder sehr geringen Kalkgehalt der Mainablagerungen und nicht, wie man vielfach annehmen könnte, durch eine starke sekundäre Entkalkung der Flugsande. Neben anderen petrographischen Unterschieden bildet gerade dieser meist fehlende Kalkgehalt ein sehr wesentliches Unterscheidungsmerkmal zu den vorwiegend stark kalkhaltigen Rhein- und Neckarsedimenten.

Eine markante Grenzlinie zwischen den stark karbonathaltigen Rhein- und Neckarflugsanden und den überwiegend kalkfreien äolischen Sedimenten des Maingebietes bildet ein auffallend langgestreckter schmaler Dünenzug, der sich über eine Entfernung von mehr als $10 \mathrm{~km}$ in ostwestlicher Richtung von Egelsbach bis Mönchbruch durchgehend verfolgen läßt. Dieser bis $8 \mathrm{~m}$ hohe Dünenrücken wird im tieferen Teil von graubraunen, kalkhaltigen, gut geschichteten Flugsanden aufgebaut, die etwa 1-2 m unter der Oberfläche von lockeren, kalkfreien, ungeschichteten Sanden überlagert werden.

Schwierigkeiten bereitet im Gelände oft die Trennung von äolischen und fluviatilen Sanden, besonders dort, wo der Flugsand nur als dünner Schleier aufliegt. Unter dem Binokular lassen sich jedoch meist gewisse Unterschiede feststellen. Während so im Flußsand eckig-splittrige Konformen vorherrschen („scharfer" Sand), erscheinen die Flugsandkörner meist stärker gerundet und an der Oberfläche mattiert.

In diesem Zusammenhang sei noch kurz auf die bereits viel diskutierte Frage der vorherrschenden Windrichtung bei der Flugsandverwehung eingegangen. Während bisher zur Bestimmung der einstigen Verwehungsrichtungen vorwiegend die Änderung der Kornzusammensetzung über größere Entfernungen hin untersucht wurde, haben wir uns wegen der möglichen Fehlerquellen dieser Methode auf die Analysierung der Kornverteilung gut verfolgbarer Einzelschichten in großen Dünen beschränkt. Im vorliegenden Fall wurde dazu in einem Aufschluß am Autobahnknoten Mönchhof (Bl. Hochheim 5916; R 3463580 : H 5543 450) einer auffallend grobkörnigen Flugsandschicht an zwei etwa $15 \mathrm{~m}$ in West-Ost-Richtung auseinanderliegenden Stellen je eine Probe entnommen. Die Siebanalyse brachte folgende Ergebnisse: 
Tabelle 3

\begin{tabular}{lcccccc} 
Proben-Nr. & $>2,0 \mathrm{~mm}$ & $2,0-1,0$ & $1,0-0,5$ & $0,5-0,2$ & $0,2-0,1$ & $<0,1$ \\
\hline 67 B westl. & 22,8 & 33,4 & 20,3 & 19,0 & 4,1 & 0,4 \\
67 B östl. & 2,2 & 18,2 & 34,9 & 38,8 & 5,5 & 0,3
\end{tabular}

Wie die Analysenergebnisse deutlich zeigen, ergibt sich aus der unterschiedlichen Kornverteilung dieser Proben eine auffallende Abnahme der Korngröße von West nach Ost. $\mathrm{Zu}$ durchaus vergleichbaren Ergebnissen führte auch die Untersuchung in einem weiteren Aufschluß. Zusammen mit der allgemeinen räumlichen Verteilung der Dünen können wir daher aus der auffallenden Korngrößenabnahme von West nach Ost innerhalb überschaubarer Bereiche ganz allgemein bei der Dünenbildung auf Winde aus vorwiegend westlichen Richtungen schließen.

\subsubsection{Dünen und ihr Aufbau}

\subsubsection{A $11 \mathrm{ge}$ e e in es}

Wie bereits eingangs aufgezeigt, wurden an zahlreichen Stellen die Flugsande zu morphologisch verschieden gestalteten Dünen aufgeweht. Während die Einzeldünen meist nur als mehr oder weniger flache Bodenwellen ausgebildet sind, kam es in den Dünenfeldern zur Aufhäufung riesiger Sandmassen von nicht selten 8-10 m Höhe. Ein solches Dünenfeld wurde östlich Raunheim beim Bau der Autobahneckverbindung Mönchhof-Darmstadt 1962/63 aufgeschlossen. Hier, wie auch in anderen Gebieten, das sei der besseren Übersicht wegen vorweggenommen, zeigt der Schichtaufbau der Dünen allgemein eine Großgliederung in drei in sich weiter untergliederte Flugsandkomplexe: 1) Basisschichtfolge, 2) Bänderflugsande, 3) Deckschichtenfolge.

\subsubsection{Die Basisschichten}

B a sale We chselfolge. Die an der Basis der Dünen entwickelte Schichtfolge ist stets gekennzeichnet durch eine unregelmäßige Wechsellagerung sandiger mit lehmig-schluffigen Lagen. Dieser Basiskomplex überlagert meist mit scharfer ebener Grenze den an der Oberfläche der Kelsterbacher Terrasse entwickelten Kryoturbationshorizont, gelegentlich aber auch jüngere, vermutlich der ONT (?) angehörende, fluviatile Ablagerungen. Für die stratigraphische Einstufung der hangenden Schichtfolge, das sei besonders hervorgehoben, erlangen gerade die letztgenannten Lagerungsverhältnisse eine wesentliche Bedeutung. Die Untergliederung der auffallend streifigen, basalen Schichtfolge bereitet infolge des dauernden kleinräumigen Fazieswechsels meist erhebliche Schwierigkeiten. Den klarsten Aufbau dieser typischen Übergangszone zu den eigentlichen Dünensanden zeigte ein Aufschluß am Autobahnknoten Mönchhof. Das im folgenden beschriebene Einzelprofil wurde an der Westseite des Aufschlusses an einer Stelle aufgenommen, wo die basale Schichtfolge ihre mächtigste Entwicklung erkennen läßt.
1) $0-30(30 \mathrm{~cm})$
dunkelbrauner unten bräunlichgrau gefleckter Sand bis anlehmiger Sand, schwach kohärentes Gefüge, Bleichfleckenhorizont
2) $30-90(60 \mathrm{~cm})$
gelblichbrauner Sand, undeutlich geschichtet, locker, mit vereinzelten Ton- anreicherungsbändern
3) $90-112(22 \mathrm{~cm})$
gelblichbrauner 10 YR 5/4, lehmiger Sand, weich, schmierig, im unteren
Teil Anreicherung von Kalkkonkretionen, Schicht zum Teil kryoturbat gestört

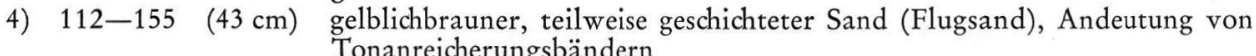
5) 155-163 ( $8 \mathrm{~cm})$ fahlgraubrauner, lehmiger Sand, schwach kalkhaltig, wenig aggregiert
6) $163-173(10 \mathrm{~cm})$ gelbbrauner, lockerer Sand, Einzelkorngefüge
7) $173-178(5 \mathrm{~cm})$ bläulichgrauer, lehmiger Sand, schwach kalkhaltig, kleinpolyedrisches
8) 178-228 $(50 \mathrm{~cm})$ gelblichbrauner Sand, ungeschichtet, locker mit 5-6 ein bis zwei $\mathrm{cm}$ Gefüge
9) $228+$ starken, lehmigen Sandbändern
Terrassenoberfläche mit Interglazialboden, kryoturbat gestört. 


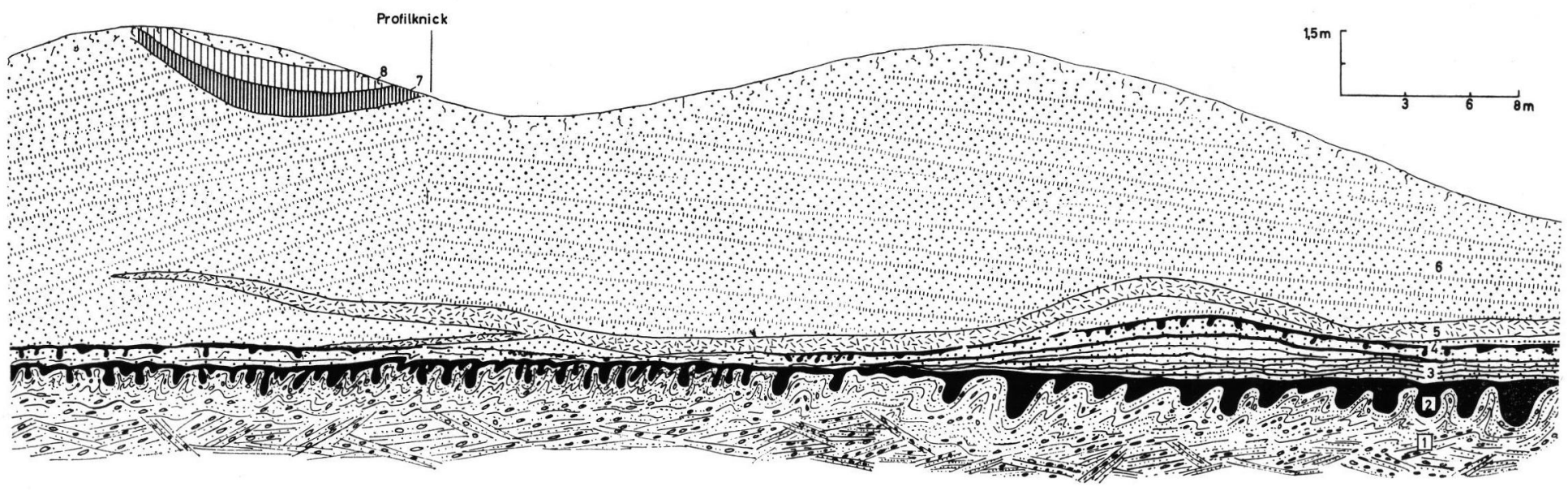

Abb. 7. Profilentwicklung in einer Düne am Autobahnknoten Mönchhof. 1 Kelsterbacher Terr., 2 Eem-Boden, 3 Basale Wechselfolge, 4 Grenzhorizont, 5 Naßfleckenhorizont, 6 Bänderflugsande, 7 Gelbbrauner Tuffboden, 8 Fossile Braunerde. 
Die sandig-schluffigen, meist stärker gewellten Streifen dieser Wechselfolge unterscheiden sich von den mächtigeren Sandlagen im allgemeinen sehr deutlich in ihrer jeweiligen Kornverteilung. Während das sandige Material, wie verschiedene Körnungsanalysen $(61 \mathrm{~B}, 70 \mathrm{~B})$ ergaben, eine typische Flugsandkörnung mit weniger als 5\% Feinanteil und So-Werten zwischen 1,2-1,3 aufweist, lassen die schluffigen Bänder, deren Kalkgehalt gelegentlich zwischen 0,2 und 1,5\% schwankt, eine deutliche Lößbeimengung erkennen. In den Histogrammen kommt dieser Anstieg der Schluffkomponente in einer charakteristischen Doppelung der Korngrößenmaxima zwischen $20-50$ und $200-500 \mu$ sehr klar zum Ausdruck. Mit So-Werten, die zwischen 2,8-3,7 streuen, ist dieses Bändermaterial als ausgesprochen schlecht sortiert zu bezeichnen.

Die häufig beobachtete bläulichgraue Verfärbung und die Ausbildung schwacher Fließstrukturen - besonders im unteren Teil der Wechselfolge - deuten auf verhältnismäßig feuchte Entstehungsbedingungen bei der Bildung der schluffigen Lagen hin. Es erscheint sogar nicht ausgeschlossen, daß gelegentlich auch fließendes Wasser bei der Sedimentation dieser Lagen eine gewisse Rolle spielte, worauf besonders die petrographische Ähnlichkeit mit rezenten Hochflutlehmabsätzen hindeutet. Wir möchten daher annehmen, daß die Bildung dieser Basisschichten vorwiegend unter kühlfeuchten Klimabedingungen erfolgte. Wie aus dem Schichtaufbau hervorgeht, überlagerten sich während dieses Zeitabschnittes äolische und aquatische Vorgänge noch in mannigfaltiger Weise. Andererseits sollen aber nach Rohdenburg (1962, S. 41/42) das auch im Aufschluß Mönchhof zu beobachtende längere Aushalten und die kleinräumige Wellung der Bänder eine äolische Sedimentation beweisen.

Im oberen Teil der Abfolge werden die schluffigen Lagen seltener. Mit dem Übergang $\mathrm{zu}$ reinem Flugsand deutet sich in diesem Niveau bereits ein gewisser Sedimentationsumschwung an.

Grenzhorizon t. Den Abschluß der basalen Wechselfolge bildet ein kryoturbat stark gestörter $20-25 \mathrm{~cm}$ mächtiger, stellenweise noch kalkhaltiger, blaßbrauner Horizont, der eine ähnliche Kornverteilung besitzt ( $63 \mathrm{~B})$ wie die schluffigen Bänder. An Stellen, wo dieser lehmig-schluffige Horizont in der horizontalen Verbreitung von sandigeren Schichtlagen vertreten wird, kam es zur Ausbildung einer kryoturbat wenig gestörten Bleichfleckenzone mit teilweise mehrere $\mathrm{cm}$ starken Tonanreicherungsbändern. Das Maximum in der Schlufffraktion ist in diesem Horizont jedoch noch stärker ausgeprägt als in den Bändern. Außerdem fällt die außerordentlich schlechte Sortierung (So $=5,15$ ) dieses Materials auf, was allerdings teilweise auch auf die starke kryoturbate Durchmischung zurückzuführen sein dürfte.

Damit erhebt sich die Frage nach der Entstehung dieses auffälligen Horizontes. Eine echte Bodenbildung dürfte sich in diesem Horizont nur schwer nachweisen lassen. Allenfalls könnten die schwache Grau- und Rostfleckung, der geringe Humusgehalt sowie eine stärkere Kalkverlagerung als die Anzeichen einer allerdings nur schwachen Verwitterungsbildung gedeutet werden. Wie die chemische Untersuchung ergab, ist der Sorptionskomplex bei geringen $\mathrm{Sk}$-Werten noch weitgehend mit $\mathrm{Ca}$-Ionen abgesättigt.

Aber ganz unabhängig davon, ob es sich um eine echte Bodenbildung handelt oder aber nur um eine weitgehend unveränderte Sedimentlage, kommt diesem Horizont doch insofern eine gewisse stratigraphische Bedeutung zu, als er die Grenze zur reinen Flugsandabfolge deutlich markiert. Bedingt wurde dieser im Hangenden des Kryoturbationshorizontes zu beobachtende ausgeprägte Sedimentationsumschwung wohl in erster Linie durch den Übergang von kühlfeuchten zu mehr kalt-ariden Klimaverhältnissen.

Interstadia ler Fleckenboden. Obwohl mit dem Schlufflehmhorizont die basale Schichtfolge scharf abgeschlossen wird, soll die nur im Aufschluß Mönchhof deutlich ausgebildete $Z$ wischenzone zu den eigentlichen Bänderflugsanden mit dem Basisschichtenkomplex zusammengefaßt werden. Über dem Grenzhorizont folgen in unserem Pro- 
fil geringmächtige, meist feingeschichtete, nur gelegentlich von dünnen Tonanreicherungsbändern durchzogene Flugsandlagen, die nach oben von einer etwa $30-50 \mathrm{~cm}$ mächtigen Bleichfleckenzone abgeschlossen werden. Die hellen, unregelmäßig verteilten Bleichflecken dieses Horizontes werden vorwiegend von dunkelgraubraunen, etwas bindigeren gezackten Randzonen umsäumt, wodurch der Gesamteindruck einer als Pantherung zu bezeichnenden Fleckung entsteht. In der Korngrößenzusammensetzung unterscheidet sich das ungeschichtete Material des Fleckenhorizontes (71 B) nur unwesentlich von dem über- und unterlagernden, unverwitterten. Flugsand. Durch die auffallende Fältelung sekundär in dieser Zone entstandener Tonbänder wird die starke Störung der ursprünglichen Feinschichtung deutlich hervorgehoben.

Obwohl die Bleichfleckenzone nur in wenigen Aufschlüssen und auch dort meist nur stellenweise zu beobachten ist, dürfte es sich bei diesem Horizont doch um eine echte, allerdings nur schwach ausgeprägte Bodenbildung handeln. Wie der geringe Verwitterungsgrad deutlich anzeigt, entstand dieser Boden vermutlich unter dem Einfluß einer kurzdauernden Wärmeschwankung während einer längeren kalt-ariden Klimaphase. Das heute nur noch sehr lückenhafte Vorkommen läßt sich wohl damit erklären, daß einmal der Flugsand im Gegensatz zum Löß als schlechter Zeichner zu bewerten ist, zum anderen infolge der leichten Beweglichkeit des Flugsandes meist nur ungünstige Erhaltungsbedingungen gegeben waren. Die genetisch schwer deutbare Fleckenbildung beruht möglicherweise auf einer intensiven Wurzelbleichung, wie wir sie häufig auch um rezente Wurzeln beobachten können. Aus der geringen Mächtigkeit und der scharfen Begrenzung dieser Bleichfleckenzone könnte man vielleicht mit Vorsicht auf das Vorhandensein einer spärlichen, niederen Vegetation mit einheitlicher Durchwurzelungstiefe schließen.

\subsubsection{B ̈̈nderf 1 ug s a nde}

Uber dem durch einen kleinräumigen Fazieswechsel gekennzeichneten, nach oben meist durch den Fleckenboden begrenzten Basiskomplex baut sich eine zuweilen $6-8 \mathrm{~m}$ mächtige, reine Flugsandabfolge auf. Bei der Aufwehung dieser gewaltigen Flugsandmassen kam es zu den für äolische Sandablagerungen beze:chnenden, verschiedenartigen Formen der Dünenbildung. In den größeren Dünenfeldern führte diese besondere Art der Sedimentation zur Ausbildung eines meist stärker gegliederten hügeligen Reliefs, das häufig den Eindruck eines lebhaft kuppigen Dünengewoges vermittelt. Die meist mehrere Meter mächtigen Dünensandkomplexe werden stets gekennzeichnet durch eine weitgespannte Parallelschichtung verschiedenkörniger Flugsandlagen. In zahlreichen Dünen kann man ein schwaches Einfallen der einige $\mathrm{mm}$ bis mehrere $\mathrm{cm}$ starken fein- und grobkörnigen Flugsandschichten in vorwiegend östliche Richtungen beobachten.

Die Korngrößenverteilung der einzelnen Lagen entspricht den bereits durch Körnungsanalysen bestimmten Standardeinheiten 2-4 (s. Tab. 2), umfaßt also vorwiegend den Mittel- bis Grobsandbereich. Auffallend grobkörnige Schichten (5-6) treten vorwiegend an der Basis der Bänderflugsandfolge häufiger auf. Gelegentlich können sich sogar dünne Kiesschnürchen ( $\phi$ bis $15 \mathrm{~mm}$ ) einschalten, wie dies vor allem im Aufschluß Haßloch an mehreren Stellen dicht über dem Fleckenboden deutlich zu beobachten war. Aus dem petrographischen Aufbau dieser durch ständige Wechsellagerung fein- und grobkörniger Flugsandschichten charakterisierten Vertikalprofile der Dünensande läßt sich jedoch im allgemeinen eine klare Gesetzmäßigkeit im Sedimentationsablauf nicht erkennen. Lediglich in den Aufschlüssen Rüsselsheim und nördlich Nauheim deutet sich, wie bereits erwähnt, durch eine wiederholte, jeweils im Abstand von 1,5-3 m zu beobachtende auffallende Korngrößenabnahme von der Basis gegen das Hangende hin ein gewisser rhythmischer Sedimentationsablauf an.

Neben der in allen mächtigeren Flugsandprofilen entwickelten Feinschichtung werden die Dünensande des Maingebietes weiterhin charakterisiert durch eine vorwiegend an die 
Schichtung gebundene rotbraune Bänderung. Vertikale Verbindungen zwischen den meist parallel laufenden Bändern sind nur selten zu beobachten. In ungeschichteten Flugsanden werden die sonst maximal $2-3 \mathrm{~cm}$ dicken Bänder $5-8 \mathrm{~cm}$ stark und sind dann meist gefältelt sowie gelegentlich untereinander durch Übergänge verbunden. Auf Grund zahlreicher Korngrößenanalysen (Tab. 8) konnte nachgewiesen werden, daß diese auffallende Bänderung im wesentlichen auf einer erheblichen Anreicherung schluffig-toniger Substanz in einzelnen Flugsandlagen beruht. Beträgt der Gesamtanteil der Fraktionen $\langle 0,1 \mathrm{~mm}$ in den bänderfreien Flugsanden selten mehr als 3\%, so steigt die Schluff-Ton-Komponente in den Bänderlagen auf $15-25 \%$ (davon 6-12\% Tonanteil) stark an. Die Bildung dieser Bänder setzt stets ein völlig kalkfreies Substrat voraus. Schon bei geringen Kalkgehalten, wie sie besonders in tieferen Lagen der Mainsande gelegentlich noch auftreten, setzt daher die Bänderung oft unvermittelt aus.

Die mächtige Schichtenfolge der Bänderflugsande zeigt in fast allen Aufschlüssen des Maingebietes den gleichen einförmigen Aufbau aus vorwiegend gebänderten, feingeschichteten Flugsandlagen. Daraus kann gefolgert werden, daß bei der Dünenbildung, vermutlich unter dem Einfluß einer länger dauernden kalt-ariden Klimaphase, weitgehend einheitliche Sedimentationsbedingungen innerhalb eines größeren Raumes geherrscht haben müssen.

In größeren Dünenaufschlüssen, wo die Bänderflugsande von jüngeren Deckschichten meist diskordant überlagert werden, schaltet sich stellenweise zwischen beide Schichtkomplexe eine durchschnittlich $20-50 \mathrm{~cm}$ mächtige, meist stärker gebleichte Zone ein. Dieser Bleichhorizont greift nicht selten in Form von unregelmäßig begrenzten, zum Teil stark zerlappten Taschen und Zapfen in die unterlagernde Schichtfolge ein. An den gezackten Rändern ist die Wiederauflösung bereits gebildeter Bänder deutlich zu erkennen. Auch an Stellen, wo die Bänderflugsande infolge späterer Deflationsvorgänge die heutige Dünenoberfläche bilden, kommt es zu einer beginnenden Wiederauflösung der Bänder. Das Vorkommen dieser Ausbleichungszone unter einer teilweise mächtigen jüngeren Überdeckung beweist deutlich ihre bereits fossile Entstehung. Allerdings, das bleibt unbestritten, dürfte sie an Stellen stärkerer Durchfeuchtung auch unter den gegenwärtigen Bedingungen noch weitergebildet werden.

\subsubsection{Die Deckschichten}

Der gleichförmig aufgebaute Komplex der Bänderflugsande wird überlagert von einer mehrfach gegliederten Schichtenfolge jüngerer Flugsande. Diese Deckschichtenfolge gewinnt durch die Einlagerung einer datierbaren Bims-Tuffschicht und die Ausbildung einer mächtigen fossilen Verwitterungsdecke eine besondere stratigraphische Bedeutung für die Gesamtgliederung der Dünensande. Einen guten Einblick in den Schichtenaufbau dieses jüngsten Flugsandkomplexes bot eine zeitweilig gut erschlossene Sandgrube am Schützenhaus von Raunheim (B1. Hochheim 5916; R 3462320 : H 5541 680). Hier konnte im April 1962 folgendes Profil aufgenommen werden:
1) $\mathrm{A}$
$0-6$
$(6 \mathrm{~cm})$
dunkelgraubrauner 10 YR 3/2, lockerer Sand, schwach humos
2) $B_{V}$
$6-40$
$(34 \mathrm{~cm})$
3) $f(A) \quad 40-55$
$(15 \mathrm{~cm})$
4) $\mathrm{f}_{1} \mathrm{~B}_{\mathrm{v} 1} \quad 55-78$
$(23 \mathrm{~cm})$
blaßbrauner 10 YR 7/4, lockerer Sand, teilweise schwach ver- kittet, sonst Einzelkorngefüge, nur ganz schwache Verbraunung schwach graubrauner 10 YR 5/2-5/3 Sand bis anlehmiger Sand (schwach humos), wenig aggregiert
5) $\mathrm{f}_{1} \mathrm{~B}_{\mathrm{v} 2} \quad 78-162$
6) $\mathrm{f}_{2} \mathrm{~B}_{\mathrm{v} 3} \quad 162-187 \quad(25 \mathrm{~cm})$
dunkelbrauner 7,5 YR 5/6, anlehmiger Sand mit hellbraunen 7,5 YR 6/4 unregelmäßigen Flecken, schwach kohärentes Gefüge, allmählicher Übergang zu
gelblichbrauner 10 YR anlehmiger Sand, vorwiegend kohärentes Gefüge
dunkelgelblichbrauner 10 YR 4/4, feinsandig schluffiger Lehm, weich schmierig, wenig aggregiert 
7) C 187-205 $(18 \mathrm{~cm})$ bräunlichgraues 10 YR 6/2, schluffiges Tuffmaterial zu harten, eckig-splittrigen Einzelaggregaten schlackig verbacken. An der Basis nesterartige Einlagerung von gelblichbraunem, lockerem, körnigem Bimsstein, stark durchsetzt mit schwärzlichen Gesteinsblättchen

8) $\mathrm{Cv} \quad 205-213(8 \mathrm{~cm})$ dunkelgrauer, anlehmiger Sand, durch graue Einwaschungen aus dem Hangenden leicht verkittet

9) $\mathrm{Cn} 213+$

hellgelblichbrauner, lockerer Sand, ab 250 von rötlichbraunen Tonanreicherungsbändern durchzogen.

Zur näheren Bestimmung der Herkunft und des Alters der vulkanogenen Sedimente dieses Profils wurde eine orientiert entnommene Probe von Professor Frechen in Bonn eingehend untersucht. Die makroskopische und mikroskopische Prüfung des Bims-Tuffs ergab, daß darin alle Bestandteile enthalten sind, die den Laacher Bims-Tuff charakterisieren. Die einzelnen Bimskörner enthalten in der glasigen Grundmasse als Einsprenglinge Natronsanidin, Plagioklas, seltenen Hauyn, Aegirinaugit, barkevikitische Hornblende, Magnetit, Apatit, Titanit und Zirkon. Wie in den Laacher Bims-Tuffen kommen diese Minerale auch in unserer Probe als isolierte Einzelkristalle in der feinen Fraktion vor. Einen wichtigen Hinweis auf die Herkunft des Tuffs von Raunheim bilden auch die in ihm zahlreich enthaltenen Splitter von Tonschiefern und Grauwacken, die in den Laacher Bims-Tuffen den Hauptanteil der nichtmagmatischen Bestandteile bilden. Sie stammen aus dem durchbrochenen Rheinischen Schiefergebirge. Aus diesen Befunden geht eindeutig hervor, daß der Tuff von Raunheim den Laacher Bims-Tuffen zuzurechnen ist, die während des Mittelalleröd gefördert wurden. Das Material des Raunheimer Tuffhorizontes ist ungeschichtet und teilweise schwach mit Flugsand vermischt. Linsen- und nesterartige, unregelmäßig verteilte Anreicherungen von körnigem Bims finden sich vor allem an der Basis dieses Horizontes. Die teilweise intensive Durchmischung des Bims-Tuffs mit Flugsand deutet auf spätere Umlagerungen hin.

Wie aus einer schematischen Darstellung der Lagerungsverhältnisse und des Schichtaufbaus im Aufschluß Raunheim hervorgeht, füllt die junge Deckschichtenfolge eine ehemalige Depression zwischen zwei Dünen aus. Der Bims-Tuff fiel demnach bei seiner Ablagerung in ein stark gegliedertes Dünenrelief. Auf den Dünenscheiteln wurde das leichtbewegliche Material vermutlich bereits während oder kurz nach seiner Ablagerung wieder verweht und verschwemmt. Als Sedimentfallen wirkten dabei, wie das heutige Vorkommen des Tuffs zeigt, die zwischen den Dünenkämmen liegenden Deflationswannen, in denen das bereits leicht mit Flugsand vermengte Bims-Tuff-Material wieder zum Absatz kam und dort vor neuerlicher Erosion geschützt in größererMächtigkeit erhalten blieb.

Unveränderter Bims-Tuff konnte innerhalb des gesamten Flugsandgebietes lediglich noch in einem Aufschluß südlich Rüsselsheim an der Basis der Deckschichtenfolge beobachtet werden. Dieses Vorkommen ist heute jedoch infolge des rasch fortschreitenden $\mathrm{Ab}$ baus der Dünensande bereits wieder verschwunden.

In dem weiter westlich gelegenen Mainzer Flugsandgebiet wurden in Dünen und auf Rheinterrassen solche Tuffhorizonte dagegen an zahlreichen Stellen nachgewiesen (SoNNE \& STÖHR 1959). Die vulkanogenen Sedimente dieses Raumes lassen sich nach der Art ihres inneren Aufbaus in zwei Gruppen einteilen: a) die geschichteten, b) die ungeschichteten Tuffe. Der Raunheimer Tuffhorizont wäre demnach bei gleicher Altersstellung mit der zweiten (ungeschichteten) Gruppe zu vergleichen.

Nach SonNe \& STÖHR (1959, S. 115) kann aus der regelmäßigen, ungestörten Abfolge der umgelagerten, geschichteten Tuffe in der Sandgrube Walter auf einen ruhigen Klimaablauf während und unmittelbar nach der Sedimentation geschlossen werden. Außerdem deutet nach ihnen die scharfe Überlagerung der Tuffe durch Flugsande auf eine einheitliche und kurze Umlagerungszeit hin, so daß auch die umgelagerten Tuffschichten als 


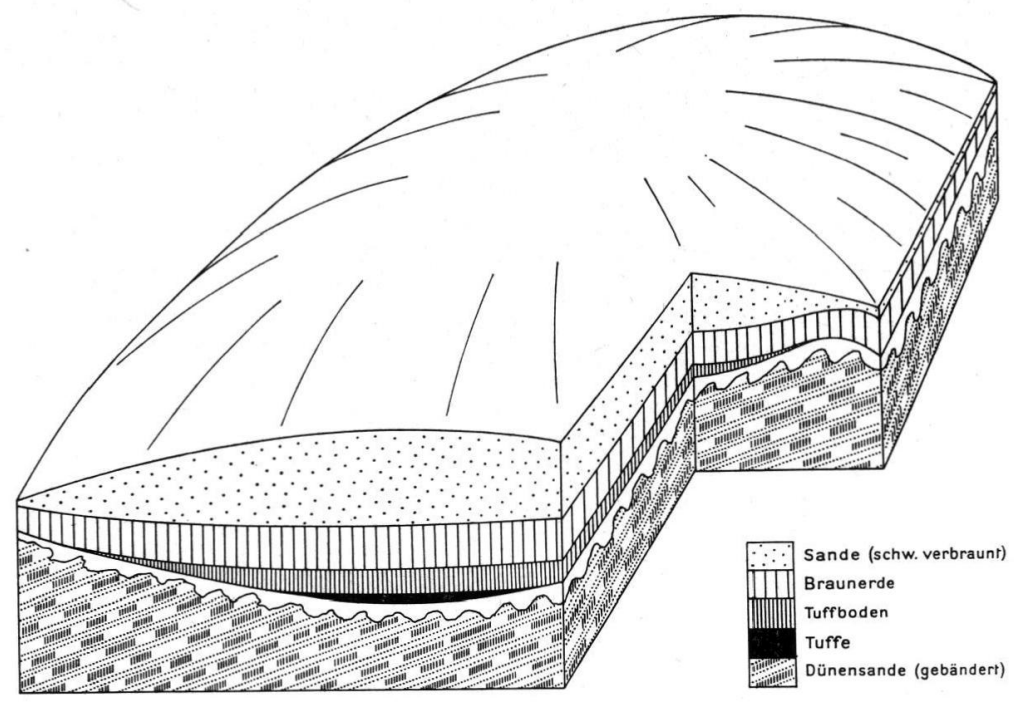

Abb. 8. Blockdiagramm der Sandgrube Raunheim/M.

absoluter Zeitmesser anzusehen seien. Dieser Auffassung dürfen wir uns auch für das Raunheimer Vorkommen anschließen.

Der gelbbra une Tuffboden. Der Bims-Tuff geht im Profil Raunheim nach oben allmählich in einen gelblichbraunen, in feuchtem Zustand schwach gelbolivbraun gefärbten, feinsandigen Lehm über. Eine diesem Bodenhorizont vergleichbare, meist jedoch weniger stark verlehmte Bildung konnte in zahlreichen anderen Dünenaufschlüssen beobachtet werden, allerdings stets ohne die Unterlagerung durch unverändertes vulkanisches Material. Die in den Flugsandkomplexen etwas fremdartig wirkende Farbtönung sowie die von Flugsandböden stark abweichende mechanische Kornzusammensetzung des Horizontes ließen jedoch bald die Vermutung eines engeren genetischen Zusammenhangs zwischen dieser Bildung und dem Tuff aufkommen. Den Beweis für die Richtigkeit dieser Annahme erbrachten schließlich sowohl makroskopische als auch quantitative chemischphysikalische Untersuchungen:

Neben dem charakteristischen Farbton wird der Tuffboden durch einen auffallend hohen Tonanteil gekennzeichnet (bis zu 11\%). Wie aus dem Korngrößendiagramm des Profils Raunheim weiterhin eindeutig hervorgeht, wurde besonders der obere Teil des Tuffbodens von einer intensiven Verlehmung erfaßt. Während der Tongehalt von 6,5\% $\left(\mathrm{II}_{6} \mathrm{C}\right)$ auf $11,5 \%\left(\mathrm{II}_{5} \mathrm{f}_{2} \mathrm{~B}_{\mathrm{v}}\right)$ im oberen Profilabschnitt ansteigt, verhalten sich die Schluffanteile (unverwitterter Tuff) gerade umgekehrt. Die stärkere Beteiligung der Fraktionen von $0,2-1,0 \mathrm{~mm}$ in der Probe $\mathrm{II}_{5}$ können auf die bereits stärkere Einmischung von Flugsandkomponenten in dieser Zone zurückgeführt werden.

In der chemischen Analyse kommt diese bemerkenswerte Tonmineralneubildung durch einen, im Vergleich zu den aus reinem Flugsand entstandenen Braunerden auffallenden Anstieg der SK-Werte (SK = Summe der sorbierten Kationen) deutlich zum Ausdruck. Dieser bei $11,8 \mathrm{mval} / 100 \mathrm{~d}$ Bd. liegende Wert deckt sich übrigens auffällig mit dem aus einer Bims-Tuff-Probe ermittelten Wert von $11,4 \mathrm{mval} / 100 \mathrm{~g} \mathrm{Bd}$. Entsprechend hoch liegen auch in beiden Substraten die Werte für lösliches $\mathrm{Fe}_{2} \mathrm{O}_{3}, \mathrm{Al}_{2} \mathrm{O}_{3}$ und $\mathrm{SiO}_{2}$. Bei der röntgenographischen Untersuchung der Tonsubstanz des Tuffbodens konnte im Unterschied zu zahlreichen anderen Bodenbildungen Kalifeldspat als Hauptgemengteil nachgewiesen werden. 


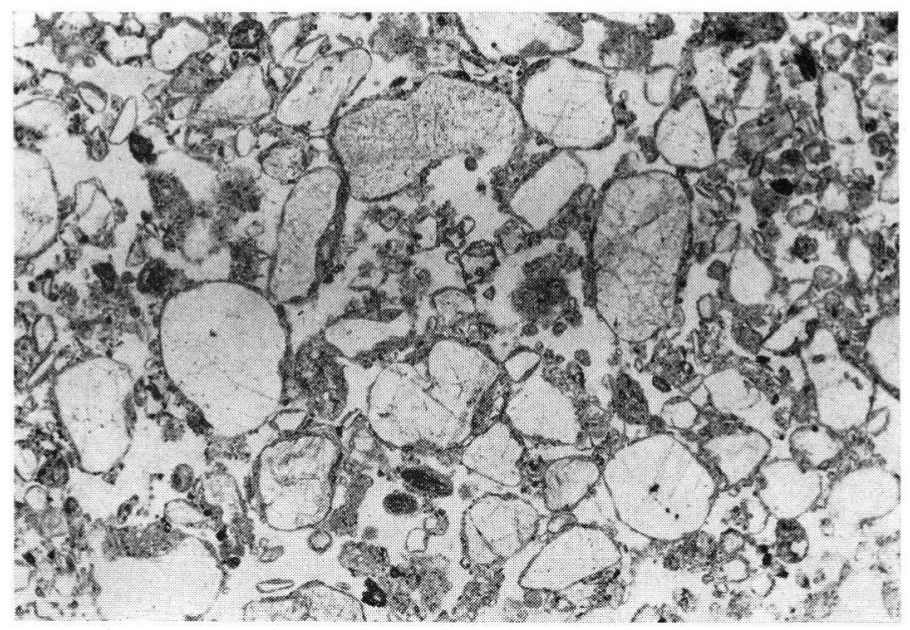

Abb. 9. Gelbbrauner Tuffboden (Profil Raunheim). An Kornoberflächen und in Kornzwischenräumen (feinkörnigere Partien) des locker gelagerten Skelettmaterials geflockte, „erdige" Feinsubstanz. $\times 40$. Übersichtsaufnahme.

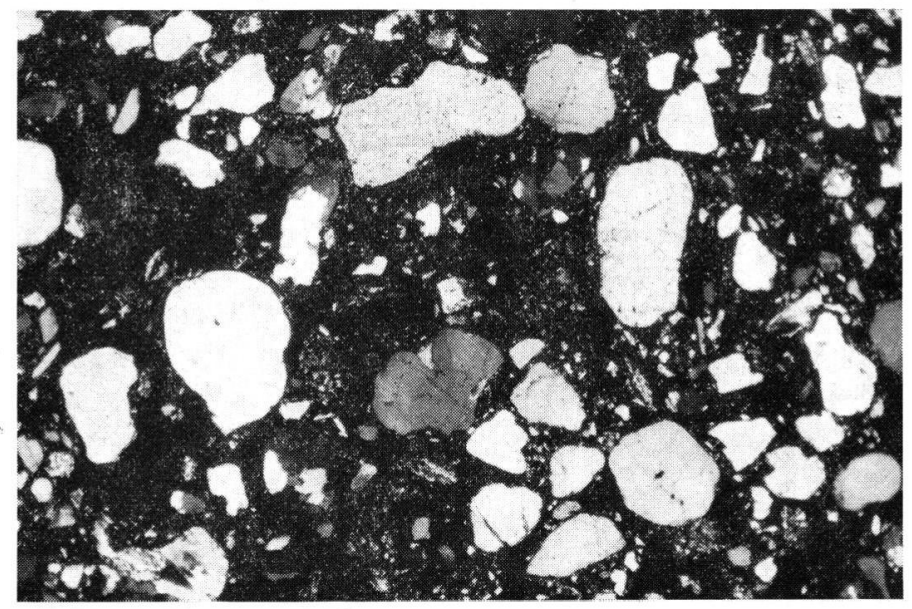

Abb. 10. Aufnahme wie Abb. 9 bei + Nic. Die kolloidale Tonsubstanz zeigt keine Doppelbrechung. $\times 40$.

Im Schliffbild dieses Bodenhorizontes fällt die bemerkenswert lockere Lagerung des Skelettanteils auf. Am Aufbau der stabil geflockten $\mathrm{Z}$ wischensubstanz beteiligt sich vorwiegend blaßgelblich gefärbter Grobton. Um die Einzelkörner ist eine meist stärker ausgeprägte Hüllenbildung aus locker gelagerten Tonanteilen zu beobachten, so daß man auch von einer "Hüllenbraunerde" sprechen könnte. Anzeichen einer bemerkenswerten Tonverlagerung sind nicht zu erkennen. Über den gesamten Schliff verteilt finden sich stark inkohlte, fossile Holzreste. Nicht selten kann man in dem lehmigen Material des Tuffbodens auch makroskopisch noch deutlich dunkle Gesteinsblättchen erkennen, die sich bei näherer Untersuchung als schwer verwitterbare Relikte des nichtmagmatischen Anteils des Tuffmaterials erweisen.

Diese Untersuchungsergebnisse führen damit eindeutig zu dem Schluß, daß es sich bei dem Tuffboden nur um ein Verwitterungsprodukt des unterlagernden Bims-Tuff-Horizontes handeln kann. In den zahlreichen Vorkommen, wo der Bims-Tuff unter dieser 

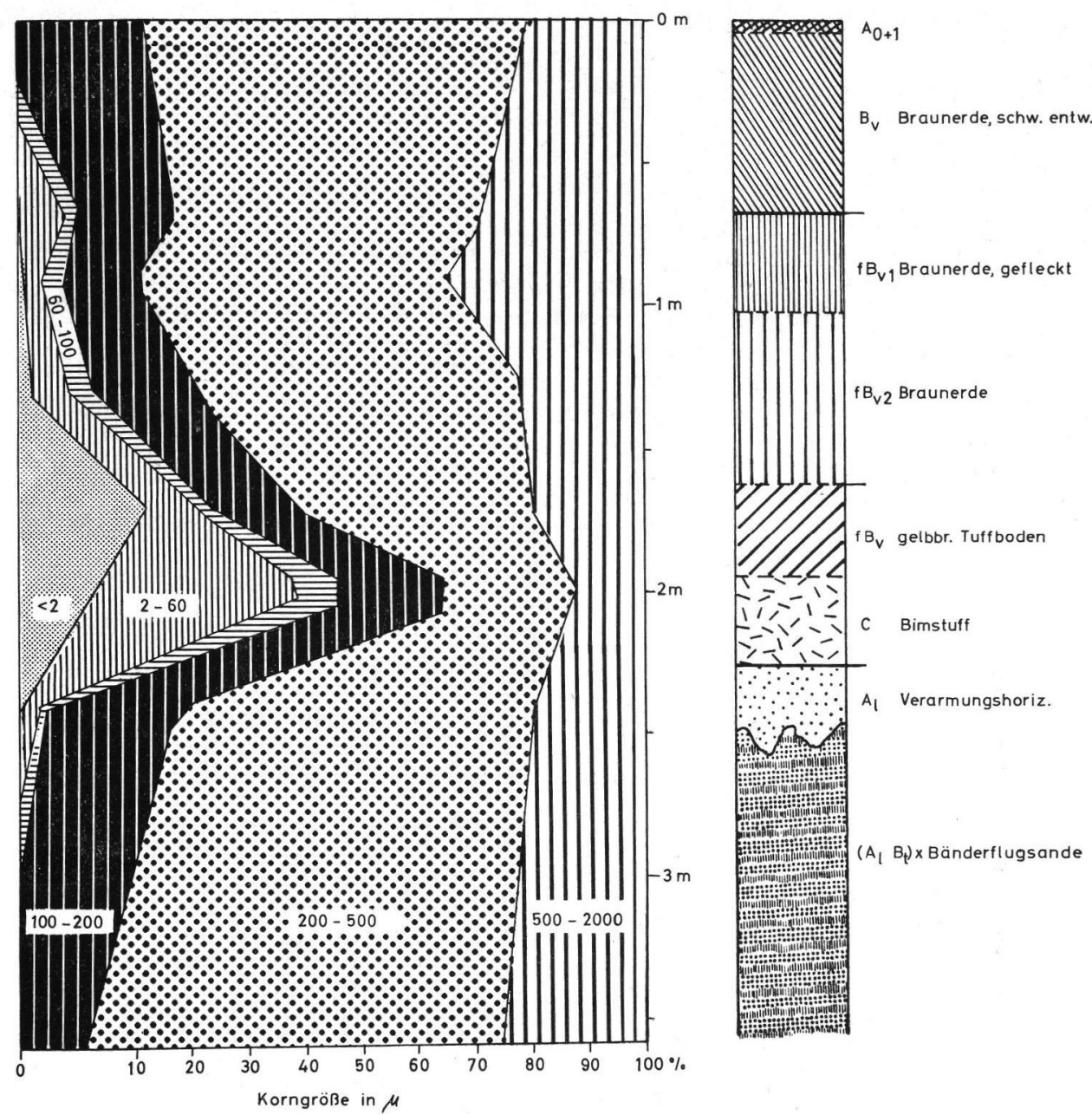

Abb. 11. Korngrößendiagramm des Profils Raunheim.

Bodenbildung heute fehlt, wurde demnach das gesamte stets mit Flugsand vermischte, vulkanische Material bereits vollständig zum Tuffboden umgebildet. Genetisch dürfte die Verlehmung des Bims-Tuffs einer intensiven Verbraunung auf sandigem Substrat entsprechen, so daß wir den Tuffboden typologisch als Braunerde einstufen können.

Es bleibt nun noch die Frage zu erörtern, ob es sich bei diesem Horizont um eine selbständige Bodenbildung handelt oder aber die Verwitterung des vulkanischen Materials erst zusammen mit der späteren Braunerdebildung im Hangenden erfolgte. Für eine einheitliche gleichzeitige Verwitterungsbildung spricht vor allem der stets vorhandene unmittelbare Übergang von der Braunerde aus Sand zu dem liegenden, lehmigen Horizont. Wenn diesem Horizont trotzdem der Rang einer möglicherweise nur geringen, selbständigen Bodenbildung zuerkannt werden soll, dann vor allem auf Grund der Einlagerung zahlreicher, im Schliffbild gut zu erkennender fossiler Holzrestchen $(0,6 \%$ Humus), die in der überlagernden Braunerde nicht beobachtet werden konnten $(0,1-0,2 \%$ Humus). Zweifellos wurde jedoch der Tuffhorizont von der nachfolgenden Braunerdebildung noch mit erfaßt. Aber ganz unabhängig davon, ob es sich hierbei um eine selbständige Boden- 
bildung handelt oder nicht, kommt diesem Horizont doch ebenso wie dem unveränderten vulkanischen Material die Bedeutung eines wichtigen stratigraphischen Leithorizontes zu.

Fossile Braunerden. Der Tuffboden geht nach oben in allen bekannten Vorkommen ohne scharfe Grenze in eine tiefgründige, sandige Braunerde über. Dieser Boden zeichnet sich sowohl durch eine intensive Verbraunung als auch durch eine bemerkenswerte Mächtigkeit, die in Muldenlagen nicht selten 1,2 m erreicht, aus. Das Ausgangsmaterial dieser Bodenbildung besteht ausschließlich aus Flugsand, vulkanische Beimengungen sind darin nicht mehr enthalten (vgl. Korngrößendiagramm Abb. 11). Entsprechend dem geringen Gehalt an verwitterbaren Silikaten und dem Zurücktreten der Schluffkomponente im Ausgangsmaterial liegen die Werte des Tonanteils meist zwischen 1-2\%. Dieser geringe Tongehalt bedingt wiederum eine äußerst niedrige AK (Kationen-Austauschkapazität), die zwischen 2,2-2,8 mval/100 g Bd. schwankt. Die geringen Prozentgehalte an löslichem $\mathrm{Fe}_{2} \mathrm{O}_{3}, \mathrm{Al}_{2} \mathrm{O}_{3}$ und $\mathrm{SiO}_{2}$ entsprechen den in rezenten Braunerden festgestellten Werten.

Tab. 4 : Chemische Untersuchungsergebnisse des Profiles Raunheim (Schützenhaus) (Mtbl. Hochheim 5916; R 3462320 : H 5541680 )

Analytiker: Dr. Fastabend

\begin{tabular}{|c|c|c|c|c|c|c|c|c|c|c|c|c|c|c|c|}
\hline \multirow{2}{*}{ Bezeichnung d. Probe } & \multirow{2}{*}{$\begin{array}{l}\text { Entnahme- } \\
\text { tiefe im Gel. } \\
\text { in } \mathrm{cm}\end{array}$} & \multirow{2}{*}{$\begin{array}{c}\mathrm{DH} \\
(\mathrm{KCl})\end{array}$} & \multirow{2}{*}{$\begin{array}{c}\text { Karbonate } \\
\% \\
\end{array}$} & \multirow{2}{*}{$\begin{array}{c}\text { Ore Subst. } \\
\%\end{array}$} & \multirow{2}{*}{$C: N$} & \multicolumn{2}{|c|}{ mval/100g Boden } & \multicolumn{5}{|c|}{ Kationen in mval/100o Boden } & \multirow{2}{*}{ Loel. Fe } & \multirow{2}{*}{ Loel. Al } & \multirow{2}{*}{ Lö́s. S S } \\
\hline & & & & & & $T$-Wert & sk & H & $\mathrm{ca}$ & $\mathrm{Mg}$ & $\kappa$ & $\mathrm{Na}$ & & & \\
\hline $11 / 0$ & 5 & 3.2 & & 14,0 & & 30,0 & 31,0 & 25.5 & 4.9 & 0.2 & 0.2 & 0.2 & 0.41 & 0,48 & 0.62 \\
\hline $11 / 1$ & 25 & 6.7 & & 0.3 & & 2,2 & & & & & & & 0,47 & 0,35 & 0.19 \\
\hline $11 / 2$ & 30 & 4,6 & & 0,3 & & 2,8 & & & & & & & 0.47 & 0,60 & 0,34 \\
\hline $11 / 3$ & 90 & 4,4 & & 0,1 & & 2,2 & & & & & & & 0,38 & 0,63 & 0,35 \\
\hline $111 / 4$ & 130 & 4,3 & & 0,2 & & 2,3 & & & & & & & 0,7 & 0,02 & 0,39 \\
\hline $11 / 6$ & 200 & 4,4 & & 0,6 & & 10,3 & 11.8 & 6,5 & 4,3 & 0.1 & 0,5 & 0.4 & 1,67 & 2,88 & 1,60 \\
\hline $\mathrm{tt} / 7$ & 220 & 4,9 & & 0.2 & & 11,1 & 11,4 & 4,9 & 4,6 & 0,2 & 0,9 & 0,8 & 1,38 & 2,46 & 1,60 \\
\hline $11 / 8$ & 240 & 4,9 & & 0.1 & & 1.1 & & & & & & & $\% \begin{array}{c}0,3 \\
0_{0}^{2} \mathrm{O}_{3}\end{array}$ & \begin{tabular}{c}
0,10 \\
\hdashline.$A i_{2} 0_{3}$
\end{tabular} & $\because .1110$ \\
\hline
\end{tabular}

Das Gefüge dieses $\mathrm{fB}_{\mathrm{v}}$-Horizontes entspricht dem der Braunerden. In den Kornzwischenräumen des locker gelagerten, ungleichkörnigen Skelettanteils befindet sich vorwiegend stabil geflockte, gelblichbraune Tonsubstanz. Vereinzelt macht sich eine schwache Hüllenbildung an Kornoberflächen bemerkbar. Verlagerungserscheinungen der feindispergierten Tonsubstanz sind nicht zu beobachten.

In Muldenlagen, wo die Braunerde eine größere Mächtigkeit erlangt, ist häufig eine deutliche $\mathrm{Z}$ weiteilung dieses braunen Horizontes in einen unteren gleichmäßig sattbraun gefärbten und einen oberen stark gefleckten Abschnitt zu erkennen. Die beiden Horizonte gehen stets diffus ineinander über. Worauf diese unterschiedliche Aufhellung bestimmter, unregelmäßig begrenzter Partien beruht, läßt sich bisher nur vermuten. Es wäre denkbar, $\mathrm{da} ß$ die unterlagernde, etwas verdichtete Bodendecke bereits eine gewisse Stauwirkung auf die, wenn auch vermutlich nur geringen, Sickerwassermengen ausübt und es dadurch zu einer gerade eben angedeuteten Pseudovergleyung in diesem oberen Horizont kommt. Nicht auszuschließen ist daneben die Möglichkeit einer allerdings nur schwach ausgeprägten Wurzelbleichung. Nach RöschmanN (1960, S. 750) entstehen solche Bleichzonen in der näheren Umgebung von Wurzeln durch die Lösung und Fortführung des Fe durch die bei der Wurzelatmung entstehenden Säuren (s. a. SCHRöDER \& SCHWERTMANN 1955). In den Aufschlüssen am Schützenhaus bei Raunheim sind an verschiedenen Stellen noch ge- 
ringe Reste eines ehemaligen A-Horizontes der fossilen Braunerde erhalten. Von den meist kräftig braungefärbten $B_{\mathrm{v}}$-Horizonten unterscheidet sich dieser $15-25 \mathrm{~cm}$ mächtige, stark von graubraunen Flecken durchsetzte Horizont vor allem durch seinen in den dunkleren Partien 0,6-0,9\% betragenden Humusgehalt. Das Vorkommen dieses autochthonen Humushorizontes im obersten Profilabschnitt beweist, daß es sich bei der Braunerde auch in den Muldenlagen um eine in situ entstandene Bodenbildung handelt und diese in ihrer heutigen Mächtigkeit nicht erst, wie man auf Grund der für Dünen auffallenden Profiltiefe zunächst vielleicht annehmen könnte, durch kolluviale Vorgänge entstanden ist.

Jüngste Deckschichten. Über der tiefgründigen Braunerde folgt abschließend eine jüngste Flugsanddecke unterschiedlicher Mächtigkeit. Die vorwiegend gelblichbraun gefärbten, mittel- bis grobkörnigen Sande zeigen eine meist auffallend lockere Kornlagerung. Im Gegensatz zu den Bänderflugsanden werden diese jungen Decksande daneben durch ihre fehlende Schichtung gekennzeichnet. Ob hier eine ehemals vorhandene Schichtung durch die wühlende Tätigkeit von Tieren und die in Oberflächennähe zu beobachtende stärkere Durchwurzelung wieder zerstört wurde oder aber die Sande bereits ungeschichtet sedimentiert wurden, läßt sich heute nicht mehr feststellen. Allenfalls könnten die während dieser Verwehungsperiode entstandenen kleineren Dünen, deren Material ebenfalls ungeschichtet ist, einen gewissen Hinweis auf eine bereits primär weitgehend unsortierte Ablagerung geben. Eine deutlich erkennbare rezente Bodenbildung läßt sich auf dieser, die heutige Dünenoberfläche bildenden, jüngeren Flugsanddecke meist nicht beobachten. Lediglich in den oberen $20-30 \mathrm{~cm}$ deutet sich eine zuweilen geringe Verbraunung an. Dagegen werden die lockeren Sande häufig von dünnen, meist unregelmäßig gefältelten Tonanreicherungsbändern $(2-7 \mathrm{~mm})$ durchzogen. Das erste Band setzt gewöhnlich $20-40 \mathrm{~cm}$ unter der Oberfläche ein.

Wie aus der Darstellung der Lagerungsverhältnisse in der schematischen Zeichnung des Profils Raunheim deutlich hervorgeht, kam es bei der Aufwehung der jüngsten Flugsanddecke zu einer starken Reliefumbildung insbesondere der Dünenkämme. In den Dünenscheiteln wurde die geringmächtige, fossile Bodendecke vermutlich ganz oder teilweise wieder durch verstärkte Deflation abgetragen. Relikte dieser intensiven Bodenbildung konnten in den jungen Decksanden jedoch nicht beobachtet werden.

\subsection{Die Klima- und Bodenentwicklung im Untermaingebiet seit dem Riß/Würm-Interglazial}

Fassen wir die in den weitverstreuten Aufschlüssen meist unterschiedlich ausgeprägten Schichtfolgen in einem idealisierten Übersichtsprofil zusammen, so ergibt sich für die äolischen Deckschichten des Maingebietes folgende Gesamtgliederung:

Aus diesem Schichtaufbau läßt sich für das Jungpleistozän im Maingebiet kurzgefaßt folgender bodenkundlich-geologischer Gesamtablauf rekonstruieren:

1) Bildung eines rötlichbraunen, braunerdeartigen Interglazialbodens im Riß/Würm.

2) In den Gebieten außerhalb des Akkumulationsbereiches des würmzeitlichen Mains teilweiser Abtrag und frostdynamische Verwürgung des Interglazialbodens.

Im Aufschüttungsbereich des Mains beginnende Aufschotterung der ältesten Würmterrasse.

3) Stellenweise schwach ausgeprägtes Bodenfließen, das zur Bildung geringmächtiger, autochthoner Solifluktionsdecken führt.

An exponierten Stellen erste Flugsandakkumulation. Im flußnahen Bereich Bildung der lehmstreifigen Basisschichtfolge.

4) Regional verbreitet Flugsandbildung.

5) Schwach entwickelter Naßfleckenboden. 


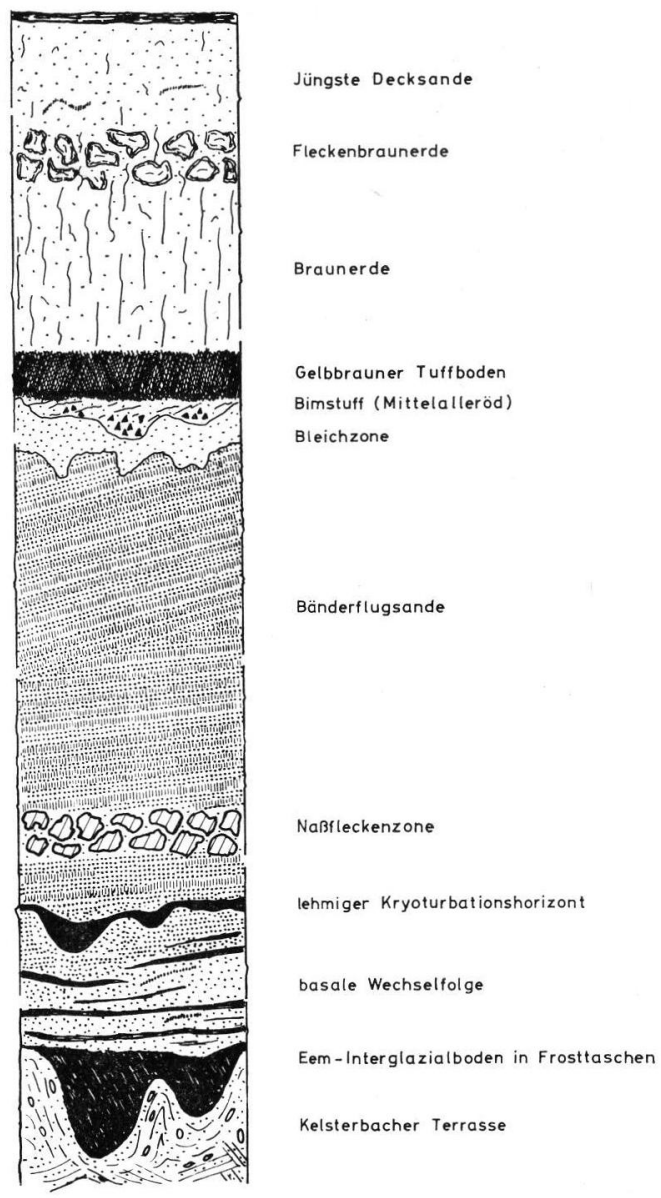

Abb. 12. Úbersichtsprofil der äolischen Deckschichten im Maingebiet.

6) Verstärkte Flugsandverwehung, Anfänge der Dünenbildung.

7) Bänderbildung (Tonverlagerungsprozesse).

8) Geringmächtige Bims-Tuff-Ablagerungen (Raunheim, Rüsselsheim).

9) Verwitterung des mit Flugsand vermengten Bims-Tuffs zu einem braunerdeartigen, gelbbraunen Boden.

10) Erneute verbreitete Flugsandverwehung.

11) Braunerdebildung auf den Dünen; Verlehmung der Hochflutabsätze auf der jüngeren Niederterrasse.

12) Letzte starke Flugsandverwehung (vermutlich anthropogen mitbedingt), die eine deutliche Reliefumbildung der älteren Dünen bewirkte.

13) Schwache Verbraunung des jüngsten Flugsandes, geringe Bänderbildung.

Nach dieser kurzen Skizzierung der Ereignisabfolge erhebt sich nun die Frage nach der absoluten zeitlichen Einordnung der verschiedenen Bildungen im Rahmen des seit Beginn des letzten Interglazials allgemein bekanntgewordenen klimatischen Gesamtablaufs. Eine nähere Erörterung dieser Altersfragen erfordert in besonderem Maße eine Berücksichtigung der sowohl klimatischen als auch geologischen Sonderstellung des Oberrheintal- 
grabens. Klimatisch zeichnet sich dieser Raum gegenüber den umgebenden Landschaften in erster Linie durch relativ geringe Niederschläge $(500-550 \mathrm{~mm} / \mathrm{a})$ und eine hohe mittlere Jahrestemperatur von $9-10^{\circ} \mathrm{C}$ aus. In geologischer Hinsicht beruht diese Sonderstellung in einer ausschließlich auf dieses Gebiet beschränkten starken Flugsandsedimentation; sämtliche umgebenden Landschaften wurden dagegen von Lößdecken unterschiedlicher Mächtigkeit überzogen. Durch diese enge, gleichsam inselartige, räumliche Begrenzung der Flugsandvorkommen in einem klimatisch besonders begünstigten Raum ergeben sich hinsichtlich eines Profilvergleichs zu weiter entfernten Flugsandgebieten (Westfalen, Niederlande und Bayern) meist erhebliche Schwierigkeiten.

Bei entsprechender Berücksichtigung der klimatischen und räumlichen Verschiedenartigkeit lassen sich jedoch, wie im folgenden zu zeigen sein wird, auch typologisch unterschiedliche Bodenbildungen weit auseinanderliegender Flugsandvorkommen zuweilen in eine enge zeitliche Beziehung zueinander bringen. Im übrigen können auch, trotz materialmäßiger Unterschiede, besonders ausgeprägte fossile Bodenbildungen in Löß- und Flugsandabfolgen angrenzender Gebiete stratigraphisch miteinander verglichen werden, so daß schließlich eine Einordnung der äolischen Deckschichtenprofile unseres Raumes in das allgemeine jungpleistozän-holozäne Gliederungsschema ermöglicht wird.

Von der ältesten, weitverbreiteten Bodenbildung des Untersuchungsgebietes blieben nur spärliche Reste in Gestalt eines ausgeprägten Kryoturbationshorizontes an der Oberfläche der Kelsterbacher Terrasse erhalten. Bei der rotbraunen, lehmigen Füllung dieser Taschen, Zapfen und Säcke dürfte es sich um die Relikte eines Interglazialbodens handeln, denn nach allem, was wir bisher über die Bodenbildung im Periglazialgebiet wissen, entsteht ein so kräftig gefärbter und stark verlehmter Boden nur während einer ausgesprochenen Warmzeit. Daß diese Bodenbildung in das letzte Interglazial zu stellen ist, geht einmal aus den Lagerungsverhältnissen hervor (s. S. 18), zum anderen konnten dieser terrestrischen Verwitterungsdecke äquivalente Flußschlicklagen auf Grund ihrer Pollenspektren mit hoher Wahrscheinlichkeit ins Eem-Interglazial eingestuft werden.

Mit beginnender Abkühlung und allmählicher Entwaldung gegen Ende der letzten Warmzeit wurde dieser Boden in den der fluviatilen Akkumulation entzogenen Gebieten unter dem Einfluß einer zunehmend feuchteren Klimaentwicklung bevorzugt in Muldenlagen durch Staunässeeinwirkung in den oberen Horizonten stärker pseudovergleyt. Das nachfolgende frühglaziale Geschehen war zunächst vermutlich durch einen stärkeren Bodenabtrag gekennzeichnet, wie dies BRUNNACKER (1957/1959) auch in Bayern an zahlreichen Stellen nachweisen konnte. Die noch verbliebenen Bodenreste wurden nach der allmählichen Herausbildung eines Dauerfrostbodens infolge der durch ständiges Gefrieren und Wiederauftauen an der Oberfläche wirksam werdenden frostdynamischen Vorgänge in die unterlagernden Terrassenkiese intensiv eingewürgt. In den Flußrandgebieten erfolgte vermutlich zur selben Zeit die Aufschotterung der ältesten Würmterrasse des Mains. Der anfänglich breit ausgedehnte fluviatile Akkumulationsbereich schrumpfte bei nachlassender Schuttzufuhr allmählich wieder auf einen schmalen Aufschüttungsstreifen zu beiden Seiten des Flusses zusammen.

Der folgende Zeitabschnitt war an der Oberfläche der Kelsterbacher Terrasse durch wenig ausgeprägte Solifluktionsvorgänge gekennzeichnet, die an geeigneten Stellen der schwach gewellten Oberfläche zur Bildung geringmächtiger, autochthoner Solifluktionsdecken führten. Auch die basale Wechselfolge sandiger und sandig-schluffiger Schichten, sowohl im Hangenden des Kryoturbationshorizontes als auch randlich auf dem bereits gebildeten geringmächtigen Schotterkörper des Mains, entstand vermutlich noch unter dem Einfluß eines kühlfeuchten Klimas. Durch die gelegentliche Zwischenschaltung von Flugsanden in diesem Schichtkomplex deutet sich jedoch bereits der Übergang zu mehr trockenkalten Klimaverhältnissen an. 
Den Abschluß der basalen Wechselfolge nach oben bildet im Aufschluß Mönchhof ein kryoturbat gestörter, brauner, lehmig-schluffiger, gelegentlich noch kalkhaltiger Horizont, dem ähnliche Bildungen in benachbarten Aufschlüssen entsprechen. Da sich in diesem Horizont eine Bodenbildung mit Sicherheit nicht nachweisen läßt, muß seine stratigraphische Einstufung unsicher bleiben. In Anlehnung an die Lößstratigraphie in Hessen wäre es vielleicht denkbar, daß es sich bei dieser Bildung möglicherweise um ein Äquivalent des W I/II handelt. Sicherlich kommt dieser Schicht jedoch ein höheres Alter zu als einer auf Grund von Pollenanalysen ins Bölling Interstadial eingestuften (V. D. Hammen 1951, zit. n. DüCKer \& MaArleveld 1958), ähnlich zusammengesetzten, die Wechselfolge der „Alteren Decksande“ nach oben abschließenden Grenzschicht in den niederländischen Flugsandgebieten. Aber ganz unabhängig davon, ob es sich in unserem Falle nun um eine echte Bodenbildung oder nur um eine wenig veränderte Sedimentlage handelt, gewinnt diese Schicht doch insofern eine gewisse stratigraphische Bedeutung, als sie einen deutlichen Sedimentationswechsel anzeigt.

Das allgemein durch kühlfeuchte Klimabedingungen charakterisierte frühglaziale Geschehen im Maingebiet zeigt im übrigen eine gute Übereinstimmung zu der von DücKeR \& MaArleveld (1958, S. 132) in den niederländischen Flugsandgebieten beobachteten Entwicklung.

Der folgende Zeitabschnitt ist gekennzeichnet durch eine erstmals reine Flugsandsedimentation. Da allgemein für die Bildung von Flugsand ebenso wie für Löß ein möglichst kalttrockenes Klima vorausgesetzt wird, dürfen wir am Ende des Frühglazials mit einem deutlichen Klimaumschwung rechnen. Die Flugsandbildung wird nach einem kürzeren Zeitraum von einer geringen Wärmeschwankung, die einen schwach entwickelten $\mathrm{Naß}$ fleckenboden hinterläßt, kurzfristig unterbrochen. Dieser nur an wenigen Stellen erhaltene Fleckenboden könnte wiederum in Anlehnung an die Lößstratigraphie mit allem Vorbehalt vielleicht dem W II/III (BRUNNACKER W I/II) gleichgestellt werden.

In der Folgezeit erreicht die Flugsandakkumulation dann mit einer noch schwach ausgeprägten Dünenbildung ihren Höhepunkt. Flugsandverwehungen in dem genannten Ausmaß sind aber an klimatische Voraussetzungen gebunden, wie sie nach der bisherigen Kenntnis vor allem während des langdauernden, trocken-kalten Hochglazials gegeben waren. Schon Dewers (1934/35, S. 347/48) nahm auf Grund der engen Verzahnung von Löß-Flottsand und Flugsand in Norddeutschland eine im wesentlichen gleichzeitige, hochglaziale Entstehung der verschiedenen Bildungen an. Auch die niederländischen Bearbeiter der dortigen Flugsande vertreten allgemein die Auffassung einer vorwiegend hochglazialen Entstehung der „Älteren Flugdecksande“ (DüCKer \& MAarleveld 1958, S. 221).

Den ältesten Flugsanden im bayrischen Donautal als auch in Nordbayern kommt nach Brunnacker (1959, S. 122) ebenfalls ein hochglaziales Alter zu. Dagegen konnte MaAs (1950, S. 76) in den westfälischen Dünengebieten eine vorwiegend spätglaziale Entstehung der dortigen Dünen nachweisen.

Die, wie gezeigt wurde, seit Beginn des Hochglazials kräftig in Gang kommende Dünenbildung setzte sich vermutlich unter allmählicher Abschwächung bis zum Ende der Alteren Tundrenzeit fort. In dem zwischen dem Hochglazial und dem Alleröd-Interstadial liegenden, als Spätwürm bezeichneten Zeitabschnitt erfolgte vermutlich die für diese Dünensande charakteristische Bänderbildung (Ton-Eisenanreicherung). BRUNNACKER (1959, S. 120), der diese von ihm als Rostbänder bezeichneten Lagen unter einem allerödzeitlichen Podsol im Rednitztal beobachten konnte, hält eine Entstehung der dünnen Anreicherungshorizonte hauptsächlich während des relativ kühlfeuchten Bölling-Interstadials für wahrscheinlich. In unserem Falle dagegen möchten wir auf Grund bestimmter Überlegungen zur Genese dieser Bildungen eine weniger enge zeitliche Begrenzung für die Bänderentwicklung annehmen. Der Zeitraum, in dem die Bildung dieses als Sandparabraunerde zu bezeichnenden Bänderkomplexes erfolgte, dürfte vielmehr das gesamte 
Spätwürm umfaßt haben. Diese Annahme könnte auch durch die an Lößprofilen beobachtete spätglaziale Bodenentwicklung gestützt werden. So gelang es SchöNHAls (1961, S. 283 ff.) durch eingehende Profilstudien an Lößabfolgen, die unter einer mächtigen allerödzeitlichen Bimsbedeckung gleichsam konserviert wurden, nachzuweisen, daß die Bodenbildung auf Löß bis zum Alleröd stellenweise bereits das Parabraunerde-Stadium erreicht hatte. Zu vergleichbaren Ergebnissen kommt auch BRUNNACKER (1957/1959) für die bayerischen Lößgebiete.

Im Hangenden der Bänderflugsande erhalten wir durch die Einlagerung einer, nachweisbar im Mittelalleröd entstandenen, Bims-Tuffschicht die absolute Zeitmarke unserer Schichtfolge. Dieser durch Umlagerungen mit Flugsand vermischte Bims-Tuff wurde in den meisten Fällen zu einer schwach olivgelb gefärbten Braunerde umgebildet. Es läge nun nahe, diese charakteristische Bodenbildung in das vermutlich durch günstigere Klimabedingungen gekennzeichnete Alleröd einzustufen. Da dieser Bodenhorizont jedoch

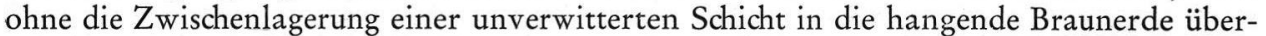
geht, können wir diesen nicht ohne weiteres dem Alleröd zuordnen. Andererseits spricht aber der höhere Humusgehalt - im Dünnschliff kenntlich an der Einlagerung verkohlter Pflanzenreste - für eine selbständige Bodenbildung. Auch der zur Verfügung stehende Zeitraum von 500-700 Jahren dürfte für die Bildung eines braunerdeartigen Bodens ausgereicht haben. Wenn man weiterhin berücksichtigt, daß in Bayern während des Alleröd ein Podsol und in den Niederlanden ein holzkohleführender Bleichhorizont gebildet wurden, so könnte dem in unserem Gebiet durchaus eine schwache Braunerdeentwicklung entsprechen. Andererseits hat sich der Nachweis einer auffallenden Wärmetönung während des Alleröd gerade im Oberrheintal pollenanalytisch bisher nicht führen lassen (G. v. D. BRelie, Vortrag 1962 Tgg. D.G.G., Ffm.).

In der jüngeren Tundrenzeit kommt die Flugsandverwehung infolge eines stärkeren Rückgangs der Vegetation, ausgelöst durch einen erneuten Kälterückschlag, nochmals kräftig in Gang. Dieser Befund steht allerdings in gewissem Widerspruch zu der Auffassung von FIrbas (1952, S. 45), der es für unwahrscheinlich hält, daß die jüngere TundrenZeit im Oberrheingebiet noch zu einer stärkeren Entwaldung führte.

Auf diesen jüngeren bis zu 2 m mächtigen Flugdecksanden kommt es im Postglazial zu einer sehr intensiven Braunerdebildung. Der in Muldenlagen nicht selten über einen Meter mächtige $B_{v}$-Horizont entstand vermutlich zur selben Zeit wie die Steppenböden auf Löß im benachbarten, trockenen Rheinhessen (ZAKoseK 1962, S. 30). Die Hauptbildungszeit der Braunerden aus Flugsand lag demnach im Boreal, das durch sein trocken-warmes Klima besonders gekennzeichnet war. Dieser den Steppenböden auf Löß vergleichbaren Sandbraunerde dürften andererseits auch die aus den hessischen Mittelgebirgen bekanntgewordenen Lockerbraunerden (SснӧNHALs, 1957) entsprechen. Im klimatisch weniger begünstigten Westfalen setzte zu dieser Zeit (Atlantikum) auf den spätglazialen Dünen eine bereits kräftige Podsolierung ein (MaAs 1950, S. 74).

Die intensive boreale Bodenbildung auf den silikatarmen Mainsanden erfaßte vermutlich auch noch die unterlagernde, bereits im Alleröd vorgebildete Bimsbraunerde und führte zur weiteren „Verlehmung“ des leicht verwitterbaren Bims-Tuffes. Wie aus dem Fund römischer Scherben dicht unter der Oberfläche der Braunerde und der C14-Datierung einer Brandschicht im Hangenden dieser Verwitterungsbildung deutlich hervorgeht, dürfte sich diese Bodenentwicklung bis ins 6. bis 7. Jahrhundert n. Chr. hinein ziemlich ungestört fortgesetzt haben. Die auf den Steppenböden des Rheinhessischen Lößgebietes unter veränderten Klimabedingungen (Atlantikum/Subboreal) einsetzende Degradations- und Regratationsphasen sind in der Braunerde allerdings nicht nachzuweisen.

In den Dünengebieten wurde diese Bodenentwicklung schließlich $\mathrm{zu}$ einem uns nicht genau bekannten Zeitpunkt durch das wohl letztmalige starke Wiederaufleben der Flugsandverwehung beendet. Während die Braunerden besonders bei der starken Reliefum- 
Tab. 5 : Stratigraphische Gliederung des Jungpleistozäns und Holozäns im nördlichen Oberrheintal

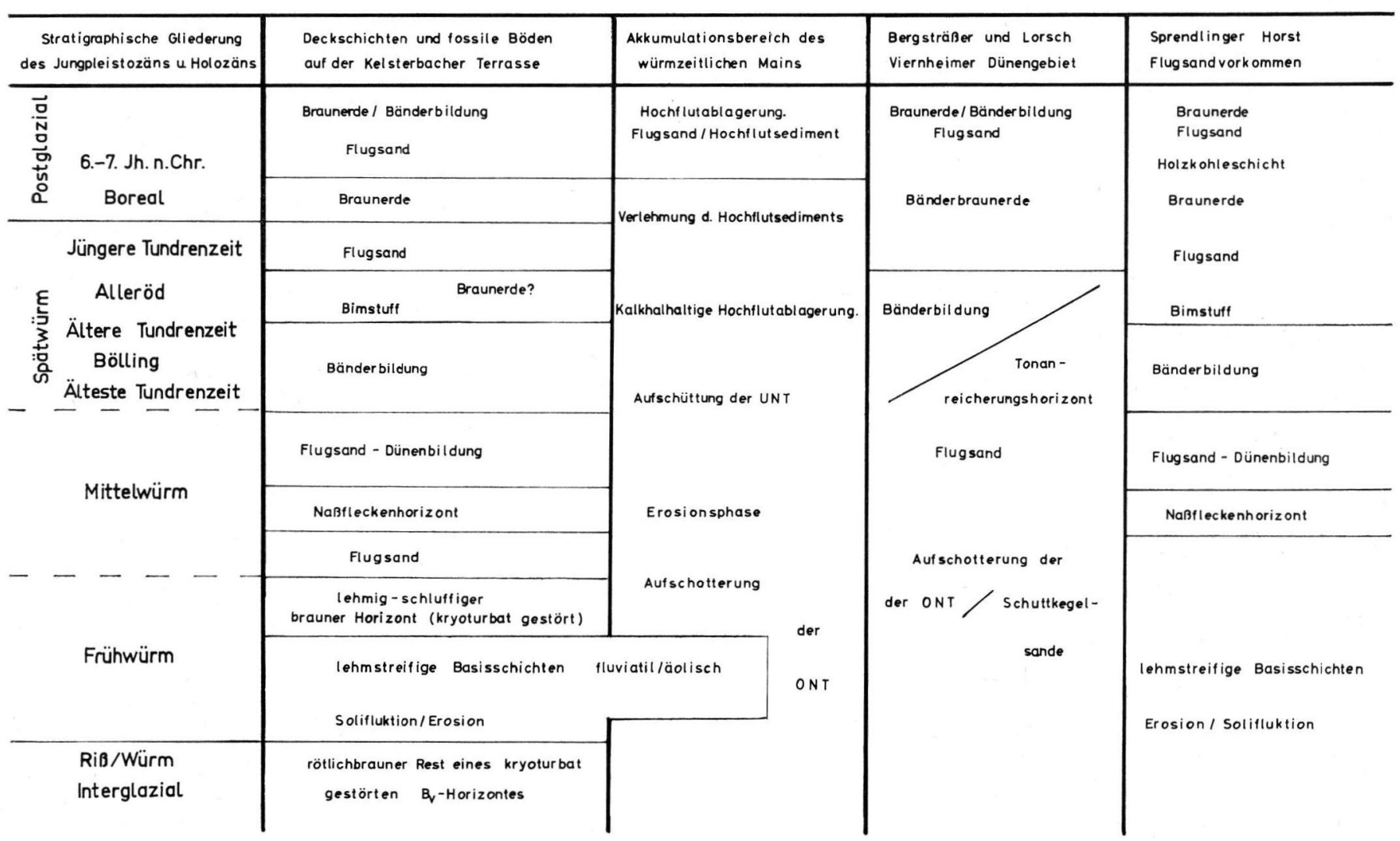


bildung der Dünenkämme im höheren Niveau teilweise erodiert wurden, blieben sie in Muldenlagen meist erhalten und wurden dort von jüngsten Flugsanden überdeckt. In den flußferneren Gebieten kam es vermutlich zur selben Zeit zu einer geringen Flugsandüberwehung des „blutlehmartigen“ Bodens. Auf welchen Ursachen diese erneute, starke Flugsandbildung letztlich beruht, konnte nicht mit Sicherheit festgestellt werden. $\mathrm{Da}$ jedoch, wie bereits dargelegt, das Ingangkommen der Flugsandbildung eine Beseitigung der Vegetation voraussetzt, ein natürlicher Rückgang der Bewaldung zu dieser Zeit aber nicht mehr erwartet werden kann, dürften hier Eingriffe des Menschen eine größere Rolle gespielt haben. $\mathrm{Zu}$ welchem Zeitpunkt diese jüngsten Flugsande schließlich wieder festgelegt wurden, läßt sich nur abschätzen. Will man die nur schwache „rezente“ Bodenbildung auf den Dünen als Zeitmaßstab heranziehen, dann dürfte die Beendigung der weiträumigen, äolischen Sedimentation im nördlichen Oberrheintalgraben allerdings nicht sehr weit zurückliegen.

\section{Quartäre Bildungen im Gebiet von Rhein und Neckar}

\subsection{Fluviatile Ablagerungen}

\subsubsection{A 11 gemeines}

Im Akkumulationsbereich von Rhein und Neckar kam es in dem von uns untersuchten Gebiet der eigentlichen Grabenzone zu einer regelmäßigen Überlagerung älterer durch jüngere Flußabsätze. Morphologisch erkennbare ältere Terrassenstufen konnten sich in diesem, während des Pleistozäns ständig weiter einsinkenden Trog nicht entwikkeln, so daß der Gesamtaufbau der eingeschütteten Lockersedimente der unmittelbaren Beobachtung nicht zugänglich ist. Ausgehend vom heutigen Rheinlauf wird die Oberfläche der relativ ebenen Talsohle gegliedert in das nur schwach eingetiefte Hochflutbett $(88 \mathrm{~m}$ über NN) und die 10-15 km breite Niederterrassenstufe (Hochgestade, etwa 91-96 m über NN), die ihrerseits wiederum durch die stellenweise ausgedehnten Neckarauen stärker zerschnitten wurde.

\subsubsection{Hochflut leh m d e ke}

Die aus vorwiegend feinkörnig-tonigen Sedimenten aufgebaute Hochflutlehmdecke (SснӧNHals 1954, S. 89 ff.) wechselt in ihrer flächenhaften Ausdehnung meist sehr stark, erstreckt sich jedoch nicht selten über eine Breite von mehreren Kilometern. Ihre Mächtigkeit schwankt $z$ wischen 0,4 und über $2 \mathrm{~m}$ in alten Erosionsrinnen. Neben einem noch im gesamten Profil nachweisbaren, 1,5\% übersteigenden Anteil organischer Substanz werden diese Hochflutabsätze vor allem durch ihren stets vorhandenen Karbonatgehalt gekennzeichnet. Eine deutliche Profildifferenzierung ist in diesem vorwiegend tonigen, bei tiefem Grundwasserstand stark austrocknenden Hochflutlehm nicht zu beobachten. Die Entwicklungstendenz der vermutlich bereits primär humushaltigen Sedimente ging bei hochstehendem Grundwasser zunächst wohl in Richtung der Anmoorbildung. Nach stärkerer Absenkung des Grundwassers (Riedkultivierung) dürfte sich derzeit eine mehr terrestrische Bodenentwicklung vollziehen. GANSSEN \& HARTH (1957, S. 217) bezeichnen diese Bildungen als „tschernosemartige Wiesenböden“ oder auch als „Auenschwarzerden“; Schönhals (1954, S. 93) nimmt unter den gegenwärtigen Bedingungen eine Entwicklung zu „rendzinaartigen Auenböden" an.

\subsubsection{Nied e r ter rasen}

Die fast über den gesamten Raum zwischen der Rheinaue ( $84 \mathrm{~m}$ über $\mathrm{NN}$ ) und dem Gebirgsrand, mit Ausnahme der alten Neckarbetten, verbreitete Niederterrasse ist gegen das Hochflutbett durch eine meist scharfe, etwa 1-2 m hohe Geländekante $(86 \mathrm{~m}$ über NN) deutlich abgesetzt. Der Terrassenkörper wird vorwiegend aus grauen bis rötlichgrauen, feinkörnigen, kalkhaltigen Sanden mit gelegentlichen Kieseinschaltungen aufgebaut. Auf weiten Flächen werden diese jungpleistozänen Sande von Flugsanddecken unterschiedlicher Mächtigkeit überlagert. Auf diesen meist noch kalkhaltigen, äolischen 
Sedimenten entwickelten sich vornehmlich Braunerden unterschiedlichen Ausprägungsgrades. Ihre nähere Charakterisierung erfolgt zusammen mit der Beschreibung der Flugsande.

Am östlichen durch Sprendlinger Horst und Odenwald begrenzten Grabenrand verzahnen sich die jungpleistozänen, fluviatilen Ablagerungen mit den nach Westen vorgeschütteten Schuttkegelsanden und Schottern der aus dem Bergland kommenden Bäche. Eine größere flächenhafte Verbreitung erreichen die feinkörnigen, von Schuttstreifen durchzogenen Sande im Gebiet westlich Darmstadt und in der Arheilger Bucht, wo sie die Rhein- und Neckarsedimente stellenweise in größerer Mächtigkeit überlagern.

\subsubsection{Flugs a nde}

\subsection{Aolische Ablagerungen}

Ein ausgedehntes, vorwiegend bewaldetes Flugsand- und Dünengebiet erstreckt sich im Raum Darmstadt-Zwingenberg zwischen dem heute verlassenen Bergsträßer Neckarlauf und dem Westabfall des Odenwaldes. Vielfach werden auch die weniger steilen Randhöhen des Gebirges noch von Flugsanden und Dünen meist lückenhaft überzogen.

Die Darmstädter Flugsande unterscheiden sich von den Mainflugsanden in Farbe, Korngröße und Kalkgehalt meist sehr deutlich. Besonders gekennzeichnet werden diese Sande durch einen bemerkenswert hohen Kalkgehalt, der im unverwitterten Material nicht selten $15 \%$ überschreitet. Das Karbonat überzieht vorwiegend hüllenartig die Kornoberflächen, wodurch die hellgraue, gelegentlich auch gelbgraue Färbung der Flugsande hauptsächlich hervorgerufen wird. Größere Mengen des Karbonats werden durch zuweilen bis in tiefere Schichten vordringendes $\mathrm{CO}_{2}$-haltiges Niederschlagswasser auch im unverwitterten Flugsand bereits wieder gelöst und bevorzugt an wasseraufnehmenden Pflanzenwurzeln abgeschieden. Dadurch entstehen die knochenförmigen, oft bis zu Armdicke die Wurzeln umhüllenden Kalkgebilde, die auch „Osteokolle“ oder „Beinbrech“ genannt werden (SснӧNhals 1954, S. 78). Plattige Kalkanreicherungen kommen besonders in gut geschichteten Flugsanden häufiger vor.

Im Vergleich zu den relativ grobkörnigen Mainsanden treten hier vorwiegend feinkörnigere Flugsande auf. Die vorherrschende Korngröße liegt zwischen 200-100 $\mu$, die Schlufffraktion übersteigt nur selten $5 \%$ des Gesamtanteils. Höhere Anteile der Fraktionen $>200 \mu$ kommen nur gelegentlich in einzelnen petrographisch auffallenden Schichten vor.

\begin{tabular}{|c|c|c|c|c|c|c|c|c|c|c|c|c|c|}
\hline Lokalität und Nr. der Probe & $>2,0 \mathrm{~mm}$ & $2,0-1,0$ & $1,0-0,5$ & $0,5-0,2$ & $0,2-0,125$ & $<0,125$ & $0,1-0,063$ & $0,063-0,02$ & $0,02-0,0063$ & $30,0063-0,002$ & $<0,002$ & $\begin{array}{r}\text { Md- } \\
\text { Wert }\end{array}$ & $\begin{array}{l}\text { So- } \\
\text { Wert }\end{array}$ \\
\hline $\begin{array}{l}\text { 1.) Dunnengebiet s. Eberstadt, } \\
\text { aus } 0,5 \mathrm{~m} \text { u. } \quad 26 / 41\end{array}$ & - & - & 1,4 & 20,5 & 66,8 & - & 9,2 & 1,6 & 0.4 & - & - & 150 & 1,26 \\
\hline $\begin{array}{l}\text { 2.) Dỉne am Rotböhl sw. Wixhausen, } \\
\text { aus } 2,7 \mathrm{~m}\end{array}$ & 0,1 & 1,0 & 1,1 & 26,2 & 58.1 & - & 12,2 & - & 1,1 & - & - & 155 & 1,32 \\
\hline $\begin{array}{l}\text { 3.) Bodeneinschlag w. Weiterstadt, } \\
\text { aus } 1,0 \mathrm{~m} \quad 52 / 50\end{array}$ & - & - & 0.4 & 26,7 & 62,18 & - & 8,0 & 2,32 & - & - & - & 159 & 1,29 \\
\hline 4.) Oüne $\begin{array}{r}1 \mathrm{~km} \text { n. Malchen, aus } 1,5 \mathrm{~m} \\
11 / \mathrm{O}_{2}\end{array}$ & 0,3 & 0,78 & 2.23 & 43.1 & 43,8 & - & 4,5 & 3,0 & 2,1 & - & - & 185 & 1,31 \\
\hline
\end{tabular}

\subsubsection{Der stratigraphische Aufbau der Dünen}

Im Gegensatz zum Maingebiet liegen von dem Bergsträßer Flugsandvorkommen bereits mehrere eingehende stratigraphische Bearbeitungen vor. So konnten SCHOTTLER (1926) und O. DieHL (1933) die Dünensande dieses Gebietes übereinstimmend in „ältere“ und „jüngere“ Flugsande, die durch eine auffallende Bodenbildung voneinander getrennt werden, untergliedern. Die von O. Sснмітт (1955) in neuerer Zeit durchgeführten stratigraphischen Untersuchungen brachten im wesentlichen eine Bestätigung der von den älteren Autoren vorgelegten Ergebnisse. Wie das im folgenden beschriebene Profil jedoch 
zeigt, ergibt sich durch die Einschaltung jener bisher nicht bekannten fossilen Bodenbildung im jüngeren Flugsand die Möglichkeit einer weiteren Untergliederung.

Profil Zwingenberg, am Hundetressurplatz (Bl. Zwingenberg 6217; R 3471350 : H 5510 850):
1) $\mathrm{A}_{\mathrm{p}} \mathrm{O}-20 \quad(20 \mathrm{~cm}$ '
2) $\mathrm{B}_{\mathrm{v}} \quad 20-62(42 \mathrm{~cm})$
stark dunkelgraubr. 10 YR 3/2, feinkörniger, schw. humoser
Sand, stark durchwurzelt

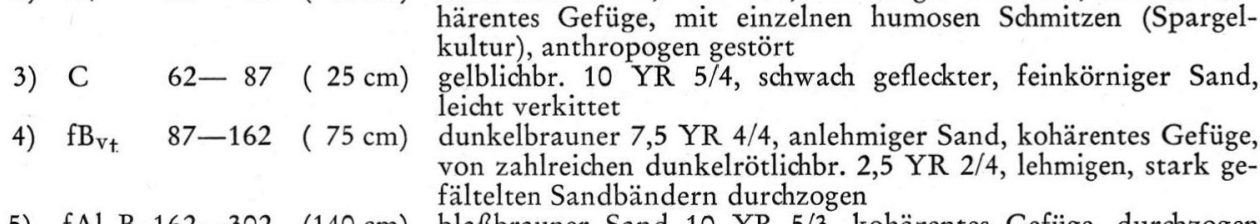
dunkelbrauner 7,5 YR 4/4, anlehmiger Feinsand, schwach ko-
härentes Gefüge, mit einzelnen humosen Schmitzen (Spargel-
kultur), anthropogen gestört
5) fAl, $B_{t} 162-302(140 \mathrm{~cm})$ blaßbrauner Sand 10 YR 5/3, kohärentes Gefüge, durchzogen von zwölf $2-3 \mathrm{~cm}$ starken rötlichbr. 5 YR $4 / 4$ stark gefältelten Tonanreicherungsbändern
6) $\mathrm{fB}_{\mathrm{t}} \quad 20-200 \mathrm{~cm}$ gelblichroter 5 YR $4 / 6$, lehmiger Sand, stellenweise stark rost- gefleckt, kohärentes Gefüge, zuweilen schwach aggregiert in Form von Taschen und Zapfen bis $2 \mathrm{~m}$ tief in den Untergrund ein- greifend
7) $\mathrm{Cn}$ graubrauner Taschenboden, 10 YR 5/2, feinkörniger, gutgeschich- teter Sand, kalkhaltig, vereinzelt starke osteokollartige Kalkab- scheidung.

Tab. 7 : Chemische Untersuchungsergebnisse des Profiles Zwingenberg

(Mtbl. Zwingenberg 6217; R 3471350 : H 5510 850)

Analytiker: Dr. Fastabend

\begin{tabular}{|c|c|c|c|c|c|c|c|c|c|c|c|c|c|c|c|c|}
\hline \multicolumn{2}{|c|}{ Bereichnung } & \multirow{2}{*}{$\begin{array}{l}\text { Entnahme- } \\
\text { tiefe im } \\
\text { Gel. in cm }\end{array}$} & \multirow{2}{*}{ (KCI) } & \multicolumn{2}{|c|}{ Karbonate Org Subst. } & \multirow{2}{*}{$C: N$} & \multicolumn{2}{|c|}{ mval $/ 100 \mathrm{~g}$ Boden } & \multicolumn{5}{|c|}{ Kationen in mval / $100 \mathrm{~g}$ Boden } & \multirow{2}{*}{$\begin{array}{l}\text { Lösi. } \\
\text { F。 }\end{array}$} & \multirow{2}{*}{$\begin{array}{l}\text { Lösl. } \\
\text { A! }\end{array}$} & \multirow{2}{*}{$\begin{array}{l}\text { Lösl. } \\
\text { si }\end{array}$} \\
\hline der & Probe & & & $\%$ & $\%$ & & T-Wert & sk & $H$ & ca & Mg & $\mathrm{k}$ & $\mathrm{Na}$ & & & \\
\hline & 3 & 30 & 7,0 & 0 & 0.3 & & 5,0 & & & & & & & 0.52 & 0.48 & 0.21 \\
\hline & 4 & 80 & 6,8 & 0,1 & 0,2 & & 2,7 & & & & & & & 0,55 & 0,37 & 0,25 \\
\hline & 5 & 120 & 7,1 & 0,1 & 0,3 & & 6,2 & 7.2 & 1,3 & 5.4 & 0,3 & 0.1 & 0,1 & 0,66 & 1,04 & 0,50 \\
\hline & 6 & 125 & 6,7 & 0,2 & 0,2 & & 3,2 & & & & & & & 0,57 & 0.47 & 0.25 \\
\hline & 7 & 130 & 6,6 & 0,1 & 0,2 & & 15,4 & 16,0 & 1,6 & 12,6 & 1,2 & 0,3 & 0,3 & 1,68 & 1,67 & 0,78 \\
\hline & 8 & 180 & 7,5 & 15,9 & 0.1 & & 2,6 & & & & & & & Q.47 & 0,21 & $0,2 t$ \\
\hline & & & & & & & & & & & & & & $\mathrm{C}_{2} \mathrm{O}_{3}$ & $\cdot \mathrm{Al}_{2} \mathrm{O}_{3}$ & $\% \mathrm{Si} \mathrm{O}_{2}$ \\
\hline
\end{tabular}

Die grauen, feinkörnigen, stark kalkhaltigen Sande im Liegenden des Zapfenbodens werden von den vorgenannten Autoren als die „älteren“ Flugsande bezeichnet. Ihre Untergrenze und damit ihre Mächtigkeit lassen sich meist nur schwer angeben, da diese Flugsandfolge nach unten allmählich in einen von Kiesschnüren und Schuttstreifen durchzogenen Sandkomplex übergehen. Die häufig nur schwach gerundeten Gerölle von unterschiedlichem Durchmesser entstammen ausschließlich dem nahen kristallinen Odenwald. Während die Geröllagen zweifellos fluviatil entstanden sind, lassen sich bei der Sedimentation der feinkörnigen Sande äolische Einflüsse nicht ohne weiteres ausschließen. Offenbar treten besonders in diesem basalen Bereich beide Transportmedien noch in vielfache Wechselwirkung. Diese mit der im Maingebiet beobachteten kaum vergleichbaren Entwicklung der basalen Schichtfolge erklärt sich aus den großräumigen geologischen Verhältnissen am westlichen Odenwaldrand. Nach SchotTLER (1926, S. 191) bildeten sich vor dem Westrand des Odenwaldes mächtige Schuttkegel aus, die sich mit Rhein- und Neckarsedimenten ständig verzahnen. Im jüngeren Pleistozän erhoben sich die Schuttkegel allmählich über die fluviatile Aufschüttungsebene hinaus, so daß fortan Rhein- und Neckargerölle in den Schuttkegelsanden fehlen. 
Im Laufe des Würms vereinigten sich schließlich die einzelnen Schuttfächer zu dem großen Darmstädter Schuttkegel (Schmitт 1955, S. 84), der aus den älteren Schuttkegelsanden (SCHотTLER 1926) aufgebaut wird. Während im Frühglazial die aquatischen Sandund Geröllverlagerungen vermutlich vorherrschten, kehren sich im Hoch- und Spätglazial die Verhältnisse allmählich um, bis die äolische Sedimentation überwiegt und reine Flugsande zur Ablagerung kommen.

Schotтler (1926, S. 193) und Sснмiтt (1955, S. 84) nehmen an, daß die kalkhaltigen Schuttkegelsande ehemals als Flugsande aus Rhein- und Neckarterrassen ausgeblasen und von Westwinden in den Odenwald hineingeweht wurden. Von dort sollen sie dann zusammen mit Odenwaldgeröllen vermischt teilweise wieder abgeschwemmt und vor dem Gebirgsrand in den Schuttfächern abgelagert worden sein. Trifft diese Deutung zu, so erhalten wir damit einen weiteren Hinweis auf die bereits sehr frühzeitig einsetzende Flugsandverwehung in diesem Gebiet. Das Fehlen deutlicher Zeitmarken in den tieferen Schichten läßt sich leicht damit erklären, daß auf der exponierten Oberfläche der Schuttfächer ständig neue Umlagerungen der leichtbeweglichen Sande erfolgte, wodurch mögliche Anzeichen schwacher interstadialer Bodenbildungen leicht wieder verwischt wurden.

\subsubsection{Der Z $\mathrm{Z}$ a fenboden}

Auf den älteren Flugsanden hat sich ebenso wie auf den in gleichem Niveau gelegenen Schuttkegelsanden eine eigenartige, für kalkhaltige Sande dieses Raumes aber geradezu typische Bodenentwicklung vollzogen; ein rötlichbraun gefärbter, $30-80 \mathrm{~cm}$ mächtiger Tonanreicherungshorizont greift in Form von Zapfen und Taschen bis zu $2 \mathrm{~m}$ tief in den unverwitterten Untergrund ein. Hin und wieder läßt diese Bodenbildung in den Profilen eine deutliche $\mathrm{Z}$ weiteilung in einen mächtigeren, weniger bindigen, zuweilen auch gefleckten oberen und einen stärker verlehmten unteren Horizontabschnitt erkennen. Besonders mächtig wird der von Schotтler (1926, S. 177) auch als „Brandletten“ bezeichnete Horizont in den tief nach unten greifenden Zapfen und Taschen. Während die häufig schalig aufgebauten Randzonen der Taschen stets durch eine größere Bindigkeit gekennzeichnet werden, wird das Innere dieser Gebilde meist von hellbraunem, sandigem, stark gebändertem, kalkfreiem Material ausgefüllt.

Genetisch wird diese eigenartige Form der Bodenbildung verschieden gedeutet. Schottler (1926, S. 182) nimmt an, daß eine zunächst einheitliche, braunerdeartige Bodenbildung eine spätere Umwandlung erfahren hat. Danach sollen aus dem oberen Profilabschnitt Eisenhydroxyd und Tonteilchen ausgewaschen und an der Basis in der sogenannten "Brandlettenzone" wieder angereichert worden sein. Er vergleicht diesen Vorgang mit einer durch sauren Auflagehumus bedingten, schwachen Ortsteinbildung. Nach der von Wagner (1952, S. 173) und Schmitt (1955, S. 82/83) vertretenen Auffassung handelt es sich bei diesen Taschen und Zapfen dagegen um Verlehmungszonen entlang ehemaliger Baumwurzeln. Sie gehen dabei offenbar von der Vorstellung aus, daß sich in den Wurzelröhren bevorzugt Leitbahnen für das eindringende Sickerwasser ausbilden konnten, was zu einer häufigeren und stärkeren Durchfeuchtung und damit zu einer verstärkten Karbonatlösung in diesem Bereich führte. Nach Weglösung der Karbonate kam es im weiteren Verlauf zu einer durch die Einwirkung organischer Säuren noch gesteigerten Verwitterung in der Wurzelzone, was allmählich zu einer intensiven Verlehmung führte.

Was jedoch die Karbonatlösung und Wegführung betrifft, so können wir heute gerade den umgekehrten Vorgang beobachten. Die unter dem derzeitigen Klima herrschende Dynamik führt nämlich im Bereich der Baumwurzeln nicht zu einer verstärkten Karbonatlösung, sondern im Gegenteil zu einer intensiven Kalkanreicherung bis zu Armdicke um die Wurzelstränge (Osteokolle). Ob sich dieser Vorgang unter feuchteren Bedingungen in die von WAGNeR und SchmitT geforderte Dynamik umkehrt, erscheint jedoch zweifelhaft.

Ergeben sich schon aus diesen allgemeinen Erwägungen verschiedene Einwände gegen eine stärkere Verlehmung im Sinne von WAGNER und SchmiTT, so sprechen auch die im 
Dünnschliff erkennbaren mikromorphologischen Merkmale gegen eine solche Deutung. Das sehr gleichkörnige Skelettmaterial des Tonanreicherungshorizontes wird gekennzeichnet durch einen hohen Anteil verwitterbarer Silikatminerale. Neben Quarz und Quarzit als Hauptgemengteilen treten besonders zahlreich Plagioklas, Orthoklas, Hornblende, Granat, Muskowit und Biotit als Nebengemengteile auf. Die Silikate erscheinen stets vollkommen frisch. Das Fehlen jeglicher erkennbarer Verwitterungsspuren auch in den Randpartien der leichter angreifbaren Silikate läßt aber darauf schließen, daß eine intensive Verlehmung nicht in dem geforderten Maße erfolgt sein kann. In Anlehnung an die bereits von SchotTLER (1926) geäußerte Vermutung wäre demnach die deutliche Tonanreicherung in diesem Horizont im wesentlichen auf Einwaschung größerer Mengen von Feinsubstanzen aus höheren Profilteilen zurückzuführen. Ob diese Tonverlagerung allerdings auf der Umbildung einer bereits vorhandenen Braunerde beruht, mag zunächst dahingestellt bleiben. Dagegen erscheint es nicht ausgeschlossen, daß es sich bei einem Teil der Tonsubstanz um bei der Karbonatlösung entstandene braunlehmartige Rückstandsbildungen handelt.

Im Schliffbild werden die Kornoberflächen des einheitlich feinkörnigen Skelettmaterials gleichmäßig von dünnen Hüllen orientiert angelagerter, feindisperser Tonsubstanz überzogen. Freie Intergranularräume sind noch reichlich vorhanden, so daß die Lösungsbewegung zwar gehemmt wird, aber noch möglich ist. Häufig wurden die Tonanlagerungen von Eisenhydroxydlösungen saumartig imprägniert. Diese Fe-Verbindungen wurden vermutlich ebenso wie die Tonsubstanz durch Sollösungen infiltriert; eine Entstehung am Ort scheidet aus. Nachdem somit als Ursache der Tonanreicherung im wesentlichen Einschlämmungsvorgänge erkannt werden konnten, bleibt die Entstehung des merkwürdigen Formenbildes dieses Horizontes zu klären.

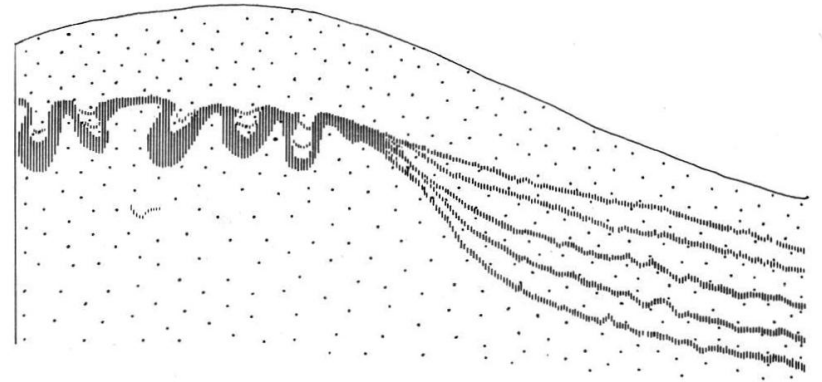

Abb. 13. Dünenprofil am Seehof südl. Lorsch. 1/100. Erläuterung s. Text.

Eine gute Deutungsmöglichkeit ergibt sich aus einem am Seehof südlich Lorsch aufgeschlossenen Dünenprofil. In diesem Profil löst sich der im Scheitel der Düne entwickelte $\mathrm{fB}_{\mathrm{t}}$-Horizont auf der Dünenflanke in zahlreiche, dünne Einzelbänder auf. Die Grenze dieser Bänderflugsande zu den liegenden, kalkhaltigen Dünensanden wird in diesem Bereich durch eine lediglich noch leicht gewellte und schwach rostgefleckte Übergangszone gebildet.

Auf Grund zahlreicher Beobachtungen könnte diese unterschiedliche morphologische Entwicklung des $\mathrm{fB}_{\mathrm{t}}$-Horizontes in den Dünen genetisch vielleicht in folgender Weise gedeutet werden: Die ehemals bis zur Oberfläche kalkhaltigen Dünen wurden durch das bevorzugt auf den Flanken ablaufende Niederschlagswasser an den Unterhängen stärker durchfeuchtet, was in diesem Bereich zweifellos zu einer erhöhten Karbonatlösung führte. Beschleunigend auf die Entkalkungsvorgänge wirkten im vorliegenden Falle vermutlich die relativ grobe Körnung des Materials (erhöhte Selbstdränung) sowie ein gegenüber den Darmstädter Flugsanden zuweilen wesentlich geringerer primärer Karbonatgehalt. In diesem in verhältnismäßig kurzer Zeit bis in größere Tiefe entkalkten Substrat konnte 
sich dann bei der nachfolgend einsetzenden Tondurchwaschung an den Unterhängen eine ausgesprochene Bänderbildung vollziehen, während auf den nur bis in geringe Tiefe kalkfreien Dünenscheiteln ein einheitlicher Tonanreicherungshorizont entstand. Entscheidend dafür, ob es zur Ausbildung einer Bänderzone $\left(A_{1} B_{t}\right)$ oder aber eines geschlossenen $\mathrm{B}_{\mathrm{t}}$-Horizontes kommt, wäre demnach in erster Linie die jeweilige Mächtigkeit des kalkfreien, sandigen Substrates bei Beginn der Tondurchschlämmung.

\subsubsection{Die Bänderbraunerde}

Der $\mathrm{fA}_{1} \mathrm{~B}_{\mathrm{t}}$-Komplex wird nach oben durch eine schwach entwickelte, mittelgründige Braunerde abgeschlossen. Das besondere Merkmal dieser Bodenbildung besteht in einer deutlichen Bänderung des $\mathrm{fB}_{\mathrm{v}}$-Horizontes, wobei das erste Band stets unmittelbar unter der Oberfläche des Verbraunungshorizontes einsetzt. Nach dem äußeren Erscheinungsbild $\mathrm{zu}$ schließen, wurde hier eine bereits vorhandene Verwitterungsbildung nachfolgend durch eine vermutlich unter geänderten Klimabedingungen in anderer Richtung ablaufende Bodenentwicklung stark überprägt. Makroskopisch ist nicht zu entscheiden, welche dieser beiden verschiedenartigen Bildungen als die primäre anzusprechen ist. Diese Frage der genetischen Deutung soll zusammen mit dem Bänderproblem diskutiert werden. Im übrigen entspricht diese Verbraunungszone, deren Untergrenze meist nur schwach gewellt ist, in ihren morphologischen Merkmalen weitgehend den Braunerden auf den Mainflugsanden.

\subsubsection{Die jüngsten Flugdecksande}

Uber der gebänderten Braunerde folgen meist mit geringer Mächtigkeit die jüngsten Dünensande. Die gelblichbraunen, kalkfreien, meist locker gelagerten Sande unterscheiden sich von den liegenden Bänderflugsanden meist nur sehr unwesentlich, so daß es schwierig sein dürfte, im aufschlußlosen Gelände beide Flugsandkomplexe voneinander zu trennen. Eine deutliche Bodenbildung ist in diesem die heutige Dünenoberfläche bildenden Material nur gelegentlich an exponierten Stellen zu beobachten. Dagegen deutet sich ebenso wie im Maingebiet in $50-80 \mathrm{~cm}$ Tiefe eine beginnende undeutliche Bänderbildung an.

\subsection{Das Lorsch-Viernheimer Dünengebiet}

An das Bergsträßer Flugsandvorkommen schließen sich nach Süden zwischen Lorsch und Viernheim mehrere Dünenzüge an. Trennend zwischen beiden Dünengebiete schieben sich die breiten Schlingen des ehemaligen Bergsträßer Neckars, der seinen Lauf zwischen Zwingenberg und $\mathrm{Hahn}$ mit einer leichten Umbiegung nach Nordwesten vom Gebirgsrand weg mehr in die Ebene verlegte. Während so das Bergsträßer Dünengebiet östlich des alten Neckarlaufes liegt, erstrecken sich die Flugsandvorkommen zwischen Lorsch und Viernheim westlich dieser heute verlandeten Neckarbetten. Am Aufbau der Dünen beteiligen sich vorwiegend fein- bis mittelkörnige, kalkhaltige Flugsande. Von den Darmstädter Sanden unterscheiden sie sich zuweilen durch einen höheren Anteil der Fraktionen $0,2-0,5 \mathrm{~mm}$ und durch einen meist geringen Kalkgehalt. Nach den Untersuchungen von SCHOTTLER (1906, S. 81) beteiligen sich an der Zusammensetzung der äolischen Sedimente neben Rheinsanden in stärkerem Maße auch feinkörnige Neckarsande. Die Profilgliederung der Dünen unterscheidet sich nicht wesentlich von der des Bergsträßer Flugsandgebietes. Lediglich bei geringem primären Karbonatgehalt kam es im Verlauf der nach der Ca-Fortführung einsetzenden Tondurchschlämmung zu einer verstärkten Bänderung vorwiegend auf den Dünenflanken.

\subsection{Das Alter der Schichten}

In den zahlreichen von uns untersuchten Profilen der Bergsträßer und der LorschViernheimer Flugsandgebiete konnten vulkanische Einlagerungen oder deren Verwitterungsprodukte nicht beobachtet werden, so daß infolge des Fehlens dieser wichtigen Zeit- 
marken der Einstufung der übrigen Verwitterungsbildungen erhebliche Schwierigkeiten entgegenstehen. Ein unmittelbarer Vergleich mit den Mainflugsandprofilen wird darüber hinaus durch die materialbedingte verschiedenartige Profilgestaltung noch zusätzlich erschwert. Da die verschiedenen Flugsandvorkommen jedoch in einem sowohl morphologisch-klimatisch als auch pflanzengeographisch regional einheitlich gestalteten Raum verbreitet sind, dürfte es sich bei den charakteristischen Bodenbildungen trotz morphologischer Unterschiede im Profilaufbau um zumindest annäherungsweise zeitgleiche Bildungen handeln.

\section{Die Flugsandvorkommen des Sprendlinger Horstes}

Den östlichen Grenzraum des Untersuchungsgebietes bildet der von den Ausläufern des Odenwaldes nach Norden vorspringende schmale Rücken des Sprendlinger Horstes. Morphologisch tritt der aus Gesteinen des Rotliegenden aufgebaute Höhenrücken nur wenig hervor. Die hügelige, durch breite Täler stärker gegliederte Oberfläche erreicht eine Durchschnittshöhe von 140-160 m über NN und liegt damit etwa $40-60 \mathrm{~m}$ über der sich nach Westen anschließenden Oberrheinischen Tiefebene.

Die in größerer flächenhafter Verbreitung auftretenden äolischen Ablagerungen des Sprendlinger Horstes bestehen ebenso wie in der Ebene ausschließlich aus Flugsand. Löß konnte innerhalb des gesamten Gebietes nicht nachgewiesen werden. Gut erschlossen sind die Dünensande in einer größeren Sandgrube westlich Urberach. Der als „Häsengebirg“ bezeichnete schmale Dünenzug erstreckt sich hier über eine Länge von etwa $400 \mathrm{~m}$ in nahezu ostwestlicher Richtung auf dem schwach geneigten nördlichen Talhang des breiten Rodau-Tales. Die aus den aufgearbeiteten Rotliegend-Sedimenten ausgewehten Flugsande sind meist auffallend rötlichbraun gefärbt, was auf die meist noch geschlossene, dünne Tonumhüllung der Einzelkörner zurückzuführen ist. In der Korngrößenzusammensetzung ergeben sich im Vergleich zu den Mainflugsanden keine wesentlichen Unterschiede. Der stratigraphische Aufbau dieser Dünen stimmt mit der im Maingebiet erkannten Schichtfolge weitgehend überein. Lediglich die basale Schichtfolge scheint hier im Gegensatz zum Normalprofil unvollständig ausgebildet, was jedoch auch auf späteren, durch die exponierte Lage zweifellos begünstigten, Umlagerungen verbunden mit Abtragungsvorgängen in den tieferen Schichten beruhen kann.

Eine besondere stratigraphische Bedeutung erlangt in diesem Aufschluß das Deckschichtenprofil durch die Einlagerung einer holzkohleführenden Brandschicht im Hangenden der fossilen Braunerde. Das nachfolgende Profil wurde an der östlichen Aufschlußwand aufgenommen (B1. Langen 6018; R. 3483100 - H 5537 350):
1) $A_{h}$
$0-2$
( $2 \mathrm{~cm}$ ) dunkelgraubr. 10 YR 4/2 Sand, locker, stark durchwurzelt
2) $B_{V}$
$2-9$

$(7 \mathrm{~cm})$
dunkelbr. 10 YR $4 / 4$ Sand, locker, durchwurzelt
3) $f_{1} A_{h}$
$(3 \mathrm{~cm})$
4) $\mathrm{f}_{1} \mathrm{~B}_{\mathrm{V}} \quad 12-20$
5) $\mathrm{f}_{2} \mathrm{~A}_{\mathrm{h}} \quad 20-22$
6) $\mathrm{f}_{2} \mathrm{~B} \cdot 22-26$
7) $\mathrm{f}_{3} \mathrm{~A}_{\mathrm{h}} \quad 26-29$
8) $\mathrm{f}_{3} \mathrm{~B}_{\mathrm{v}} 29-57$
Wurzelreste
$(8 \mathrm{~cm})$ i. w. wie 2)
$(2 \mathrm{~cm})$ i. w. wie 3)
$(4 \mathrm{~cm})$ i. w. wie 2)
$(3 \mathrm{~cm})$ i. w. wie 3 )
$(28 \mathrm{~cm})$ brauner 10 YR 5/3, feinkörniger Sand bis anlehmiger Sand, stellenweise schwach hellbraun gefleckt, kohärentes Gefüge scharfer Übergang zu
9) $57-71(14 \mathrm{~cm}) \begin{aligned} & \text { schwärzlicher, feinkörniger Sand, stark humos, durchsetzt mit } \\ & \text { zahlreichen Holzkohlestückchen }\end{aligned}$

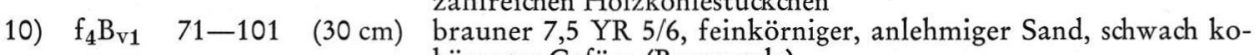 härentes Gefüge (Braunerde)
11) $\mathrm{f}_{4} \mathrm{~B}_{\mathrm{V} 2} 101-127 \quad(26 \mathrm{~cm})$ gelblichbr. 10 YR 6/4, schluffig-lehmiger Sand, weich, schmierig
12) $\mathrm{CB}_{\mathrm{t}} 137+$ rötlichbr., feingeschichteter Sand mit dünnen Tonanreicherungs- bändern.

Das nach der C14-Methode bestimmte Alter der Holzkohle beträgt $1360 \pm 90$ Jahre vor 1950. Die überlagernden jüngsten Flugsande können also erst in der Zeit nach 
600 n. Chr. aufgeweht worden sein. Da die Brandschicht der Verbraunungszone, die altersmäßig der Raunheimer Braunerde entsprechen dürfte, unmittelbar aufliegt, wird damit die bereits bei der Besprechung der Mainflugsande geäußerte Vermutung einer stärkeren Flugsandbildung in historischer Zeit vollauf bestätigt.

\section{Das Bänderproblem}

Äolische und zuweilen auch oberflächennahe fluviatile Sedimente des nördlichen Oberrheintalgrabens zeigen häufig eine charakteristische, rötlichbraune Bänderung, worauf bei der Besprechung der stratigraphischen Einheiten im einzelnen bereits hingewiesen wurde. Im folgenden Beitrag wollen wir uns vor allem mit dem bisher noch umstrittenen Bildungsmechanismus dieser Bänder und der Möglichkeit ihrer stratigraphischen Einstufung befassen.

Unter Bänderung, das sei vorausgeschickt, sollen im folgenden stets durch stoffliche Verlagerungsvorgänge sekundär gebildete Anreicherungszonen und nicht etwa eine durch primäre Sedimentationsunterschiede entstandene Schichtung (z. B. Warven, Liniensalze usw.) verstanden werden. Bänderbildung in Gesteinen ist eine weitverbreitete Erscheinung und kann in den verschiedensten Abwandlungsformen beobachtet werden. Besonders eindrucksvolle Beispiele von Bänderung finden wir in den vielfach zu Schmucksteinen verarbeiteten Achaten. In diesen vorwiegend in Hohlräumen von Rotliegend-Instrusiva vorkommenden kiesigen Abscheidungen tritt uns diese Erscheinung in ihrer wohl vollkommensten Ausbildung entgegen. Schon frühzeitig befaßten sich neben Geologen vor allem auch Chemiker mit der Erforschung der Entstehungsbedingungen dieser auffallenden Gebilde.

Allen voran ist hier wohl R. E. Liesegang zu nennen, dessen zahlreiche Arbeiten auf diesem Gebiet zur Klärung des Bänderproblems wesentlich beitrugen. Liesegang (1913, 1915 und 1924) kommt auf Grund zahlreicher Modellversuche zu der Überzeugung, daß diese Bänderungen nur durch rhythmische Niederschlagsbildungen infolge chemischer Fällungen entstanden sein können. Als geologisches Beispiel zu diesen Versuchen führt Liesegang (1915, S. 12/13) den Münzenberger Sandstein (Oberhessen) an, der durch seine auffallende Eisenoxyd-Bänderung gekennzeichnet ist. Nach LiESEGANG sollen diese Bänder bei Verwitterungsvorgängen dadurch entstanden sein, daß in „Oxydulform “ vorliegenden Eisensalzlösungen durch eindringendes sauerstoffreiches Wasser das Eisen rhythmisch ausgefällt wurde.

Diese nicht unwidersprochen gebliebene Diffusionstheorie von LIESEGANG wurde auch späterhin noch vielfach - allerdings mit gewissen Abwandlungen - zur Deutung der verschiedensten Bändererscheinungen herangezogen. So vertritt KUBIËNA (1936, S. 19/20) für die von ihm in Böden beobachtete Bänderung ebenfalls die Auffassung einer auf rhythmischen Ausscheidungen beruhenden Entstehung. Hierbei soll es sich jedoch in deutlichem Unterschied zu den LIESEGANG'schen Vorstellungen nicht um chemische Fällungen, sondern um die rhythmische Wiederholung eines „inneren Ausblühungsvorganges“ handeln. Nach KubiËNA (1936, S. 20) setzt das Ingangkommen der Bänderbildung einen „mit Lösung erfüllten Bodenkörper von gleichmäßig leitendem Gefüge“ voraus. Ausgelöst wird dann der „innere Ausblühungsvorgang" durch die Schaffung einer übersättigten Lösung an der obersten Grenzschicht des Bodens infolge einer allmählich nach unten fortschreitenden Austrocknung des Substrates.

Dagegen soll es sich bei den von Tüxen (1957, S. 9) aus den norddeutschen Sandgebieten beschriebenen bleistiftstarken Bändern vorwiegend um die Anreicherung von Eisenhydroxyden handeln. Diese äußerlich von Tonbändern nur schwer unterscheidbaren Anreicherungszonen sind nach TüxEN durch die Verlagerung von gelöstem Eisen aus dem Oberboden in tiefere Schichten entstanden. Dabei werden nach seiner Vorstellung die Eisensole zusammen mit den als Schutzkolloide wirksamen, ebenfalls gelösten Humusbestandteilen 
in den Unterboden verfrachtet. Während demnach bei KuBIËNA bodenphysikalische Vorgänge bei der Lösung und Wiederausscheidung der mobilen Substanzen ausschlaggebend waren, sollen hier in erster Linie chemische Prozesse für die Bänderbildung verantwortlich sein.

In ganz ähnlicher Weise wie Tüxen versucht auch BrunNacker (1959, S. 127), die Entstehung von ihm in Flugsanden des Rednitztales beobachteten sog. Rostbändern zu deuten. Nach seiner Auffassung handelt es sich bei diesen Bändern möglicherweise um dünne, im wesentlichen durch chemische Prozesse gebildete Anreicherungszonen.

In einer kürzlich erschienenen Arbeit vertritt Kundler (1962, S. 112) die Ansicht, $\mathrm{da}$ die unter den $\mathrm{B}_{\mathrm{v}}$-Horizonten von Braunerden im norddeutschen Tiefland auftretenden dünnen, braunen Bänder durch Toneinschlämmung aus dem überlagernden, verbraunten Horizont $\left(B_{v}\right)$ entstanden seien. Diese als $B_{t}$-Horizonte angesprochenen dünnen Lagen werden durch eine deutliche Anreicherung von Ton und freien Oxyden gekennzeichnet. Auch PaAs (1961, S. 172) kommt auf Grund seiner Beobachtungen an Bänderprofilen in äolischen und fluviatilen Sedimenten am Niederrhein zu der Überzeugung, daß das Bändermaterial im wesentlichen aus dem überlagernden $\mathrm{B}_{\mathrm{v}}$-Horizont stammt.

In den Vereinigten Staaten, wo diese auffallende Bänderung ebenfalls in vielen Profilen und vor allem auch in äolischen Sedimenten beobachtet wurde, versuchten neuerdings Folks \& Riecken (1956, S. 575-580), die Entstehung dieser Bänder in Modellversuchen nachzuahmen. Zu diesem Zwecke füllten sie ein Glasrohr mit Bodenmaterial aus der Bänderzone (Länge des Glasrohres 1,25 m) und ließen durch diese Bodensäule eine 0,01 n Oxalatlösung kontinuierlich $(1,5 \mathrm{ml} / \mathrm{min})$ hindurchlaufen. Nach etwa acht Tagen zeigte sich in einer Tiefe von 0,75-0,86 m eine deutliche Bänderung. Die mehrere mm starken Bänder waren offensichtlich zu gleicher Zeit entstanden. Eine Analyse dieser Bänder war zwar infolge ihrer geringen Dicke nicht möglich, doch dürfte es sich in diesem Falle im wesentlichen um Eisenanreicherung handeln.

Wie die wenigen im vorstehenden angeführten Beiträge zeigen, gehen die Ansichten über die Bänderentstehung teilweise weit auseinander. Aus diesen gegensätzlichen Auffassungen ergibt sich für uns folgende eingehender $\mathrm{zu}$ behandelnde Fragestellung:

1) Wird die am Aufbau der Bänder beteiligte Substanz im wesentlichen aus einem bereits vorhandenen Verwitterungshorizont $\left(B_{v}\right)$ infolge intensiver Durchschlämmung nach unten verlagert oder kommt es zur Bänderbildung auf Grund von differenzierten Verlagerungsvorgängen innerhalb des gesamten noch unverwitterten Sediments?

2) Erfolgt die Tondurchschlämmung in erster Linie mechanisch oder bewirken daneben auch kolloidchemische Prozesse in stärkerem Maße eine Substanzverlagerung?

3) Läßt sich die Bänderbildung als besondere Form der Bodenbildung stratigraphisch einordnen?

$\mathrm{Da}$, wie wir gesehen haben, die genetische Deutung der Bänderbildung oft entscheidend davon abhängt, welche Materialzusammensetzung die Anreicherungshorizonte aufweisen, sei die im Arbeitsgebiet allgemein angetroffene Bänderung zunächst kurz charakterisiert: Die im nördlichen Oberrheintal beobachteten Bänderprofile erreichen in den sandigen Sedimenten nicht selten eine Mächtigkeit von 5-6 m, gelegentlich auch bis $8 \mathrm{~m}$. Bänder sind jedoch stets nur in den äolischen oder fluviatilen Ablagerungen ausgebildet, deren Karbonatgehalt 0,5\% nicht wesentlich übersteigt. In lehmigem oder lehmig-schluffigem Material tritt die Bänderung gegenüber geschlossenen Anreicherungshorizonten meist stark zurück.

Wie aus der beigefügten Kornverteilungs-Tabelle zu ersehen ist, zeichnen sich die Bänder vor allem durch eine bemerkenswerte Tonanreicherung aus. Der Tonanteil schwankt zwischen 5-15\% und beträgt im Durchschnitt 9\% mit Ausnahme der Bänder aus dem 
südlichen Gebiet, deren Tongehalt von zuweilen nur $2-3 \%$ relativ niedrig liegt. Diese auffallende Abweichung von den Normalwerten mag auf den stärkeren Unterschieden des Tonanteils im Ausgangsmaterial beruhen. Neben Tonanreicherung erfolgte in den Bändern auch eine deutliche Eisenanreicherung. Im allgemeinen übersteigt der Fe-Gehalt in den Bändern den Anteil der Zwischenbänderlagen um das Zwei- bis Dreifache und liegt damit auch deutlich über den in Braunerden gefundenen Werten. Die Anreicherungshorizonte sind daher entsprechend ihrer Materialzusammensetzung allgemein als Ton-EisenBänder zu bezeichnen.

Tab. 8 : Korngrößenverteilung in Tonanreicherungsbändern und Zwischenbänderlagen

\begin{tabular}{|c|c|c|c|c|c|c|c|c|c|c|c|}
\hline Proben - Nr. & $>2,0 \mathrm{~mm}$ & $2,0-1,0$ & $10-0,5$ & $0,5-0,2$ & $0,2-0,125$ & $<0,125$ & $0,1-0,063$ & $0,063-0,02$ & $0,02-0,0063$ & $0,0063-0,002$ & $<0,002$ \\
\hline $\begin{array}{l}\text { Kiesgrube Mitteld ort } \\
\text { Morrtelden Band } \\
\text { FluBsand } 57 / 71\end{array}$ & - & - & 2,4 & 79,9 & 8 & - & 0,5 & - & 0,5 & - & 8,5 \\
\hline $\begin{array}{cr}\text { Autobahnanschluß } & \text { Haßloch } \\
\text { Band } & 58 / 85\end{array}$ & 0.1 & 0,3 & 5,6 & 51,2 & 211 & - & 4,5 & - & 0.5 & 1,0 & 15,5 \\
\hline $\begin{array}{cc}\text { AutobahnanschluB } & \text { HaBloch } \\
\text { Band } & 78 / 97\end{array}$ & - & 0.5 & 10.9 & 43,8 & 20.9 & - & 7.8 & 2,4 & 0,6 & 1,1 & 12,0 \\
\hline $\begin{array}{cc}\text { Autobahnanschlua } & \text { Haßloch } \\
\text { Band i. }+B_{\mathrm{V}} & 70 / 96\end{array}$ & 0.2 & 2.1 & 12,9 & 38,9 & 20,7 & - & 9,5 & 5,5 & 3.0 & 1,2 & 5.7 \\
\hline $\begin{array}{l}\text { Sandgrube Rüsselsheim } \\
\text { Band Flußsand } 73 / 104\end{array}$ & - & 0,5 & 23,0 & 59,5 & 6.5 & - & 1.5 & 0.6 & - & - & 80 \\
\hline $\begin{array}{l}\text { Sandgrube Hahnlein } \\
\text { Band }\end{array}$ & - & 0,8 & 3,3 & 42,2 & 40.1 & - & 9,4 & 1.1 & 1,0 & - & 2.0 \\
\hline $\begin{array}{l}\text { Zwischenbanderlage } \\
\text { A. Mönchhof }\end{array}$ & - & 23 & 23,9 & 66.2 & 7.0 & 0.3 & - & - & - & - & - \\
\hline $\begin{array}{l}\text { Zwischenbänderlage } \\
\text { S. Rüssel sheim }\end{array}$ & - & 1.2 & 19.3 & 56,3 & 15,2 & - & 5,2 & 0.6 & - & 0.2 & - \\
\hline $\begin{array}{l}\text { Zwischenbände rlage } \\
\text { A. Halsloch }\end{array}$ & 0.1 & 4.3 & 30,3 & 52.1 & 11.2 & 1.9 & - & - & - & - & - \\
\hline
\end{tabular}

Wenden wir uns nun den genetischen Fragen zu: Die Bänderbildung läßt sich am anschaulichsten an solchen Profilen erörtern, in denen eine Bänderfolge von fossilen Verwitterungshorizonten, in unserem Falle Braunerden, überlagert wird. Diese wurden wieder durch jüngste Decksande begraben. Besonders günstige Voraussetzungen in dieser Hinsicht bietet der im stratigraphischen Teil (s. S. 40) eingehend beschriebene Aufschluß am Schützenhaus in Raunheim. In diesem Dünenprofil folgt über den Bänderflugsanden zunächst eine unregelmäßige stärker aufgehellte Zone, die nach oben durch eine dünne Bims-Tufflage abgeschlossen wird. Dieser im oberen Teil zu einem lehmigen Substrat verwitterte Bims-Tuffhorizont geht ohne scharfe Grenze in eine mächtige Braunerde über, die von jungen, wenig verwitterten Flugdecksanden überlagert wird. Eine makroskopisch feststellbare Durchschlämmung ist in diesem Profil nicht zu beobachten, allenfalls könnte die merklich aufgehellte Zone zwischen Bims-Tuff und Bänderkomplex als Eluvialhorizont angesprochen werden.

$\mathrm{Zu}$ dem gleichen Ergebnis führte auch die mikromorphologische Untersuchung der einzelnen fossilen Bodenhorizonte. In den Braunerden werden die Kornzwischenräume des meist locker gelagerten, aus verschiedenen Körnungen aufgebauten Skelettanteils von stabil geflockter Feinsubstanz ausgefüllt. Gelegentlich deutet sich in dem gelbbraunen Tuffboden um größere Sandkörner eine schwache Hüllenbildung aus locker gelagerten Tonanteilen an. Anzeichen einer Verarmung an Feinsubstanz waren in der gleichmäßig gelbbraun gefärbten, geflockten $Z$ wischenmasse nicht zu erkennen. Der mikromorphologische Aufbau der Braunerden zeigt in den meisten Fällen dieses völlig intakte Braunerdegefüge. Auch die Analysenwerte chemischer Untersuchungen an gebänderten und bänderfreien 
Profilen lieferten keinen Hinweis, der auf eine stärkere kolloiddisperse Verlagerung von $\mathrm{Fe}, \mathrm{Al}$ und $\mathrm{Si}$ aus den $\mathrm{B}_{\mathrm{v}}$-Horizonten der Bänderprofile schließen ließe. Die Mengenverhältnisse dieser Stoffe in den verschiedenen Profilen waren nahezu gleich.

Tab. 9 : Chemische Untersuchungsergebnisse von Bändern und einer Zwischenbänderlage

Analytiker: Dr. Fastabend

\begin{tabular}{|c|c|c|c|c|c|c|c|c|c|c|c|c|c|c|c|}
\hline \multirow{2}{*}{$\begin{array}{l}\text { Lokalität und } \\
\text { Nr. der Probe }\end{array}$} & \multirow{2}{*}{$\begin{array}{l}\text { Entnahme- } \\
\text { tiefe im } \\
\text { Gel. in cm }\end{array}$} & \multirow{2}{*}{$\begin{array}{l}\mathrm{pH} \\
(\mathrm{KCl})\end{array}$} & \multirow{2}{*}{$\begin{array}{c}\text { Karbonate } \\
\%\end{array}$} & \multirow{2}{*}{$\begin{array}{c}\text { Org. Subst. } \\
\%\end{array}$} & \multirow{2}{*}{$v$-wert } & \multicolumn{2}{|c|}{ mval $/ 100 \mathrm{~g}$ Boden } & \multicolumn{5}{|c|}{ Kationen in mval/100g Boden } & \multirow{2}{*}{ Lösl. Fe } & \multirow{2}{*}{ Lösl. Al } & \multirow{2}{*}{ Löst Si } \\
\hline & & & & & & T-Wert & SK & $H$ & $\mathrm{Ca}$ & $\mathrm{Mg}$ & k & $\mathrm{Na}$ & & & \\
\hline $\begin{array}{l}\text { Düne Hähnlein } \\
108\end{array}$ & 170 & 7,1 & 0.1 & 0,2 & 100 & 6,1 & 6,5 & 0 & 6,0 & 0.1 & 0,1 & 0.3 & 0,82 & 0,74 & 0.44 \\
\hline $\begin{array}{r}\text { Band im Br-Horiz } \\
\text { Ha Bloch } 15 \mathrm{~B}\end{array}$ & 80 & 4,9 & 0,5 & - & 35,7 & 8,4 & 9,8 & 5,4 & 3,5 & 0.6 & 0,3 & 0.2 & 0.93 & 2,17 & 1.01 \\
\hline $\begin{array}{l}\text { Ton-Eisen-Band } \\
\text { Düne b HaBloch } 16\end{array}$ & 150 & 4,9 & 0,2 & - & 59,5 & 8,4 & 9,5 & 3.4 & 4.0 & 1,4 & 0,5 & 0.2 & 0,98 & 0,23 & 0,45 \\
\hline \multirow{2}{*}{ 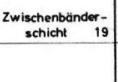 } & 130 & 5,1 & 0,2 & - & - & 1,7 & - & - & - & - & - & - & 0,38 & 0,26 & 0,17 \\
\hline & & & & & & & & & & & & & $\% \mathrm{Fe}_{2} \mathrm{O}_{3}$ & $\% \mathrm{Al}_{2} \mathrm{O}_{3}$ & $\% \mathrm{~S} \mathrm{O}_{2}$ \\
\hline
\end{tabular}

Noch klarer werden die Verhältnisse, wenn man die in den Bändern angereicherte und die im $\mathrm{B}_{\mathrm{v}}$-Horizont maximal zur Verfügung stehende verlagerbare Tonsubstanz miteinander vergleicht. Eine rein qualitative Bilanzierung in mehreren Profilen zeigte, daß die zusammengefaßte Mächtigkeit der erkennbaren Tonanreicherungshorizonte häufig die des $\mathrm{B}_{\mathrm{v}}$-Horizontes wesentlich überschritt. Der Tongehalt der $\mathrm{B}_{\mathrm{t}}$-Horizonte beträgt im Durchschnitt 9\%, in den Sandbraunerden geht dieser (Tonanteil) im allgemeinen jedoch nicht über 3\% hinaus, wie in bänderfreien Profilen nachgewiesen werden konnte. Daraus erhellt in welchem Mißverhältnis die Menge der angereicherten Tonsubstanz zu der aus dem $\mathrm{B}_{\mathrm{v}}$-Horizont unter günstigen Bedingungen ausschlämmbaren Tonsubstanz steht. Damit erhebt sich die Frage nach der Möglichkeit einer stärkeren Tonmineralneubildung. Wenn auch eine solche Tonneubildung in geringem Umfang nicht bestritten werden soll, so zeigt doch gerade der geringe Tongehalt in den Bändern des südlichen Flugsandgebietes, dessen Material sich durch einen relativ hohen Biotitanteil (leicht verwitterbar) auszeichnet, daß diese mengenmäßig kein großes Ausmaß erreicht haben dürfte. Nach diesen Befunden scheint es schwer vorstellbar, daß die in den Bändern angereicherte Tonsubstanz nahezu ausschließlich dem $\mathrm{B}_{\mathrm{v}}$-Horizont entstammt.

Können aber die in den $\mathrm{B}_{\mathrm{t}}$-Horizonten angereicherten Tonanteile rein mengenmäßig nicht mit einer Verlagerung aus den Braunerden und einer Nachlieferung durch nennenswerte Tonmineralneubildung erklärt werden, so bleibt als einzige Möglichkeit, eine Durchschlämmung des C-Horizontes selbst anzunehmen. Aus den Zwischenbänderlagen wäre demnach Feinsubstanz in größerer Menge über meist kurze Entferungen bewegt und in den Bändern angereichert worden. Wie man sich diese Durchschlämmungs- und Anlagerungsprozesse genetisch vorstellen könnte, wurde von KubiëNA (1936, S. 19/21) im einzelnen aufgezeigt. Inwieweit diese Annahmen Kuвı̈̈NAs tatsächlich zutreffen, mag dahingestellt bleiben, immerhin ergeben sich aus dem mikromorphologischen Aufbau der Bänder einige Hinweise, die einen solchen „inneren Ausblühungsvorgang“ zumindest als genetischen Teilprozeß wahrscheinlich machen.

Das Skelettmaterial der Bänder des Maingebietes setzt sich im allgemeinen aus einem unregelmäßigen Korngemisch grob- und feinkörnig-schluffiger Partien zusammen. Die Tonanlagerung in den Kornwinkeln und $\mathrm{Z}$ wischenräumen erfolgte meist unregelmäßig. In den deutlich leitfähigen Bereichen (grobk. Partien) zeichnet sich diese Anlagerung besser $a b$, als in den feinkörnig-schluffigen, dichter gelagerten Partien. Das verlagerte Material zeigt teilweise eine undeutliche Schichtung in Feintonlagen mit hoher Doppelbrechung und Schichten, die reich sind an hochlichtbrechenden gröberen Teilchen. Während die Feintonlagen gelblich gefärbt sind, werden die gröberen Schichten durch eine graubraune Fär- 
bung charakterisiert. Die größeren Partikelchen erscheinen im polarisierten Licht meist rötlich; vermutlich handelt es sich bei diesen Teilchen um Eisen-Minerale, die im Hellfeldbild nicht weiter auflösbar sind. Gelegentlich zeigt der gutgeschichtete Tonanteil eine deutliche blättchenförmige Absonderung.

Auf Grund dieses Gefügeaufbaus könnte das Initialstadium eines solchen Tonanlagerungsvorganges vielleicht in folgender Weise gedeutet werden:

1. Phase: Durchfeuchtung des Substrates bis in verschiedene Tiefen (Sickerwasserfront). Die in der Bodenlösung dispergierte Tonsubstanz wird teilweise in tiefere Bereiche durchschlämmt und an Unstetigkeitsstellen abgesetzt.

2. Phase: Verdunstung des Wassers in Oberflächennähe, dadurch allmähliche Übersättigung der Bodenlösung. Beginnende Anlagerung hauchdünner Lösungsfilme an Kornoberflächen. Zwischen den Kornwinkeln Meniskenbildung.

3. Phase: Wasser im obersten Bereich fast vollständig verdunstet, in Kornwinkeln vereinzelt schwache Brückenbildung. Nachsaugen von Lösung aus unterlagernden Schichten, weitere Anlagerungen.

4. Phase: Kapillarsaum nach unten reißt ab. Wiederholung der Vorgänge 2-4 in einer tieferen Schicht.

In diesem System kommt, das sei klar herausgestellt, den ausschließlich nach unten gerichteten Durchschlämmungs- und Anlagerungsvorgängen (1. Phase) als genetischem Teilprozeß zweifellos die weitaus größere Bedeutung zu. Das zeigt sich einmal an der starken Aufhellung der Zone über dem Bänderkomplex, zum anderen an dem unsymmetrischen morphologischen Aufbau der Bänder, deren Obergrenze meist geschnitten scharf erscheint, während die untere Begrenzung unregelmäßig, zuweilen fahnenartig ausgezogen ist.

Den Beweis aber, daß sich auch bei ständiger Berieselung (einphasiges System) ohne Verdunstungsphasen Bänder bilden können, erbrachte der von uns in Anlehnung an Folks \& RIECKEN durchgeführte Modellversuch. Bei gleicher Versuchsanordnung zeigten sich nach sechs Tagen etwa 79-93 cm unter der Oberfläche (Gesamtbodensäule 1,28 m) deutlich mehrere dünne, parallellaufende Bänder. Einschränkend muß allerdings hinzugefügt werden, daß die für die genetische Deutung wesentliche Zusammensetzung der Bänder bislang nicht endgültig geklärt werden konnte. Der Versuch zeigte außerdem sehr anschaulich, daß die Bänder — wie vermutet - mehr oder weniger gleichzeitig entstehen können.

Damit kommen wir zur zweiten Frage: Erfolgt die Tondurchschlämmung in erster Linie mechanisch oder kommen dafür auch kolloidchemische Prozesse in Frage?

Es kann mit ziemlicher Sicherheit angenommen werden, daß beide Ursachen bei der Bänderbildung wirksam werden. Dies zeigt sich vor allem in der Abhängigkeit der Tonverlagerung vom Karbonatgehalt und damit vom $\mathrm{pH}$-Wert. Wie eingangs erwähnt, findet nur im weitgehend karbonatfreien oder höchstens noch sehr schwach kalkhaltigen Substrat $(0,5 \%)$ eine Verlagerung statt. B. MeYer (zit. n. Mückenhausen 1962, S. 83) führt dies darauf zurück, „daß mit dem Verlust an Ca-Ionen das elektrokinetische Potential des Sorptionskomplexes steigt und damit die Tonsubstanz mehr und mehr beweglich wird, um dann aber im stark sauren Bereich durch das Verhalten des Eisens wieder stabil zu werden“. Damit würde sich auch die im stratigraphischen Teil beschriebene Erscheinung der bänderfreien Zonen leichter deuten lassen; eine Nachprüfung dieser Bereiche ergab nämlich in jedem Falle einen $\mathrm{pH}$-Wert, der deutlich über dem des gebänderten Materials lag (s. dazu auch PAAs 1961, S. 171). Inwieweit diese Verlagerungsprozesse durch mögliche Chelatbildungen beeinflußt werden, bleibt noch zu untersuchen.

Bleibt nun noch die Frage des Alters der Bänderbildung zu klären. Im Profil Raunheim wird der Bänderkomplex durch den Bims-Tuff und die fossilen Braunerden überlagert. Beide Bildungen stehen nachweislich in keinem unmittelbaren genetischen Zusam- 
menhang. Vergleichbare Lagerungsverhältnisse wurden auch - mit zwei Ausnahmen, in denen die fossile Braunerde deutlich gebändert war - in fast allen übrigen Profilen angetroffen. Wir möchten daher annehmen, daß die Hauptbänderbildung in den Dünen vor Ablagerung des Bims-Tuffs, also vor dem Alleröd-Interstadial erfolgt ist. Diese Annahme könnte durch die Ergebnisse der Röntgenanalyse der im Boden enthaltenen Eisenverbindungen gestützt werden. Während sich nämlich in den im Postglazial entstandenen Braunerden vorwiegend Goethit fand, konnte in den Bändern bevorzugt Hämatit nachgewiesen werden. Wenn auch die Bestimmung der Eisenformen wegen zu geringer Substanzmengen nicht mit letzter Sicherheit zu belegen ist, so dürften diese Ergebnisse doch mit einiger Wahrscheinlichkeit die Annahme einer Verschiedenaltrigkeit von Bänder- und Braunerdebildung bestätigen. Die Zusammensetzung der Tonfraktion mit Illit und Kaolinit als Hauptgemengteilen läßt keine Schlüsse auf besondere Bildungsbedingungen zu.

Die Vermutung, daß die Hauptbänderbildung im wesentlichen bereits vor dem Alleröd erfolgte, wird auch, wie bereits erwähnt, durch die Beobachtungen BRUNNACKers (1959, S. 120), der die „Rostbänder" unter einem allerödzeitlichen Podsol beobachtete, bestätigt. Ob die starke Bänderung allerdings an bestimmte klimatische Voraussetzungen, wie hohe Niederschläge und relative niedrige Jahresdurchschnittstemperaturen, gebunden ist, muß zunächst noch offen bleiben. Mit dieser stratigraphischen Einstufung der Hauptbänderbildung in den, vor dem Alleröd-Interstadial liegenden, spätglazialen Zeitabschnitt soll jedoch keineswegs bestritten werden, daß auch späterhin Ton-Eisenbänder gebildet wurden und diese möglicherweise auch unter dem heutigen Klima noch entstehen können (s. jüngste Decksande). Man wird daher bei einer Datierung solcher Bänderfolgen die jeweiligen lokalen Lagerungsverhältnisse sehr genau zu beachten haben. Aus diesem Grunde sollen aus der im Oberrheintal beobachteten und rekonstruierbaren Bodenentwicklung zunächst keine verallgemeinernden Schlüsse in stratigraphischer Hinsicht gezogen werden.

Fassen wir die Einzelergebnisse kurz zusammen, so läßt sich die Bänderung der Dünensande im nördlichen Oberrheintal genetisch und stratigraphisch vielleicht in folgender Weise deuten: Die in den Bändern angereicherte Ton-Eisensubstanz entstammt zu großen Teilen dem Sediment selbst und nicht, wie vielfach angenommen, in erster Linie den rezenten und fossilen $B_{v}$-Horizonten. Es wird daher vorgeschlagen, die $Z$ wischenbänderschichten als Al-Horizonte, die Anreicherungsbänder in Anlehnung an KundleR (1962, S. 112) als $B_{t}-$ Horizonte zu bezeichnen. An Stellen, wo wegen zu geringer Mächtigkeit der Einzellagen diese zu einer größeren Einheit zusammengefaßt werden müssen, sollte der Gesamtverband als "Horizontkomplex" benannt und mit dem Symbol $\left.\left(\mathrm{AlB}_{\mathrm{t}}\right)^{\mathrm{x} 2}\right)$ belegt werden (s. a. FolKs \& RIEKEN 1956). Die Tondurchschlämmung beruht vermutlich auf verschiedenen Ursachen; neben rein mechanischen beteiligten sich wahrscheinlich auch kolloidchemische Prozesse an den Verlagerungs- und Anreicherungsvorgängen. Bänder können in Sanden und Kiesen bei gegebenen Bedingungen zu verschiedenen Zeiten entstehen, die Hauptbänderbildung in den Dünen des nördlichen Oberrheintales dürfte jedoch bereits im Spätglazial vor dem Alleröd-Interstadial erfolgt sein.

\section{Literaturverzeichnis}

BAAS, J.: Eine frühdiluviale Flora im Mainzer Becken. Z. Botanik 25, 289-371, Jena 1932.

BredDIN, H.: Löß, Flugsand und Niederterrasse am Niederrhein. Jb. preuß. geol. L.-A. 46 (1925), 635-662, Berlin 1926.

Brelie, G. v. D.: Probleme der stratigraphischen Gliederung des Pliozäns und Pleistozäns am Mittel- und Niederrhein. Fortschr. Geol. Rheinld. Westf. 4, 371-388, Krefeld 1959.

2) $x=$ Symbol für vielfache Wiederholung. 
Brunnacker, K.: Die Geschichte der Böden im jüngeren Pleistozän in Bayern. Geol. Bavar. 34, 95 S., München 1957 (1957a). - - Zur Parallelisierung des Jungpleistozäns in den Periglazialgebieten Bayerns und seiner östlichen Nachbarländer. Geol. Jb. 76 (1958), 129150, Hannover 1959. - - Zur Kenntnis des Spät- und Postglazials in Bayern. Geol. Bavar. 43, 74-150, München 1959.

Dewers, F.: Probleme der Flugsandbildung in Nordwestdeutschland. Abh. Naturw. Ver. Bremen 29, 324-360, Bremen 1934/35.

DiEHL, O.: Einige Betrachtungen über die quartären Ablagerungen an der Bergstraße und im Ried. Notizbl. Ver. Erdk. u. hess. geol. L.-A. Darmstadt (1931/32 V), 20-24, Darmstadt 1933.

Dücker, A., \& MaArleveld, G.-L.: Hoch- und spätglaziale äolische Sande in Nordwestdeutschland und den Niederlanden. Geol. Jb. 73, 215-234, Hannover 1958.

Firbas, F.: Waldgeschichte Mitteleuropas 2, 256 S., Jena 1952.

Folks, H. C., \& Riecken, F. F.: Physical and chemical properties of some Jowa soil profils with clay-iron bands. Proc. Soil Sci. Soc. America 20, 575-580, 1956.

Ganssen, R., \& Harth, H.: Beiträge zur Kenntnis der Böden d. Oberrheingrabens und der angrenzenden Gebiete, II. Mittlg. Versuch einer Kennzeichnung wichtiger Böden im trockensten Teil des östlichen Oberrheintalgrabens. Z. Pflanzenern., Düngg., Bodenkde. 76, 213-233, Weinheim 1957.

Kubï̈NA, W. L.: Beiträge zur Kenntnis des Gefüges kohärenter Bodenmassen. Bodenkunde u. Pflanzenern. 2 (47), 1-23, 1936/37.

Kundler, P.: Zur Systematik der Ubergangsbildungen zwischen Braunerden und Podsolen. Thaer Archiv 6, 111-117, Eberswalde 1962.

Liesegang, R. E.: Geologische Diffusionen. 180 S., Dresden u. Leipzig 1913. - - Die Achate. 118 S., Dresden u. Leipzig 1915.

MaAs, H.: Das Alter der westfälischen Dünen auf Grund ihrer Bodenbildung. Diss. Münster 1950.

MülLER, E.-H.: Über die Herkunft des Lösses im Rheinland und südlichen Westfalen. Geol. Jb. 69, 401-406, Hannover 1955.

Poser, H.: Äolische Ablagerungen und Klima des Spätglazials in Mittel- und Westeuropa. Naturwissenschaften 35, 269-276, 307-312, Berlin etc. 1948.

Röschmann, G.: Die Grundmoränenböden des Emstales zwischen Rheine und Papenburg und ihre Beziehungen zur Geschichte des Emslaufes. Geol. Jb., Bd. 77, 741-820, Hannover 1960.

Rohdenburg, H., Meyer, B., Willerding, U. \& Jankuhn, H.: Quartärmorphologische, bodenkundliche, paläobotanische und archäologische Untersuchungen an einer Löß-Schwarzerde-Insel mit einer wahrscheinlich spätneolithischen Siedlung im Bereich der Göttinger Leineaue. Göttinger Jb. 36-56, 1962.

Schmitr, O.: Die Darmstädter Flugsande und Dünensande. Aufschluß, Sonderh. 2, 82-86, Darmstadt 1955.

Schönhals, E.: Die Böden Hessens und ihre Nutzung. Abh. hess. L.-Amt Bodenforsch. 2, 1-288, Wiesbaden 1954. - - Spätglaziale äolische Ablagerungen in einigen Mittelgebirgen Hessens. Eiszeitalter u. Gegenwart 8, 5-17, Öhringen 1957 - (1957a). - - Spät- und nacheiszeitliche Entwicklungsstadien von Böden aus äolischen Sedimenten Westdeutschlands. Verh. 7th Intern. Congres Soil Sci. Madison, V 40, 283-290, Wisc. 1960.

SchottLeR, W.: Erl. geol. Karte d. Großherzogtums Hessen, 1:25 000, Bl. Viernheim (Käfertal), Darmstadt 1906. - - Die quartären Sandablagerungen der Umgebung von Darmstadt und ihre Bodenprofile. Notizbl. Ver. Erdk. u. hess. geol. L.-A. Darmst. 1925 (V.), 8, 174-196, Darmstadt 1926.

SchröDER, D. \& Schwertmann, U.: Zur Entstehung von Eisenkonkretionen im Boden. Naturwissenschaften 42, 255-256, 1955.

Sindowski, K. H.: Mineralogische, petrographische und geochemische Untersuchungsmethoden, S. 161-186. In BENTZ: Lehrbuch der angewandten Geologie 1, Stuttgart 1961.

SonNe, V. \& STöHR, W.: Bimsvorkommen im Flugsandgebiet zwischen Mainz und Ingelheim. Jber. Mittlg. oberrh. geol. Ver. N. F. 41, 103-116, Stuttgart 1959.

Tüxen, R.: Schrift des Bodens. Angewandte Pflanzensoziologie 24, Stolzenau 1957.

WAGNER, W:: Diluviale Tektonik im Senkungsbereich des nördlichen Rheintalgrabens und an seinen Rändern. Notizbl. hess. L.-Amt Bodenforsch. (IV), 1, 177-192, Wiesbaden 1950. - Der geologische Aufbau an der Fundstelle der Hügel-Bronzegräber $1200 \mathrm{~m}$ südöstlich Wixhausen bei Darmstadt. Notizbl. hess. L.-Amt Bodenforsch. (V), 3, 171-175, Wiesbaden 1952.

Zakosek, H.: Zur Genese und Gliederung der Steppenböden im nördlichen Oberrheintal. Abh. hess. L.-Amt Bodenforsch. 37, 46 S., Wiesbaden 1962.

Manuskr. eingeg. 20. 4. 1966.

Anschrift des Verf.: Diplom-Geol. Dr. E. Becker, Geologisches Landesamt Rheinland-Pfalz, 65 Mainz, Flachsmarkstraße 9. 